\begin{abstract}
HALEY, REBECCA LYNNE. Operational Effects of Signalized Superstreets in North Carolina. (Under the direction of Dr. Joseph E. Hummer.)

Arterials across North Carolina and the United States are operating inefficiently and are becoming more and more congested due to growing traffic demand. Agencies tasked with improving these arterials are running out of good solutions. Superstreets, called restricted crossing u-turns by the Federal Highway Administration, are a part of a menu of unconventional arterial designs that may provide a promising solution. Up to this point, there is little valid information available on the operational and safety effects of superstreets. Studies have analyzed this new design, but the results are from macroscopic analyses, and simulations of hypothetical arterials. The purpose of this research was to determine the operational effects of the superstreet treatment on existing signalized arterials in North Carolina.
\end{abstract}

The operational analysis involved calibrating and validating VISSIM models of three existing signalized superstreets in North Carolina - two isolated intersections, and one fiveintersection superstreet corridor. Results from the three calibrated models were compared to results from models of equivalent conventional intersections at various volume levels using travel time as the main measure of effectiveness. The superstreet outperformed the conventional intersection at each location studied, reducing the overall average travel time per vehicle traveling through the intersection. The travel time savings and extra capacity at higher volumes can buy agencies more years of acceptable operation before intersection improvements are necessary.

In addition to the operational analysis, I conducted a survey to determine the perceptions of the nearby residents about superstreets. I surveyed residents living near both signalized and unsignalized superstreet across North Carolina by mail. Residents near both types felt the superstreet helps them navigate the intersection more safely. Residents living near signalized superstreets perceived longer travel times and more stopped vehicles compared to the conventional intersection, while residents living near unsignalized superstreets perceived no change in travel time and fewer stopped vehicles. 


\title{
Operational Effects of Signalized Superstreets in North Carolina
}

\author{
by \\ Rebecca L. Haley
}

A thesis submitted to the Graduate Faculty of

North Carolina State University

in partial fulfillment of the

requirements for the Degree of

Master of Science

Civil Engineering

Raleigh, North Carolina

2010

APPROVED BY:

Nagui M. Rouphail

Billy M. Williams

Joseph E. Hummer

Chair of Advisory Committee 


\section{BIOGRAPHY}

The author was born and raised in Dover, New Hampshire. She graduated from the University of New Hampshire in 2008 with a Bachelor of Science in Civil Engineering. She

moved to Raleigh, NC in August 2008 to attend North Carolina State University and pursue a Master of Science degree in Civil Engineering with a focus in transportation engineering. 


\section{ACKNOWLEDGEMENTS}

There are many people who assisted me in the completion of this research. I would like to thank my advisor, Dr. Joe Hummer, for his enthusiasm and guidance throughout this entire project and my time here at NC State. Thank you to Chris Cunningham and Bob Foyle for the time and expertise they put into the project. A big thanks to my fellow grad student and superstreet partner in crime, Sarah Ott, for her help and encouragement, and for the many hours she spent helping me collect field data. Thank you to Dr. Billy Williams and Dr. Nagui Rouphail for serving on my committee and for their help and suggestions.

I would like to acknowledge and thank the North Carolina Department of Transportation for funding this research. Thank you to our NCDOT project committee for all their help providing signal timing data, construction drawings, pictures, and answers to our questions. Thank you to the Southeastern Transportation Center for providing financial support through my graduate studies.

Thank you to my family and friends for their encouragement and support. Lastly, thank you to my awesome fiancé, Erich Fiedler, for keeping me sane and making me take vacations. 


\section{TABLE OF CONTENTS}

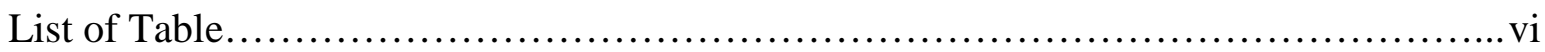

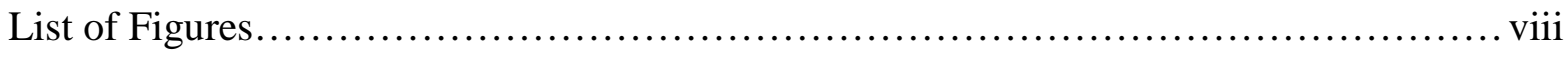

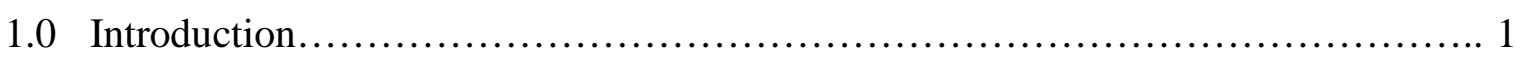

1.1 Problem Definition.................................................... 1

1.2 Background.......................................................... 1

1.3 Research Objectives................................................ 3

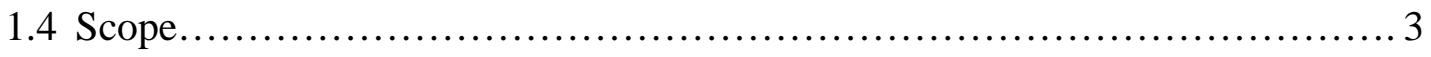

1.5 Organization of Thesis................................................. 4

2.0 Literature Review........................................................... 5

2.1 Median U-turns...................................................... 5

2.1.1 Operations....................................................... 6

2.1.2 Access Management.............................................. 9

2.2 Superstreets......................................................... 10

2.3 Other Unconventional Intersection Designs...............................15

3.0 Operational Methodology.................................................... 17

3.1 Identification and Selection of Sites........................................ 17

3.2 Data Collection...................................................... 22

3.2.1 Turning Movement Data........................................... 22

3.2.2 Travel Time Data............................................... 22

3.2.3 Free-flow Speed Data......................................... 23

3.3 Data Analysis............................................................. 24

4.0 Calibration and Validation of VISSIM Models...................................29

4.1 Model Construction......................................................... 29

4.2 Model Calibration....................................................... 31

4.3 Model Validation...................................................... 34

5.0 Operational Results................................................... 35

5.1 Travel Time Comparison................................................. 35

5.2 Travel Time Effects on the Intersection.................................. 54

5.3 Travel Time Effects on the Arterial...................................... 56 
5.4 Travel Time Effects on the Minor Road.................................... 57

5.5 Capacity Check....................................................... 58

6.0 Resident Survey Methodology............................................6 60

6.1 Identification and Selection of Sites......................................60

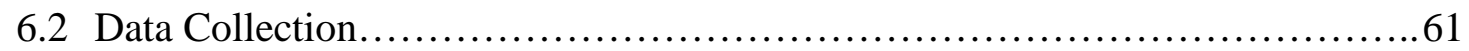

7.0 Resident Survey Results............................................... 68

7.1 Results............................................................ 68

7.2 Analysis.......................................................... 71

7.2.1 Signalized vs. Unsignalized...................................... 71

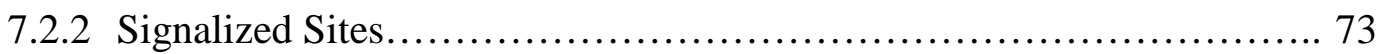

7.2 .3 Unsignalized Sites............................................ 74

8.0 Conclusions................................................................. 76

8.1 Research Results....................................................... 76

8.2 Recommendations................................................... 78

8.3 Future Research Needs..................................................... 80

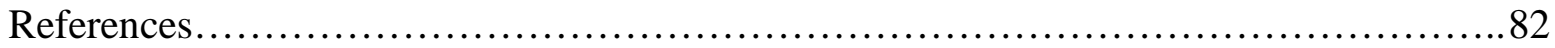

Appendices.................................................................... 85

Appendix A: Field Data from Superstreets........................................86

Appendix B: VISSIM Calibration Inputs...................................... 96

Appendix C: VISSIM Calibration and Validation Results.............................108 


\section{LIST OF TABLES}

TABLE 2.1 Summary of Network-wide Operating MOE (7).......................... 9

TABLE 2.2 Comparison of the Average Total Travel Time in Different Volume Categories (18).......................................... 14

TABLE 3.1 Signalized Superstreet Sites Selected for Operational Study............... 17

TABLE 3.2 Achieved Permitted Travel Time Error for All Movements..................23

TABLE 3.3 Lane Configurations by Approach for Study Sites........................ 25

TABLE 3.4 Cycle Lengths for Chapel Hill Superstreet and Conventional

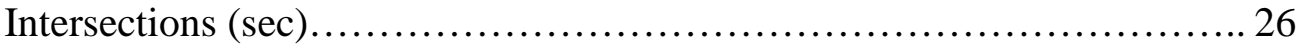

TABLE 3.5 Cycle Lengths for Wilmington Superstreet and Conventional Intersections (sec) .................................................. 26

TABLE 3.6 Cycle Lengths for US-17 Superstreet and Conventional

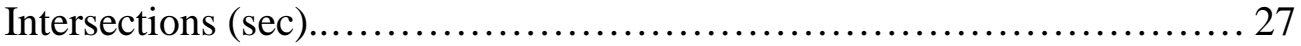

TABLE 4.1 Gap Values Used for Coding Conflict Areas in VISSIM.................... 32

TABLE 4.2 VISSIM Parameters Adjusted in Each Set of Runs During Calibration......33

TABLE 4.3 Percent Difference in Travel Time (VISSIM - field data) from Calibration..................................................... 34

TABLE 4.4 Percent Difference in Travel Time (VISSIM - field data)

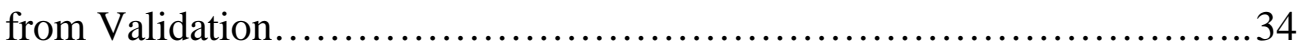

TABLE 5.1 Achieved Confidence Interval for Travel Time Results..................... 37

TABLE 5.2 Chapel Hill Volumes by Movement (vph)..............................38

TABLE 5.3 Chapel Hill Travel Times by Movement (sec)............................ 39

TABLE 5.4 Wilmington Volumes by Movement (vph)...............................40

TABLE 5.5 Wilmington Travel Times by Movement (sec)...........................41

TABLE 5.6 US-17 Volumes by Movement (vph).................................42

TABLE 5.7 US-17 Travel Times by Movement (sec) ................................44

TABLE 5.8 Analysis of Variance for Travel Time, Using Adjusted SS for Tests......... 54

TABLE 5.9 Percent Difference in Average Travel Time Per Vehicle Between Superstreet and Conventional Intersections............................. 55 
TABLE 5.10 Standard Deviation of Simulated Travel Time by movement (sec.)........ 56

TABLE 5.11 Critical Sums for Superstreet and Conventional Intersections............... 59

TABLE 6.1 Sites Selected for Resident Survey................................. 61

TABLE 7.1 Number of Responses From Each Survey Site.........................68

TABLE 7.2 Resident Survey Results by Question.............................. 69

TABLE 7.3 Value of $d$ Achieved for the Key Questions............................... 71

TABLE 7.4 Two-tailed Z-test for Proportions Results Comparing Signalized to Unsignalized Survey Responses at a 95\% Confidence Level.............72

TABLE 7.5 Two-tailed Z-test for Proportions Comparing Key Survey Question Responses for Signalized Sites at a 95\% Confidence Level............... 74

TABLE 7.6 Two-tailed Z-test for Proportions Comparing Key Survey Question Responses for Unsignalized Sites at a 95\% Confidence Level............. 75 


\section{LIST OF FIGURES}

FIGURE 1.1 Superstreet design............................................... 2

FIGURE 2.1 Median u-turn design............................................ 5

FIGURE 2.2 Reduced Conflict Intersection developed by D. Eyler, SRF Consulting

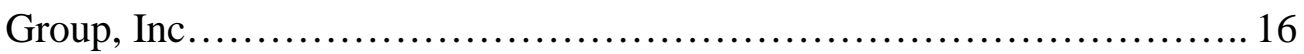

FIGURE 3.1 US-15/501 at Erwin Rd./Europa Dr. in Chapel Hill, NC.................. 18

FIGURE 3.2 US-421 at Myrtle Gardens Dr./Carolina Beach Rd. in Wilmington, NC.... 18

FIGURE 3.3 US-17 at Ploof Rd./Poole Rd. in Leland, NC.......................... 19

FIGURE 3.4 US-17 at Walmart/Gregory Rd. in Leland, NC........................ 19

FIGURE 3.5 US-17 at Grandiflora Dr./West Gate Dr. in Leland, NC.................... 20

FIGURE 3.6 US-17 at Brunswick Forest Pkwy. in Leland, NC..................... 20

FIGURE 3.7 US-17 at Lanvale Rd./Brunswick Forest Dr. in Leland, NC............... 21

FIGURE 5.1 Comparison of travel times by movement - Chapel Hill................. 47

FIGURE 5.2 Comparison of travel times by movement - Wilmington.............. 48

FIGURE 5.3 Comparison of travel times by movement - US-17 @ Ploof/Poole..........49

FIGURE 5.4 Comparison of travel times by movement - US-17@ Walmart/

Gregory...................................................... 50

FIGURE 5.5 Comparison of travel times by movement - US-17 @ Grandiflora/

West Gate........................................................... 51

FIGURE 5.6Comparison of travel times by movement - US-17 @ Brunswick

Forest......................................................... 52

FIGURE 5.7 Comparison of travel times by movement - US-17 @ Lanvale Rd........... 53

FIGURE 6.1 Initial letter for the resident survey ...............................64

FIGURE 6.2 Cover letter that accompanied the resident survey packet.................65

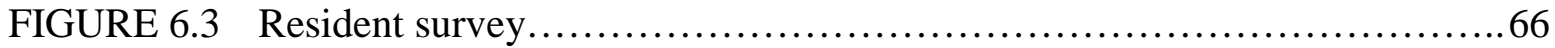

FIGURE 6.4 Reminder letter for the resident survey $\ldots \ldots \ldots \ldots \ldots \ldots \ldots \ldots \ldots \ldots \ldots \ldots 6 . \ldots \ldots \ldots$ 


\subsection{INTRODUCTION}

\subsection{Problem Definition}

Arterials across North Carolina and the United States are operating inefficiently and are becoming more and more congested due to growing traffic demands. The increasing demand on arterials is not likely to slow down anytime soon. Agencies tasked with fixing these arterials are running out of good solutions. The conventional traffic engineering solutions, such as actuated signals, turn bays, and optimized signal systems, can only go so far in

solving congestion problems. Widening roads and creating bypasses are expensive and disruptive, and may not help the operations much.

Superstreets are a part of a menu of unconventional arterial designs that provide promising solutions for congested arterials. They have the potential to move more vehicles efficiently and safely through the same amount of pavement as conventional arterials, at-grade, with minimal disruptions to the surrounding environment and businesses. To this point, there is little valid information available on the effects of superstreets. Studies have been done analyzing this new design, but the results are from macroscopic analyses, and simulations of hypothetical arterials. There has never been an evaluation on the operational effects of existing superstreets.

\subsection{Background}

A superstreet, also known as the restricted crossing u-turn (RCUT) by the Federal Highway Administration (FHWA), works by redirecting the side street left turn and through movements to a downstream, one-way median opening. Left turns from the major road can be accommodated by a u-turn maneuver after the intersection or by a left turn crossover at the main intersection. Figure 1.1 shows the superstreet design with and without the direct left turn from the arterial. Superstreets can be signalized or unsignalized. Signalized superstreets offer the benefit of having each direction of the main street operating 
independently from each other, essentially acting as one-way pairs. This allows for "perfect" progression in both directions. The traffic signals for a superstreet only require two phases instead of four or more. The reduction in the number of phases means less lost time for motorists, the potential for shorter cycle lengths, and potential time savings. Superstreets also reduce the number of conflict points from 32 to 14 (with the direct left turn) and 8 (without the direct left turn) which in theory reduces the likelihood of collisions.

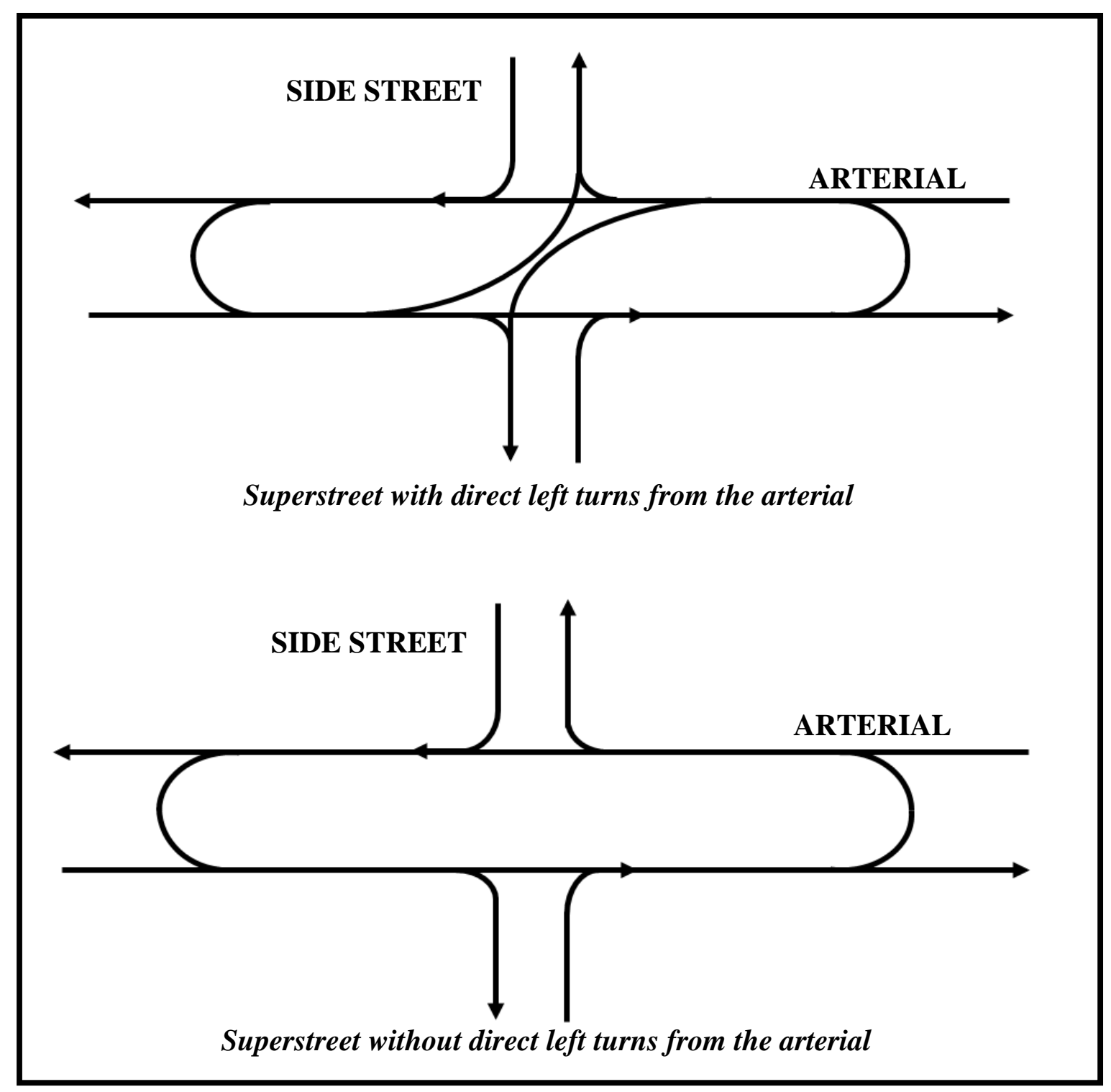

FIGURE 1.1 Superstreet design. 


\subsection{Research Objectives}

The purpose of this research is to fill the information gap and determine if superstreets are providing operational benefits for North Carolina motorists. The objectives of this study are:

1. To analyze the operational impacts of superstreets by comparing travel times of various movements to equivalent conventional intersections using calibrated and validated VISSIM models from existing superstreets in North Carolina.

2. To determine the perceived effects of superstreets on nearby residents.

Signalized superstreets are generally installed to improve congestion along arterials. It is important to determine if the superstreet is functioning as intended (e.g. improving progression of through traffic along the main road). Comparing the travel times of each movement at the intersection allows for a fair comparison between the superstreet and the conventional intersection. Another part of the evaluation of the superstreet is to determine how the design affects nearby residents. Knowing how a new design impacts the people living nearby is important because they can be influential on whether the design gets built again or not.

\subsection{Scope}

The scope of this project is limited to signalized superstreets in North Carolina. The operational comparison of superstreets and conventional intersections only analyzes the differences in travel time of vehicles traveling through the intersection. This study does not involve an assessment of the effect on pedestrians or bicycles. The supplemental residential survey involved both signalized and unsignalized superstreets in North Carolina, but was limited to those constructed in the past five years that had a comparable "before" scenario. 


\subsection{Organization of Thesis}

This thesis is organized into eight chapters. This first chapter described the problem, background information on superstreets, research objectives, and scope of the project. The second chapter presents a literature review of relevant studies on median u-turns and superstreets. Chapter three describes the methodology of the operational study, which includes the operational comparison of superstreets to conventional intersections. Chapter four explains the process behind the calibration and validation of the VISSIM models. Chapter five contains the results of the operational analyses. Chapter six explains the methodology of the resident survey. Chapter seven describes the results of the resident survey. Finally, chapter eight contains the conclusions of the research project, including recommendations and future research needs. 


\subsection{LITERATURE REVIEW}

The literature review for this project addresses operational studies on both superstreets and median u-turns. An important part of the superstreet concept is the use of directional median u-turns, which is why it is important to include median u-turns in the literature review. Most of the studies on median u-turns give similar results showing that the design decreases average total delay at an intersection and reduces the number of conflict points and collisions. There are fewer studies available on superstreets. Most of the studies on superstreets are based on macroscopic analyses and simulations of hypothetical arterials.

\section{$2.1 \quad$ Median U-turns}

Median u-turns are similar to the superstreet in that both designs eliminate left turns from the minor road to the arterial and send them instead to downstream directional u-turn crossovers. The difference between the median u-turn intersection and the superstreet is that the median u-turn allows through movements from both the arterial and minor road at the main intersection. No left turns from the arterial to the minor road are allowed at the main intersection, which operates with a two-phase signal. Figure 2.1 shows a diagram of the median u-turn design.

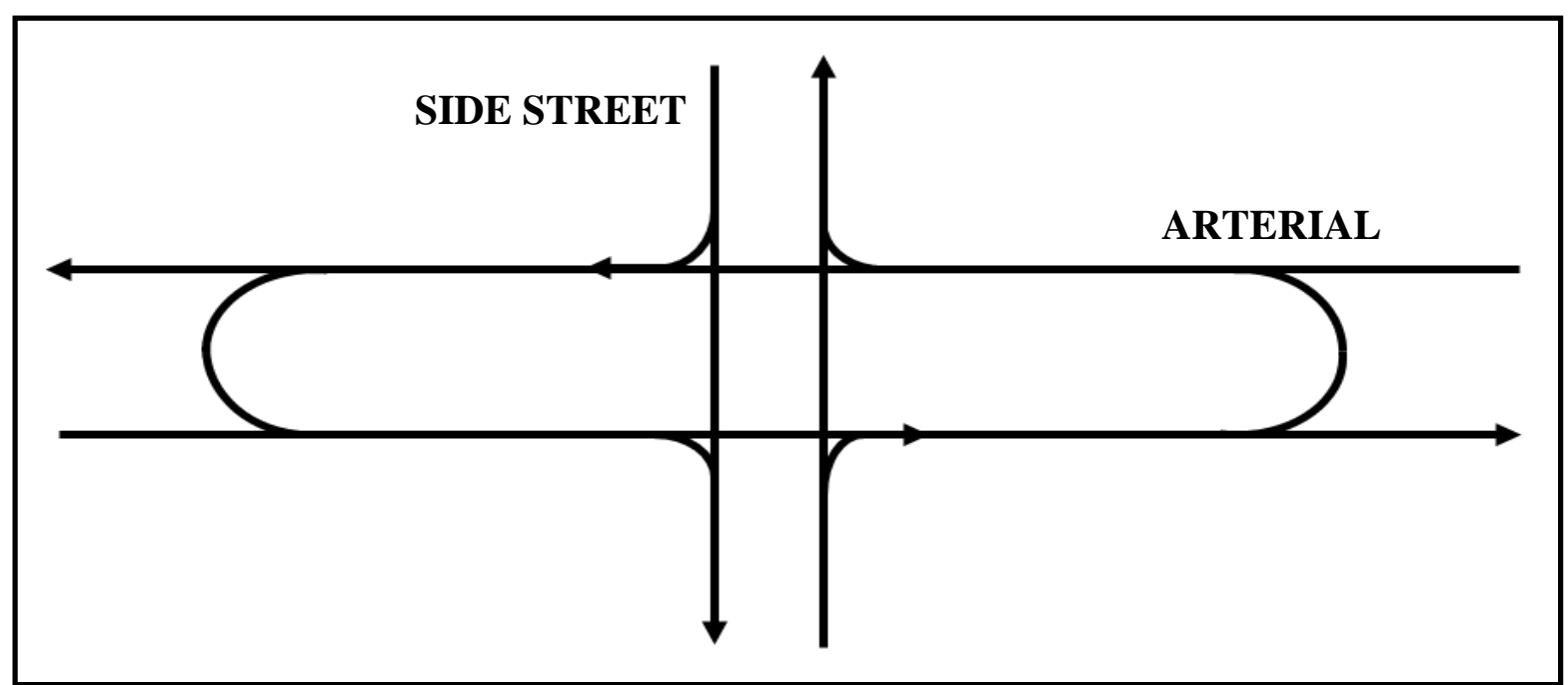

FIGURE 2.1 Median u-turn design. 
There is a large variety of literature on median u-turns. The studies of interest to this project include operational research for signalized intersections, as well as access management studies. Some of the research topics include capacity of u-turns at unsignalized and signalized openings, and travel time efficiency of median u-turns.

\subsubsection{Operations}

Al-Maseid (1) conducted a study on capacity of u-turns at median openings using two different methods- empirical and gap-acceptance. The U-turn capacity model showed strong correlation between conflicting traffic flow and average total delay. The gap-acceptance model showed that critical gap varied according to average total delay and speed of conflicting traffic flow. Both models yielded similar results for high and low conflicting traffic volumes. The differences between the models were not significant at the 95\% confidence level so he concluded that both models give similar capacity results. Al-Maseid noted that it is important to consider the delay effect on gap acceptance because drivers change behavior the longer they have to wait, therefore accepting smaller gaps.

Liu et al (2) also performed a study on capacity of u-turns at median openings. Their study was conducted on multilane highways in the Tampa Bay, Florida area. They predicted that the factors affecting u-turn capacity would be major street traffic volume in the direction of conflict, the critical gap for u-turn movements, and the follow up time for u-turn movements. Results showed that u-turns at narrow median openings have a larger critical gap than those at wide medians, and that median size can greatly affect the capacity - wide medians were found to have up to $268 \mathrm{pcu} / \mathrm{h}$ greater capacity than narrow medians. The major street traffic volume was also a major factor - u-turn capacity decreased at a faster rate than the capacity of a left turn movement from a major street when the major street volume increased.

The Michigan Department of Transportation is a frequent user of directional crossovers on their boulevards to relieve capacity problems that are associated with interlocking left turns in bi-directional crossovers. Maki reported on this strategy (3); at the time (1996) Michigan 
had over 425 miles of boulevards with 700 directional crossovers in their state highway system. A capacity analysis resulted in a $20-50 \%$ capacity improvement, although it is not clear in the report what volumes this applies to, or how many sites were analyzed. The measures of effectiveness (MOEs) used for the operational analysis were network total time and left turn total time in the network. The network consisted of six intersections. It was found that even though left-turning vehicles would have to travel a longer distance, that extra travel time was offset by delay savings at the intersection (compared to direct left turns), which is similar to findings from other papers. Since this analysis was done on a network of six intersections, it is possible that smaller networks with one, two or three intersections would yield different results.

Dorothy et al performed a study (4) that compared a five-lane highway with a two-way left turn lane (TWLTL) to a four-lane highway with a median (boulevard design). The measures of effectiveness used were network total time (total time vehicle spends in the network which includes delay and travel time), and left turn total time (time it takes to make a left turn as a combination of delay and travel time). All analysis was done using TRAF-NETSIM computer simulation and modeling. Results showed that the boulevard design with indirect left turns and signalized crossovers had best results for both total network time and left turn total time. Boulevards with direct left turns had the highest amount of delay.

Hummer and Boone's study on unconventional arterial intersection designs for NCDOT (5) compared the travel efficiency of the median u-turn, continuous green T, and the NCSU bowtie intersections to conventional intersections. They used Traf-Netsim 4.0 for network simulation which was calibrated using field data from Michigan, Florida and Maryland. The MOEs were total travel time and number of stops. The median u-turn was most effective with higher through volumes and left turns. The relative efficiency varied with the through volume. The median u-turn overall led to more travel time and stopped delay for left-turning vehicles than the standard intersection. 
Bared and Kaisar (6) performed a study investigating the operational benefits of median uturns for left-turning vehicles. They compared a typical intersection (four lanes intersecting four lanes) to a median u-turn design. Their median u-turn design implemented u-turns for the left-turning vehicles on the major road and direct left turns within the intersection for vehicles on the minor road, which is opposite from a typical superstreet. CORSIM was used for model simulation and TRANSYT-7F was used for signal optimization. Average network travel time became noticeably better for the median u-turn design for entering flows upwards of $6000 \mathrm{vph}$. Bared and Kaisar also found that the average proportion of vehicles that stop in the network is $20-40 \%$ lower for the U-turn design; however, stopping time is higher for the u-turning vehicles by 10-18 s/veh because they are likely to stop at both the main intersection and the left turn bay downstream. The significance of the results could have been greater if the models were calibrated with field data and if a series of intersections was used instead of an isolated intersection.

Henderson and Stamatiadis (7) conducted a study on how median u-turns improve traffic flow along arterials. Their study implemented median u-turns on a major arterial in Lexington, Kentucky to see how it would help relieve congestion. They looked at the both the bowtie and superstreet designs before deciding that the median u-turn would be more appropriate given the geometry of the road in an effort to keep construction time and cost at a minimum. Modeling was done using TSIS and CORSIM, while TRANSYT-7F was used for signal optimization. A p.m. peak hour travel time study validated the models. The researchers implemented median u-turns at intersections with high left turn volumes and high delays. The computer simulation had the following system-wide effects from the median uturns: increased speed, decreased average and total delay time, and an increase in move/total time ratio, therefore increasing the efficiency of the network. Peak hour travel times were reduced by $32 \%$ and delays were reduced by $35 \%$. They also ran a simulation that widened the arterial to three instead of two lanes in each direction, but the median u-turn efficiency remained superior. Table 2.1 is a summary of the network-wide operating measures of effectiveness. 
TABLE 2.1 Summary of Network-wide Operating MOE (7)

\begin{tabular}{|l|c|c|c|c|}
\hline & $\begin{array}{c}\text { Move/Total } \\
\text { time }\end{array}$ & $\begin{array}{c}\text { System } \\
\text { speed } \\
\text { (mph) }\end{array}$ & $\begin{array}{c}\text { Total } \\
\text { delay } \\
\text { (veh-hr) }\end{array}$ & $\begin{array}{c}\text { Average delay } \\
\text { (min/veh-trip) }\end{array}$ \\
\hline \hline Existing Conditions & 0.35 & 15.4 & 855 & 3.40 \\
\hline Signal Optimization & 0.36 & 16.2 & 842 & 3.22 \\
\hline Additional Lane & 0.41 & 17.8 & 703 & 2.65 \\
\hline U-turns $^{1}$ & 0.41 & 17.8 & 647 & 2.45 \\
\hline U-turns $^{2}$ & 0.44 & 19.0 & 583 & 2.19 \\
\hline U-turns \& Additional Lane & 0.47 & 20.8 & 498 & 1.85 \\
\hline
\end{tabular}

Note:

1. At four intersections

2. At six intersections

Thakkar et al (8) conducted a study to evaluate the impacts of prohibiting median opening movements. The factors that were investigated included: impacts on adjacent intersection operations, median opening/driveway operations, arterial weaving operations, overall system operations, rerouted motorist's convenience, safety, cost-benefit value, and public acceptance. The investigators made the case that preventing left turns at a median opening or driveway would shift the traffic to the nearest intersection, which would in turn decrease the operation level due to heavier u-turn traffic volumes. This would not necessarily be the case for superstreets since a designated directional crossover is built into the design, and would theoretically be able to handle the volume of traffic needing to make u-turns to switch directions.

\subsubsection{Access Management}

The TRB Access Management Manual (9) presented studies done across the country indicating that raised medians have little to no overall adverse impact on surrounding businesses. In Kansas, changes in traffic patterns did not cause a change in use in the abutting businesses. In Texas, the perception of the median installation by business owners prior to construction is usually worse than reality. Also, "accessibility to store" is usually 
ranked lower than customer service, quality of product, and product price by business owners when asked what factors were important in attracting customers.

Similar results were found in a study done by the Texas Transportation Institute (10) addressing the economic impacts of raised medians. This four-year study was done at eleven locations to assess the effects prior, during, and after construction of raised medians. Through surveys and interviews with business owners and customers, the researchers found that the only major adverse impact raised medians have is during the construction phase. For businesses that were present before, during, and after construction, property value increased by 6.7 percent after the construction of the raised median compared to the before conditions, while owners thought they would experience a decrease in value. The duration of construction typically lasted one to two years, with construction dates between 1979 and 1998 for all study locations. As with other studies, accessibility is ranked lower in importance for destination businesses, while slightly higher for pass-by businesses such as gas stations. Overall, the study concludes that there is no negative economic impact caused by raised medians.

\subsection{Superstreets}

Richard Kramer (11) first developed the superstreet concept in the 1980s as a way to alleviate congestion on arterials. While the concept was new, the techniques he used were not. Kramer listed ten "dream" characteristics of ideal operations on an arterial, with the major focus on the importance of giving through traffic priority. The ten characteristics are as follows:

1. Its three or four lanes in each direction of travel would receive a minimum of two-thirds to three-fourths of the signal cycle as green time at all intersections encountered along its entire length.

2. Each direction of travel would be signalized for progressive movement so that traffic would simultaneously flow as smoothly in each direction as if it were two parallel one way streets. 
3. Thru traffic would be protected (by signalization) from conflicting left turns from the opposing direction.

4. Direct left turns would be provided from the arterial at frequent intervals, and would be protected by signalization from conflicting thru traffic movements from the opposing direction.

5. The facility would accommodate all maneuvers of increased truck sizes and combinations allowable under the 1982 STAA.

6. Pedestrians crossing this arterial would be provided protected signal phasing and be free from (lawful) conflict with any vehicular traffic crossing their path; and the spacing of pedestrian crossing would be so convenient as to discourage pedestrian crossing at unprotected locations.

7. The facility would also provide for transit operations that would not impede thru traffic movement at any bus stop.

8. Transit bus operations would be enhanced by providing stops at all convenient locations in close proximity to protected pedestrian crossings.

9. The geometric design of the facility would accommodate the infusion of additional major traffic generators with minimal adverse affect to the road user; i.e., thru traffic could continue to receive a minimum of two-thirds to three-fourths of the signal cycle as arterial green time.

10. Signalization timing and offset programs for this arterial would be independently variable for each direction to take into account changes in traffic volumes, provide for special event (stadium) traffic, and accommodate an uninterrupted flow for emergency vehicles having onboard pre-emption equipment.

These characteristics provide the foundation for the superstreet design, which results in perfect signalized progression. Each direction of the arterial acting as independent one-way streets allows the flexibility to change progression speed, cycle lengths, and signal spacing in either direction while still maintaining optimal progression along the corridor.

Hummer (12) in 1998 presented seven unconventional alternatives for intersections that focus on left turns to and from the arterial. The two major points of the designs are to reduce delay for through traffic and decrease the number of conflict points. Both the median u-turn and superstreet are presented in this paper. While the paper does not include any quantitative studies, data, or analysis, it does present the designs with a description, variations, history, advantages, disadvantages, and when to consider each alternative. Since the superstreet design is closely related to the median u-turn design, it is not surprising that similar 
advantages and disadvantages are listed for both options. Both designs are said to operate best with low to medium left turn volumes from the minor street. The median u-turn can handle more minor street through traffic than the superstreet, but the superstreet can handle more left turns from the arterial. The superstreet also has the advantage of "perfect progression” in both directions at any time with any intersection spacing.

Hummer (13) also wrote a chapter on superstreets in an information report by the FHWA on non-traditional intersections and interchanges. The chapter covers all aspects of the superstreet design, including operations, safety, signalization treatment, pedestrian accommodations, and access management considerations. VISSIM was used to assess the operational performance of 5 geometric design cases, where 90 unique simulations were done for both superstreet and comparable conventional intersections. When the ratio of minor road volumes compared to total intersection volumes is small (less than 0.25), simulation results show that superstreets have higher intersection capacities and shorter travel times than conventional intersections. Pedestrians are accommodated better in low to medium volumes scenarios.

Kim, Edara, and Bared (14) conducted a study on the operation and safety performance of the superstreet. The study analyzed three scenarios of the superstreet design - one left lane and two through lanes on major road, one left lane and three through lanes on major road, and two left lanes and three through lanes - and compared them to the conventional intersection. Using VISSIM to run various traffic flows, the researchers came up with ideal volumes where a superstreet would function better than a standard intersection. Those volumes were 260-340 veh/h/ln for left turn traffic and 900-1150 veh/h/ln for through traffic on the major road with one left turn lane and two to three through lanes. It is important to keep in mind that this analysis was done without collecting field data to calibrate the models or check the numbers.

Reid and Hummer (15) conducted an experiment comparing travel time efficiency of median u-turns to two-way left turn lanes and superstreets. The tests were done using CORSIM with 
real traffic volumes and geometry from a median u-turn arterial in Detroit, MI. Four time periods were tested - AM peak, noon, midday, and PM peak. The superstreet proved better than the TWLTL in mean speed for all four time periods and total system time for the peak periods; however it had the highest mean stops for all time periods compared to both the TWLTL and median u-turn. The superstreet was inferior to the median u-turn for all four time periods in all three categories - total system time, mean stops per vehicle, and mean speed. At first glance it seems that the median u-turn is superior to the superstreet, but it is important to remember that the volumes used were based on an existing median u-turn arterial with high cross street through volumes. Superstreets are not designed to handle high cross street volumes, as their primary function is to serve the through vehicles. The results from this experiment were restated in another paper by Hummer and Reid (16) on unconventional left turn alternatives for urban and suburban arterials.

Another study by Reid and Hummer (17) compared travel times between seven unconventional arterial intersection designs, which included both the median u-turn and superstreet. The study obtained actual data from seven high-volume, conventional intersections in North Carolina and Virginia and used them to construct traffic models in CORSIM. For each simulation model the number of lanes, signal timing parameters, design speeds, turn bay lengths and driver characteristics were all kept constant. Three volume levels were used: peak afternoon, 15\% greater than peak afternoon, and midday (off-peak). The use of the off-peak volumes makes this study noteworthy since they take into consideration that designers will want to know how the unconventional design performs at all times of the day, not just the peak period. Results showed that while the conventional design had the fewest amount of stops, at each type of intersection analyzed there was at least one unconventional design that had a lower travel time. Superstreets only proved better than the conventional design at intersections with two-lane cross streets, although superstreets were still optimal for two-way progression. 
Lu and Liu (18) conducted a study on the operational evaluation of right turns followed by uturns in which they developed travel time regression models for right turn u-turns (RTUT) at both signalized intersections and unsignalized median openings. Data were collected from sixteen four-lane arterial sites in Florida. The sites were selected based on the following criteria: raised median with full or directional opening big enough to safely store vehicles, four lanes of through traffic (two in each direction), speed limit of $40 \mathrm{mph}$ or higher, driveway with either two lanes (one for right turn and one for left turn) or shoulder flare so the two movements do not interfere, high RTUT and direct left turn (DLT) volumes, median width wide enough to store left turn vehicles, and downstream signal with exclusive left turn lane and protected left turn phase. The travel time regression models developed were based on RTUT flow rate, length to downstream intersection, and percent split in upstream through traffic. Table 2.2 shows the comparison of the average total travel time for different volume categories for a RTUT at a signalized intersection (sig), a RTUT at a median opening (med), and a direct left turn. The model, however, does not take deceleration or acceleration into consideration, and it does not take the vehicle through the entire length of the intersection.

TABLE 2.2 Comparison of the Average Total Travel Time in Different Volume Categories (18)

\begin{tabular}{|c|c|c|c|c|}
\hline \multicolumn{2}{|c|}{ Traffic Volume (vph) } & \multicolumn{3}{|c|}{ Average Travel Time (sec) } \\
\hline $\begin{array}{l}\text { Through } \\
\text { Volume }\end{array}$ & $\begin{array}{c}\text { Left turn/U-turn } \\
\text { volume }\end{array}$ & RTUT (sig) & RTUT (med) & DLT \\
\hline 1000-1999 vph & \multirow{4}{*}{$0-49 \mathrm{vph}$} & 101.2 & 48.1 & 22.2 \\
\hline 2000-2999 vph & & 114.1 & 53.3 & 28.8 \\
\hline 3000-3999 vph & & 115.2 & 74.3 & 40.5 \\
\hline$>=4000 \mathrm{vph}$ & & N/A & N/A & 49.7 \\
\hline 1000-1999 vph & \multirow{4}{*}{$>=50 \mathrm{vph}$} & 116.7 & 50.8 & 22.8 \\
\hline 2000-2999 vph & & 122.6 & 55.1 & 32.2 \\
\hline 3000-3999 vph & & 114.7 & 64.2 & 40.8 \\
\hline$>=4000 \mathrm{vph}$ & & 111.4 & 72.6 & 48.7 \\
\hline
\end{tabular}


A paper presented at the $3^{\text {rd }}$ Urban Street Symposium by Hummer et al (19) explores the capacity and progression of superstreets. To find intersection capacity they used the HCM critical lane volume method but with modifications for the superstreet. Adjustments to the ideal saturation flow rate were made for trucks, and an average saturation headway of 2.1 seconds was used to calculate a new base critical lane capacity of $1587 \mathrm{pcu} / \mathrm{hr} / \mathrm{ln}$. Lane volumes were also adjusted to account for the slower speeds of turning movements. The authors created an Excel spreadsheet to check demand against capacity. While they recommend this procedure as a good starting tool for planners and traffic engineers to determine the feasibility of a superstreet intersection, it does have limitations since it does not address delay or travel times. FHWA recently released an alternative intersection selection tool (20) that builds upon this concept using the critical lane volume as a comparable method to determine capacity at conventional and unconventional intersections, including the superstreet.

Hummer et al (19) also researched the effects of progression speed on total travel time and total delay. A Synchro model was built representing the first superstreet opened on US-17 in Brunswick County, NC. Existing intersection spacing was used; however assumptions and simplifications were made for traffic volumes and geometry. Different scenarios were run involving different levels of entering volumes, turning volumes, and progression speed, for a total of 32 model runs. The results showed total delay staying approximately constant across varying speeds, while travel time changes with speed. It also showed that the impact of additional through vehicles is less than the impact of additional turning movements and side street volumes. This study could be expanded by using the actual geometry from the site in a model and comparing how it performs against the model with the simplified geometry.

\subsection{Other Unconventional Intersection Designs}

There are other unconventional intersections designs in place with similar concepts to the superstreet. One of those is the reduced conflict intersection (RCI), developed by Denny Eyler (21). The RCI prohibits direct left and through movements from the minor street, 
similar to the superstreet. The minor street through and lefts essentially do a two-stage crossing, first crossing one direction of traffic, but then travel away from the "center" of the intersection to cross the other direction. Figure 2.2 shows a layout of the RCI.

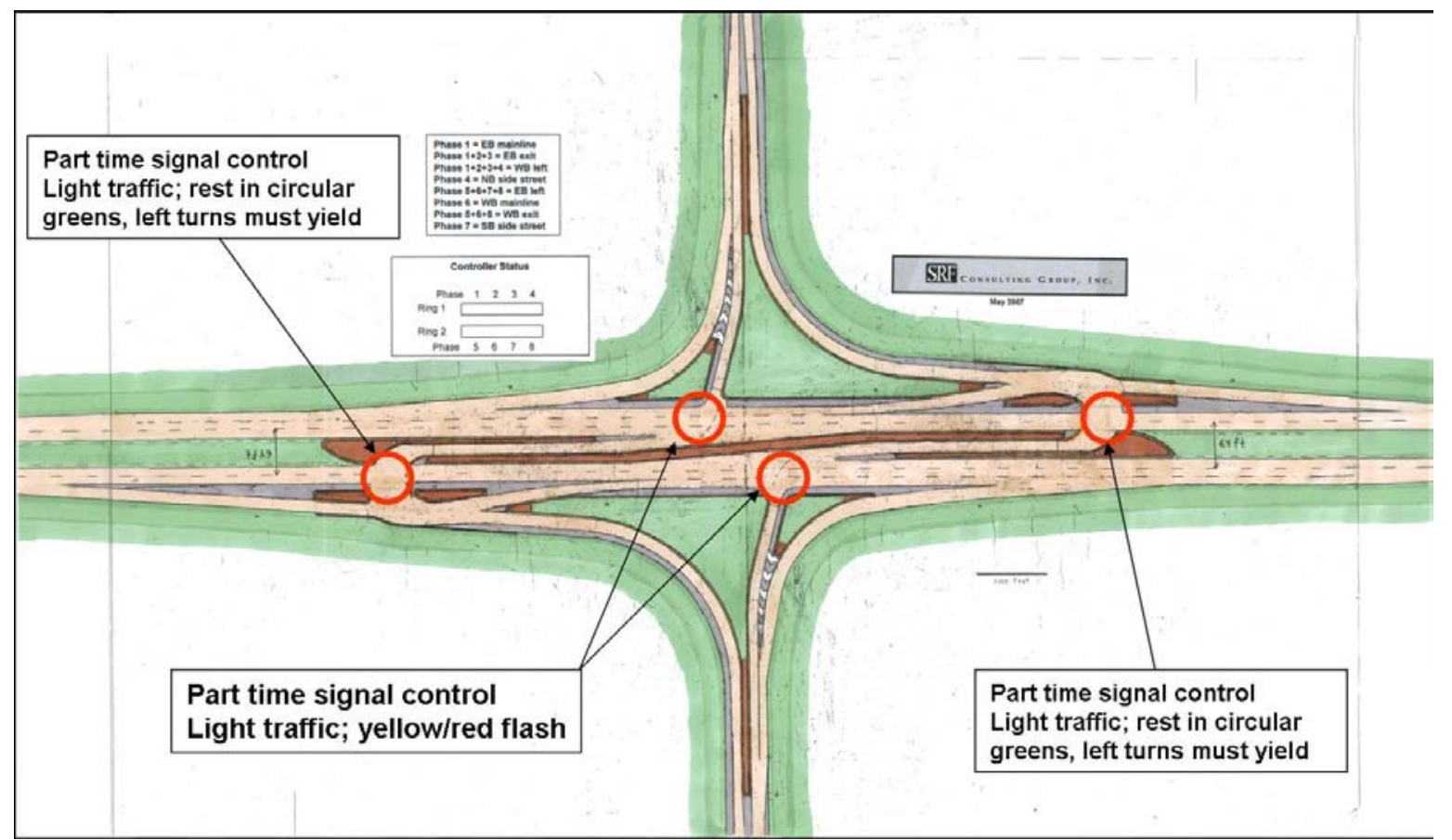

FIGURE 2.2 Reduced Conflict Intersection developed by D. Eyler, SRF Consulting Group, Inc. (21)

Demand-based signal controls are used to help guide traffic efficiently when excessive queues or delays are detected. A partial RCI was built on US 169 near Mankato, Minnesota. Currently there have not been any studies done the operational affects of reduced conflict intersections. 


\subsection{OPERATIONAL METHODOLOGY}

This chapter describes the methodology used for the operational analysis conducted for this research project. The operational analysis involved simulating three signalized superstreets in North Carolina and comparing them to the equivalent conventional intersection. This chapter describes the process behind the site selection, data collection, and data analysis.

\subsection{Identification and Selection of Sites}

The sites selected for the operational study were taken from a list that included all operating signalized superstreets in North Carolina. The criteria for selection were signalization on all legs of the intersection and at each crossover location. Unsignalized superstreet sites, also referred to as directional crossovers, were not analyzed in the operational study because they are generally implemented in rural areas as a safety countermeasure. There are currently four existing signalized superstreet sites in North Carolina. Three of these sites were selected for the study and are listed below in Table 3.1. Figures 3.1 through 3.7 show aerial photos of the study sites and the distances to the u-turn crossovers. The only site not chosen for this study was a corridor on US-17 in Pender and New Hanover counties. This site was eliminated because of low volumes along the minor roads.

TABLE 3.1 Signalized Superstreet Sites Selected for Operational Study

\begin{tabular}{|c|c|c|c|}
\hline Arterial & $\begin{array}{c}\text { No. of } \\
\text { Intersections }\end{array}$ & Cross Street(s) & Location \\
\hline \hline US-15/501 & 1 & Erwin Rd./Europa Dr. & Chapel Hill, NC \\
\hline US-421 & 1 & Myrtle Gardens Dr./Carolina Beach Rd. & Wilmington, NC \\
\hline US-17 & 5 & $\begin{array}{r}\text { Ploof Rd./Poole Rd. } \\
\text { Gregory Rd./Walmart entrance } \\
\text { West Gate Dr./Grandiflora Dr. } \\
\text { Brunswick Forest Pkwy } \\
\text { Lanvale Rd./Brunswick Forest Dr. }\end{array}$ & Leland, NC \\
& & & \\
\hline
\end{tabular}




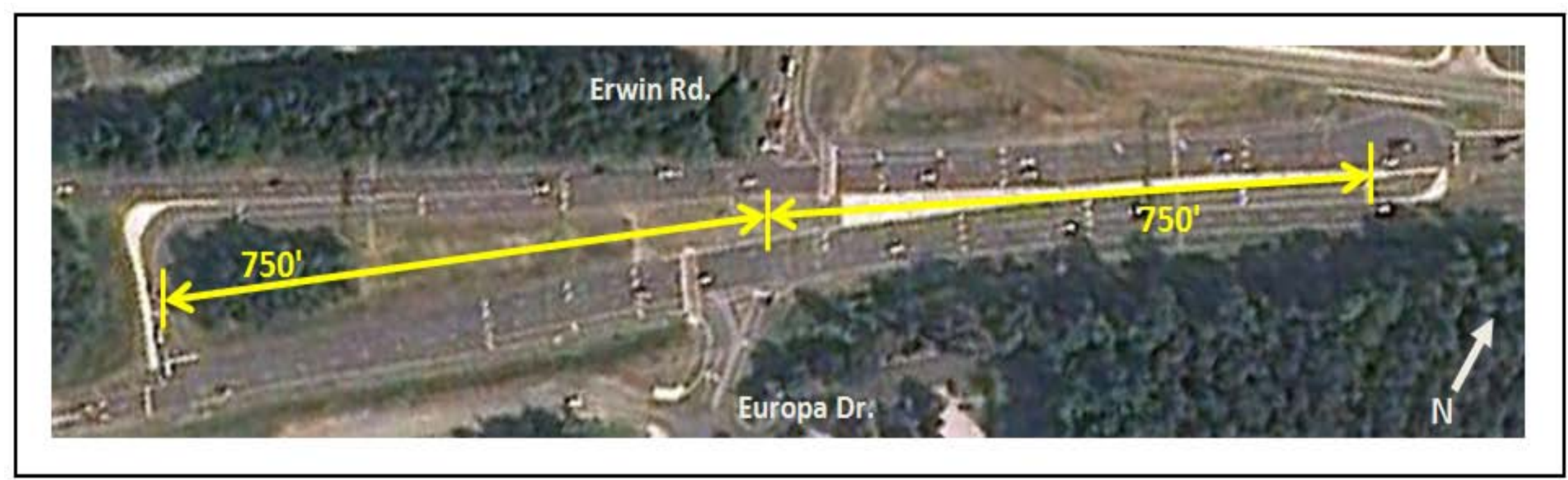

FIGURE 3.1 US-15/501 at Erwin Rd./Europa Dr. in Chapel Hill, NC.

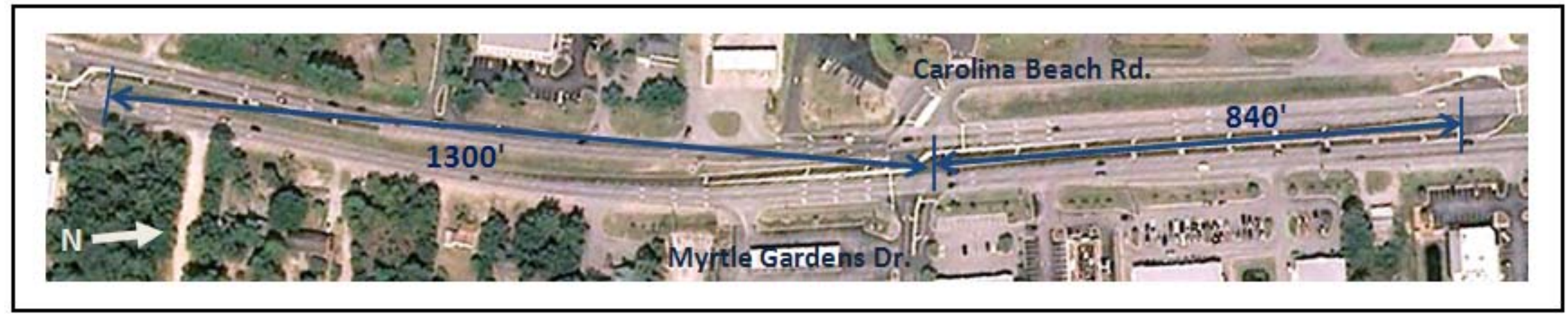

FIGURE 3.2 US-421 at Myrtle Gardens Dr./Carolina Beach Rd. in Wilmington, NC. 


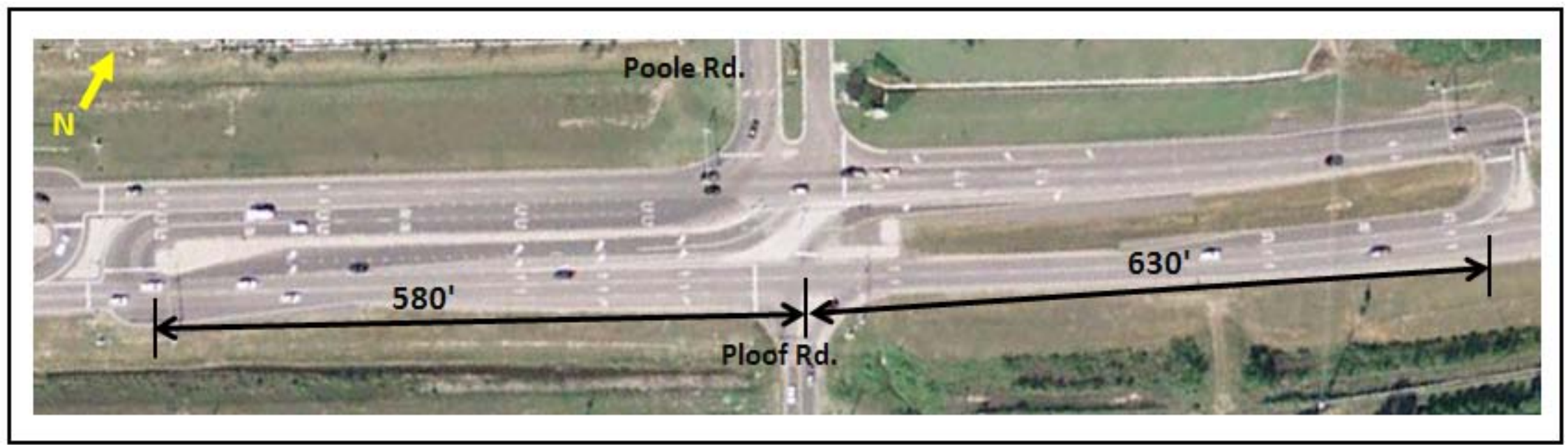

FIGURE 3.3 US-17 at Ploof Rd./Poole Rd. in Leland, NC.

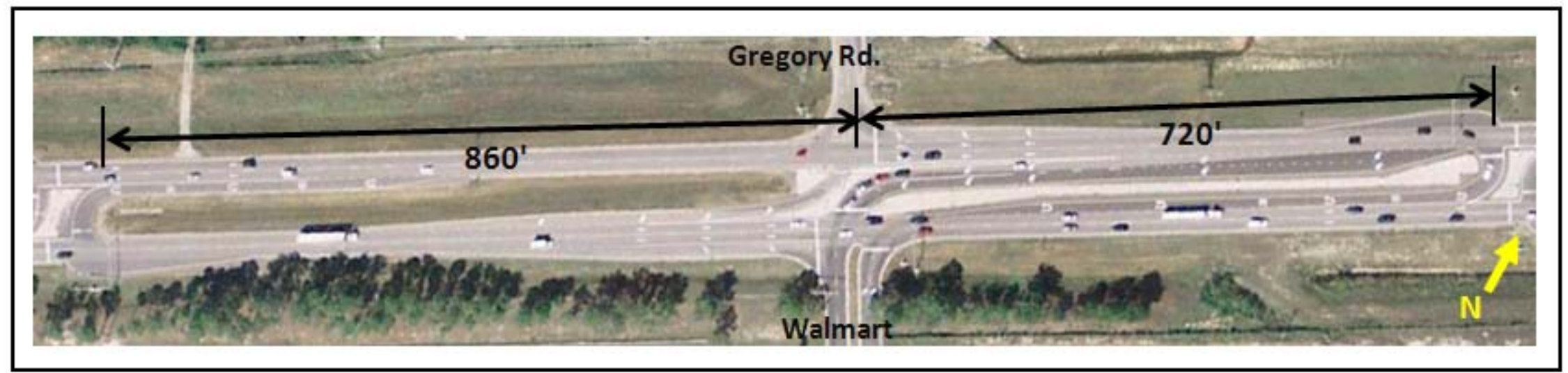

FIGURE 3.4 US-17 at Walmart/Gregory Rd. in Leland, NC. 


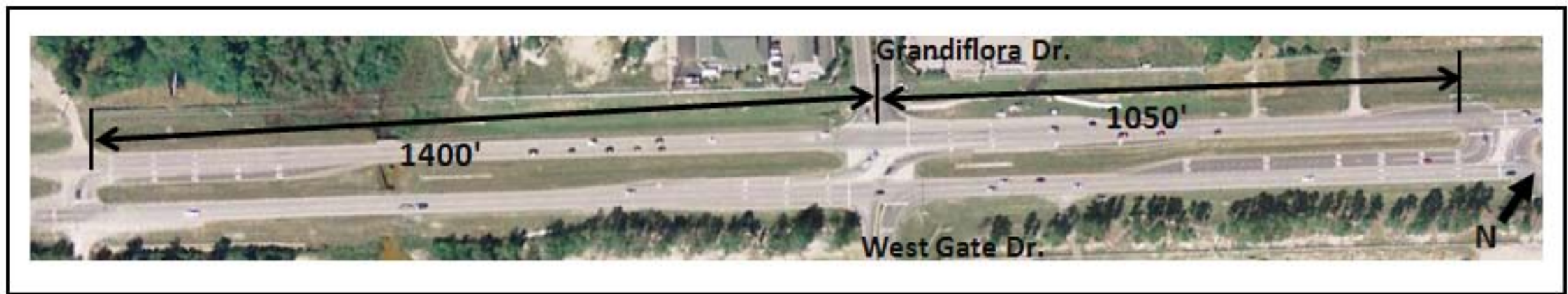

FIGURE 3.5 US-17 at Grandiflora Dr./West Gate Dr. in Leland, NC.

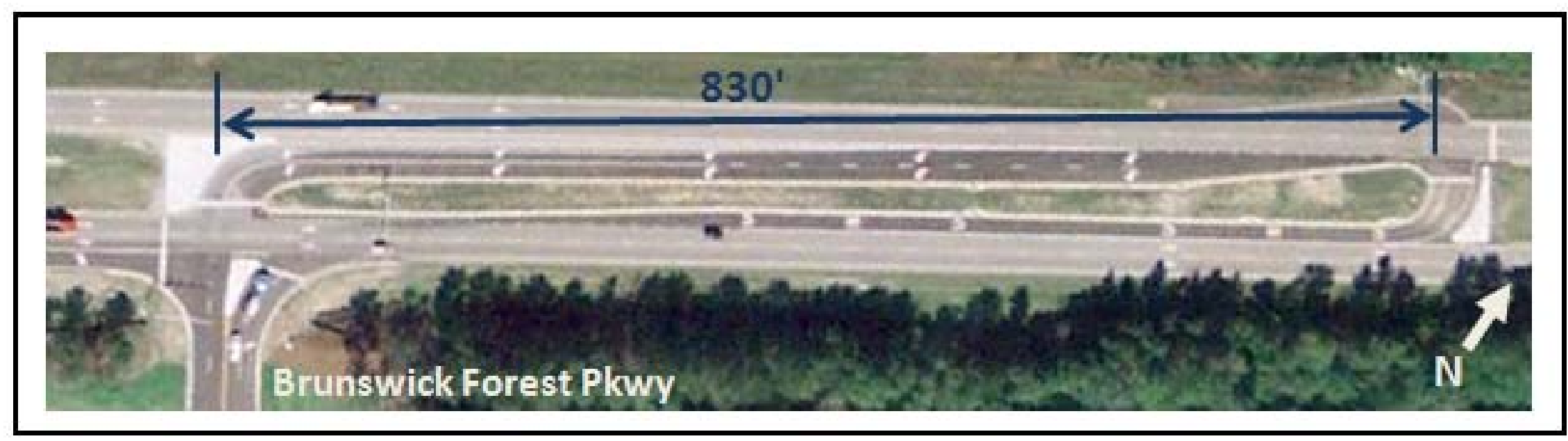

FIGURE 3.6 US-17 at Brunswick Forest Pkwy. in Leland, NC. 


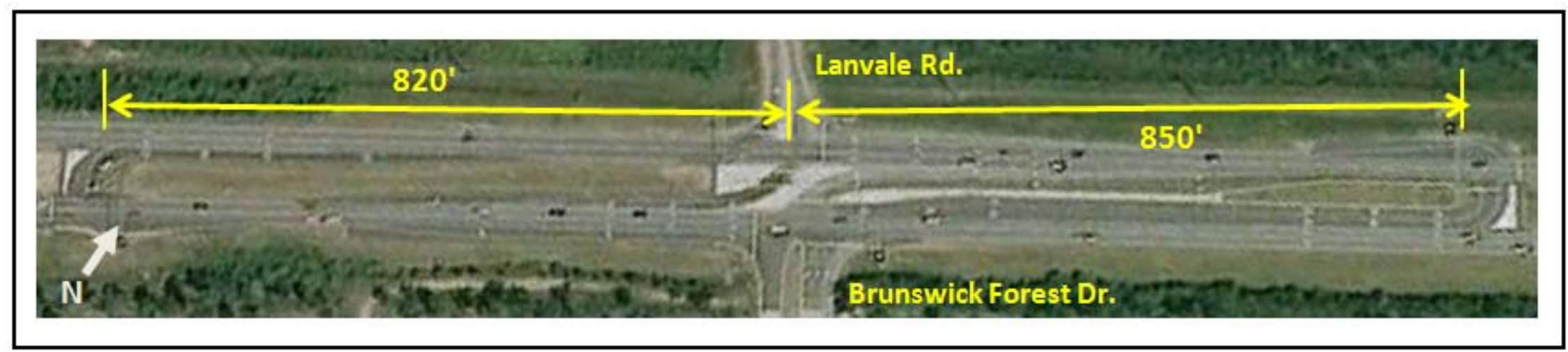

FIGURE 3.7 US-17 at Lanvale Rd./Brunswick Forest Dr. in Leland, NC. 


\subsection{Data Collection}

The field data I collected from each of the three NC study sites were turning movement counts, travel times, and free-flow speeds. The turning movement counts and free-flow speeds were used as model inputs. The travel times collected in the field were compared to the VISSIM travel time output during the calibration and validation process. The field data can be found in Appendix A.

\subsubsection{Turning Movement Data}

To collect the turning movement counts I set up video cameras (two or three depending on the site) to capture all movements at the central intersection and the crossovers. I collected the data in two 90-minute sets at each site, which was limited by the length of the video tapes.

Origin-destination counts were extracted from the videos for each of the twelve turning movements at the intersection (left, through, and right from each leg) by tracking the individual vehicles. Vehicles were counted in five-minute intervals, then converted into 15minute flows. Tracking the vehicles through the intersection is a time-consuming but necessary process due to the redirection of side street traffic at superstreets. All u-turning vehicles were ignored, as well as vehicles entering from and exiting to driveways along the arterial. I counted cars and heavy vehicles separately to determine the vehicle distribution at each site.

\subsubsection{Travel Time Data}

Travel time runs were done simultaneously with the turning movement count data collection using GPS units in the vehicle. Prior to collecting the data, I collected an initial set of travel time runs from the Chapel Hill superstreet to determine the sample size needed. At a 95\% confidence level with a $3.0 \mathrm{mph}$ permitted error, I needed a minimum of three runs for each movement (22). When collecting the actual data I conducted as many travel time runs that 
time permitted before the 90-minute video tape ran out, or before traffic volume characteristics changed.

The US 17 superstreet in Leland consists of five total intersections, with three intersections back-to-back and the remaining two farther apart. I collected data at two of the five intersections - US-17 at Walmart/Gregory Road and US-17 at Lanvale Road. Based on traffic volume observations and the number of lanes from the minor road and at the crossovers, the data from these intersections would be representative of the remaining three intersections. The data collected from these intersections were applied to the remaining intersections along the US-17 corridor.

The data collected from all three sites were post-processed in the office using GeoStats TravTime 2.0. Travel time runs were constructed in the program using the GPS data points collected in the field. I calculated the achieved permitted error for all travel time movements based on the tables from the ITE Manual of Transportation Engineering Studies (22). Table 3.2 lists the achieved permitted travel time error from each site for the combined twelve movements.

TABLE 3.2 Achieved Permitted Travel Time Error for All Movements

\begin{tabular}{|l|c|c|}
\hline Site & Range (mph) & Avg. (mph) \\
\hline \hline Chapel Hill & $1.5-5.0$ & 2.8 \\
Wilmington & $1.0-5.0$ & 2.4 \\
US-17 (Walmart/Gregory Rd.) & $1.0-3.0$ & 1.8 \\
US-17 (Lanvale Rd.) & $1.0-5.0$ & 2.3 \\
\hline
\end{tabular}

\subsubsection{Free-flow Speed Data}

The final set of data I collected was free-flow speed data. Speeds were collected during offpeak periods using a laser gun. For each of the three sites I collected speeds at a location approaching the superstreet but far enough away from the influence of signals. Using the laser gun, I collected the speeds of randomly selected non-platooned vehicles. I used these 
data to construct a speed distribution curve for each site for use in VISSIM. Each distribution was checked using the chi-squared goodness-of-fit test, and all were confirmed normally distributed.

\subsection{Data Analysis}

Using the data collected in the field, I calibrated and validated the three superstreet models in VISSIM. I also constructed models in VISSIM of an equivalent conventional signalized intersection, had the superstreet not been built. The reason for using VISSIM over other programs, such as SimTraffic, was because of the ability to specify origin-destination segments for collecting travel time. Travel time was used as the measure of effectiveness for the calibration and validation of the models, and in the comparison of the superstreet and conventional models, so it was important to be able to specify the origin and destination points for the travel time segments.

It was important to keep the comparison between the superstreet to the conventional intersection fair. For this analysis, I defined "fair" based on geometry only, not cost. This analysis was not a "before and after" comparison, but a comparison of the superstreet design to an equivalent conventional intersection. The geometries (i.e. lanes) of the conventional intersections were updated from the before scenario prior to the construction of the superstreet. This was done to replicate what the conventional improvements would have been had the superstreet not been built, assuming that improvements would have been made at each site. At the Chapel Hill site, this included adding an additional left turn lane in both directions of the major road. The superstreet along the US-17 corridor was built in conjunction with major development along the arterial - a new Super-Walmart was constructed, along with new retail, business, and residential developments. In this case I made assumptions on the number of lanes for the conventional intersections.

Table 3.3 lists the approach configurations for each site. The major road with the u-turn crossovers was the north-south street in each case. There were two approaches where there 
were fewer lanes for the conventional than the superstreet, while there were four approaches with fewer lanes for the superstreet than the conventional. As with the superstreet models, the conventional models also included the adjacent intersections. I did not make any geometric improvements to the adjacent intersections.

TABLE 3.3 Lane Configurations by Approach for Study Sites

\begin{tabular}{|c|c|c|c|c|c|c|c|c|c|c|}
\hline \multirow[b]{2}{*}{ SITE } & \multicolumn{6}{|c|}{ SUPERSTREET } & \multicolumn{4}{|c|}{ CONVENTIONAL } \\
\hline & NB & SB & EB & WB & $\begin{array}{l}\text { South } \\
\text { UT }\end{array}$ & $\begin{array}{c}\text { North } \\
\text { UT }\end{array}$ & NB & SB & EB & WB \\
\hline Chapel Hill & $\mathrm{T}, \mathrm{T}, \mathrm{R}$ & $\mathrm{T}, \mathrm{T}, \mathrm{R}$ & $\mathrm{R}, \mathrm{R}$ & $\mathrm{R}, \mathrm{R}$ & 2 & 2 & $\begin{array}{c}\mathrm{L}, \mathrm{L}, \\
\mathrm{T}, \mathrm{T}, \mathrm{R}\end{array}$ & $\begin{array}{c}\mathrm{L}, \mathrm{L}, \\
\mathrm{T}, \mathrm{T}, \mathrm{R}\end{array}$ & LT,R & LT,R \\
\hline Wilmington & $\begin{array}{l}\mathrm{L}, \mathrm{T}, \\
\mathrm{T}, \mathrm{R}\end{array}$ & $\begin{array}{l}\mathrm{L}, \mathrm{T}, \\
\mathrm{T}, \mathrm{R}\end{array}$ & $\mathrm{R}, \mathrm{R}$ & $\mathrm{R}, \mathrm{R}$ & 1 & 1 & $\begin{array}{l}\mathrm{L}, \mathrm{T}, \\
\mathrm{T}, \mathrm{R}\end{array}$ & $\begin{array}{l}\mathrm{L}, \mathrm{T}, \\
\mathrm{T}, \mathrm{R}\end{array}$ & $\mathrm{L}, \mathrm{T}, \mathrm{R}$ & $\mathrm{L}, \mathrm{TR}$ \\
\hline $\begin{array}{l}\text { US-17: } \\
\text { Ploof }\end{array}$ & $\begin{array}{c}\mathrm{L}, \mathrm{L}, \\
\mathrm{T}, \mathrm{T}, \mathrm{R}\end{array}$ & $\begin{array}{l}\mathrm{L}, \mathrm{T}, \\
\mathrm{T}, \mathrm{R}\end{array}$ & $\mathrm{R}, \mathrm{R}, \mathrm{R}$ & $\mathrm{R}$ & 2 & 1 & $\begin{array}{c}\mathrm{L}, \mathrm{L}, \\
\mathrm{T}, \mathrm{T}, \mathrm{R}\end{array}$ & $\begin{array}{l}\mathrm{L}, \mathrm{T}, \\
\mathrm{T}, \mathrm{R}\end{array}$ & $\mathrm{L}, \mathrm{T}, \mathrm{R}$ & $\mathrm{L}, \mathrm{TR}$ \\
\hline $\begin{array}{l}\text { US-17: } \\
\text { Walmart }\end{array}$ & $\begin{array}{l}\mathrm{L}, \mathrm{T}, \\
\mathrm{T}, \mathrm{R}\end{array}$ & $\begin{array}{c}\mathrm{L}, \mathrm{L}, \\
\mathrm{T}, \mathrm{T}, \mathrm{R}\end{array}$ & $\mathrm{R}$ & $\mathrm{R}, \mathrm{R}$ & 1 & 1 & $\begin{array}{l}\mathrm{L}, \mathrm{T}, \\
\mathrm{T}, \mathrm{R}\end{array}$ & $\begin{array}{c}\mathrm{L}, \mathrm{L}, \\
\mathrm{T}, \mathrm{T}, \mathrm{R}\end{array}$ & $\mathrm{L}, \mathrm{TR}$ & $\mathrm{L}, \mathrm{TR}$ \\
\hline $\begin{array}{c}\text { US-17: } \\
\text { Grandiflora }\end{array}$ & $\begin{array}{l}\mathrm{L}, \mathrm{T}, \\
\mathrm{T}, \mathrm{R}\end{array}$ & $\begin{array}{l}\mathrm{L}, \mathrm{T}, \\
\mathrm{T}, \mathrm{R}\end{array}$ & $\mathrm{R}, \mathrm{R}$ & $\mathrm{R}, \mathrm{R}$ & 2 & 2 & $\begin{array}{l}\mathrm{L}, \mathrm{T}, \\
\mathrm{T}, \mathrm{R}\end{array}$ & $\begin{array}{l}\mathrm{L}, \mathrm{T}, \\
\mathrm{T}, \mathrm{R}\end{array}$ & $\mathrm{L}, \mathrm{TR}$ & $\mathrm{L}, \mathrm{TR}$ \\
\hline $\begin{array}{c}\text { US-17: } \\
\text { Brunswick } \\
\text { Forest }\end{array}$ & $\mathrm{T}, \mathrm{T}, \mathrm{R}$ & $\begin{array}{l}\mathrm{L}, \mathrm{L}, \\
\mathrm{T}, \mathrm{T}\end{array}$ & - & $\mathrm{R}, \mathrm{R}$ & - & 1 & $\mathrm{~T}, \mathrm{~T}, \mathrm{R}$ & $\begin{array}{l}\mathrm{L}, \mathrm{L}, \\
\mathrm{T}, \mathrm{T}\end{array}$ & - & $\mathrm{L}, \mathrm{R}$ \\
\hline $\begin{array}{l}\text { US-17: } \\
\text { Lanvale }\end{array}$ & $\begin{array}{l}\mathrm{L}, \mathrm{T}, \\
\mathrm{T}, \mathrm{R}\end{array}$ & $\begin{array}{c}\mathrm{L}, \mathrm{L}, \\
\mathrm{T}, \mathrm{T}, \mathrm{R}\end{array}$ & $\mathrm{R}$ & $\mathrm{R}, \mathrm{R}, \mathrm{R}$ & 1 & 2 & $\begin{array}{l}\mathrm{L}, \mathrm{T}, \\
\mathrm{T}, \mathrm{R}\end{array}$ & $\begin{array}{l}\mathrm{L}, \mathrm{T}, \\
\mathrm{T}, \mathrm{R}\end{array}$ & $\mathrm{L}, \mathrm{TR}$ & $\mathrm{L}, \mathrm{TR}$ \\
\hline
\end{tabular}

To keep the comparison fair, I used Synchro to optimize signal timings for both the superstreets and the conventional intersections. This was done for various demand levels. I used the yellow and all-red times from the original superstreet timings from the field since the intersection widths did not change very much. All signals were coded as actuatedcoordinated with protected left turns. Signal timings and offsets were optimized for each network. Tables 3.4 through 3.6 list the cycle lengths for all intersections in this study. 
TABLE 3.4 Cycle Lengths for Chapel Hill Superstreet and Conventional Intersections (sec)

\begin{tabular}{|l|c|c|c|c|c|c|}
\hline $\begin{array}{c}\text { Demand Level } \\
\text { Intersections }\end{array}$ & $\begin{array}{c}\text { Peak- } \\
\mathbf{4 0 \%}\end{array}$ & $\begin{array}{c}\text { Peak- } \\
\mathbf{2 0 \%}\end{array}$ & $\begin{array}{c}\text { Peak- } \\
\mathbf{1 0 \%}\end{array}$ & Peak & $\begin{array}{c}\text { Peak+ } \\
\mathbf{1 0 \%}\end{array}$ & $\begin{array}{c}\text { Peak+ } \\
\mathbf{2 0 \%}\end{array}$ \\
\hline \hline Superstreet: & & & & & & \\
\hline Ephesus Church* & 80 & 90 & 110 & 120 & 100 & 110 \\
\hline South UT & 110 & 115 & 115 & 120 & 110 & 115 \\
\hline Europa & 110 & 115 & 115 & 120 & 110 & 115 \\
\hline Erwin & 90 & 105 & 105 & 120 & 85 & 95 \\
\hline North UT & 90 & 105 & 105 & 120 & 85 & 95 \\
\hline Sage/Old Durham* & 90 & 105 & 105 & 120 & 120 & 125 \\
\hline \hline Conventional: & & & & & & \\
\hline Ephesus Church & 90 & 120 & 120 & 120 & 100 & 110 \\
\hline Erwin/Europa & 90 & 120 & 120 & 120 & 110 & 130 \\
\hline Sage/Old Durham & 90 & 120 & 120 & 120 & 115 & 125 \\
\hline
\end{tabular}

*Adjacent conventional intersections

TABLE 3.5 Cycle Lengths for Wilmington Superstreet and Conventional Intersections (sec)

\begin{tabular}{|l|c|c|c|c|c|c|}
\hline $\begin{array}{c}\text { Demand Level } \\
\text { Intersections }\end{array}$ & $\begin{array}{c}\text { Peak- } \\
\mathbf{4 0 \%}\end{array}$ & $\begin{array}{c}\text { Peak- } \\
\mathbf{2 0 \%}\end{array}$ & $\begin{array}{c}\text { Peak- } \\
\mathbf{1 0 \%}\end{array}$ & Peak & $\begin{array}{c}\text { Peak+ } \\
\mathbf{1 0 \%}\end{array}$ & $\begin{array}{c}\text { Peak+ } \\
\mathbf{2 0 \%}\end{array}$ \\
\hline \hline Superstreet: & & & & & & \\
\hline Sanders* & 75 & 80 & 100 & 90 & 110 & 120 \\
\hline South UT & 75 & 80 & 100 & 90 & 110 & 120 \\
\hline Myrtle Gardens & 75 & 80 & 100 & 90 & 110 & 120 \\
\hline Carolina Beach & 80 & 110 & 90 & 120 & 130 & 130 \\
\hline North UT & 80 & 55 & 90 & 60 & 130 & 130 \\
\hline College/Piner* & 80 & 110 & 90 & 120 & 130 & 130 \\
\hline \hline Conventional: & & & & & & \\
\hline Sanders & 75 & 115 & 115 & 120 & 120 & 120 \\
\hline Myrtle Gardens & 75 & 115 & 115 & 120 & 120 & 120 \\
\hline College/Piner & 75 & 115 & 115 & 120 & 120 & 120 \\
\hline
\end{tabular}

*Adjacent conventional intersections 
TABLE 3.6 Cycle Lengths for US-17 Superstreet and Conventional Intersections (sec)

\begin{tabular}{|l|c|c|c|c|c|c|}
\hline Intersections & $\begin{array}{c}\text { Peak- } \\
\mathbf{4 0 \%}\end{array}$ & $\begin{array}{c}\text { Peak- } \\
\mathbf{2 0 \%}\end{array}$ & $\begin{array}{c}\text { Peak- } \\
\mathbf{1 0 \%}\end{array}$ & Peak & $\begin{array}{c}\text { Peak+ } \\
\mathbf{1 0 \%}\end{array}$ & $\begin{array}{c}\text { Peak+ } \\
\mathbf{2 0 \%}\end{array}$ \\
\hline \hline Superstreet: & & & & & & \\
\hline Ploof & 110 & 95 & 120 & 120 & 120 & 120 \\
\hline Ploof North UT & 70 & 90 & 90 & 100 & 105 & 120 \\
\hline Poole & 70 & 90 & 90 & 100 & 105 & 120 \\
\hline Poole South UT & 110 & 95 & 120 & 120 & 120 & 120 \\
\hline Walmart & 110 & 95 & 120 & 120 & 120 & 120 \\
\hline Walmart North UT & 70 & 90 & 90 & 100 & 105 & 120 \\
\hline Gregory & 70 & 90 & 90 & 100 & 105 & 120 \\
\hline Gregory South UT & 110 & 95 & 120 & 120 & 120 & 120 \\
\hline West Gate & 110 & 95 & 120 & 120 & 120 & 120 \\
\hline West Gate North UT & 70 & 90 & 90 & 100 & 105 & 120 \\
\hline Grandiflora & 70 & 90 & 90 & 100 & 105 & 120 \\
\hline Grandiflora South UT & 110 & 95 & 120 & 120 & 120 & 120 \\
\hline Brunswick Forest Pkwy & 70 & 90 & 60 & 70 & 105 & 120 \\
\hline Brunswick Forest North UT & 110 & 95 & 90 & 100 & 120 & 120 \\
\hline Brunswick Forest Dr. & 70 & 90 & 60 & 70 & 105 & 120 \\
\hline Brunswick Forest North UT & 110 & 95 & 90 & 100 & 120 & 120 \\
\hline Lanvale & 110 & 95 & 90 & 100 & 120 & 120 \\
\hline Lanvale South UT & 70 & 90 & 60 & 70 & 105 & 120 \\
\hline \hline Conventional: & & & & & & \\
\hline Ploof/Poole & 95 & 115 & 120 & 120 & 150 & 150 \\
\hline Walmart/Gregory & 95 & 115 & 120 & 120 & 150 & 150 \\
\hline Grandiflora/West Gate & 95 & 75 & 120 & 120 & 150 & 150 \\
\hline Brunswick Forest & 75 & 75 & 120 & 120 & 105 & 105 \\
\hline Lanvale/Brunswick Forest & 75 & 75 & 120 & 120 & 105 & 105 \\
\hline
\end{tabular}

With varying volume levels and optimized signal timings, the travel time output from the superstreet model was compared to the travel time output from the conventional model for all three sites. Using travel time as the measure of effectiveness in this analysis allows for a fair comparison between superstreets and conventional intersections because superstreets have 
additional signals and require drivers to travel an extra distance to complete certain maneuvers. The analysis was done comparing the travel times for each turning movement, as well as comparing the average travel time per vehicle for the intersection as a whole. 


\subsection{CALIBRATION AND VALIDATION OF VISSIM MODELS}

This chapter describes the processes used to calibrate and validate the superstreet models in VISSIM. I collected two sets of field data from each site - turning movement counts, travel times, and free-flow speeds - to calibrate and validate each model.

The measure of effectiveness (MOE) used for calibration and validation was the travel time output from VISSIM compared to the travel times collected in the field for all 12 movements at the intersection (left, through, and right turn from each leg). This was also the MOE used in the analysis of the results. Superstreets have additional signals and require drivers to travel and extra distance to complete certain movements. Using travel time as the MOE allows for a fair comparison between the superstreet and conventional intersection because it takes into account any extra delay at the signals and the extra time it might take to complete a turning movement.

\subsection{Model Construction}

The VISSIM models were calibrated using field data collected at each of three superstreet sites. I collected two sets of data from each site - the first data set was used for the calibration, and the second data set was used for validating the models. The data included turning movement counts, travel times, and free flow speeds at four intersections - two out of the five superstreet intersections from the US-17 corridor, and one superstreet intersection each at US-15/501 in Chapel Hill and US-421 in Wilmington. This set of intersections makes up most of the signalized superstreets in North Carolina. Currently, the only other signalized site in NC is on US-17 near the Pender and New Hanover County lines. This site was not included in the study because of low minor street volumes. I used the turning movement counts for the vehicle inputs and origin-destination routing decisions, and the free-flow speeds for speed distributions specific to each site. 
The models were coded to replicate the superstreets using construction drawings and aerial photography from Google Earth. Both the Chapel Hill and Wilmington superstreets have adjacent conventional signalized intersections, which I included in the models to account for platooning effects as vehicles enter the superstreet. All the signal timing data that were used in the models, for both the superstreet and adjacent conventional intersections, were actual field timings that were received from the NCDOT, the City of Wilmington, and the Town of Chapel Hill.

Since I included the adjacent intersections in the models, I made assumptions on the percentages of the vehicle inputs that were coming from each leg of the adjacent intersection. For Chapel Hill I assumed a 60/40 split for the northbound vehicles, and a 80/20 split for the southbound vehicles (the larger percentage of vehicles coming from the main arterial). For Wilmington, I assumed a 75/25 split for the northbound vehicles, and a 70/30 split for the southbound vehicles. These assumptions were based on knowledge on the operations of the adjacent intersection from field observations. The US-17 corridor does not have adjacent signalized intersections, so the model only includes the five superstreet intersections along the corridor. Vehicles arrived at the first signal on US-17 in a random arrival distribution. Vehicle counts were binned into 15-minute counts, then converted to 15-minute flows since VISSIM requires volume inputs to be entered in vehicles per hour.

Each superstreet model was run in sets of 10 runs. I applied a 15-minute seeding period to provide adequate time to fill the network with vehicles. The simulation period for Chapel Hill and Wilmington was 5400 seconds (1.5 hours), and the period was 6300 seconds (1.75 hours) for US-17. The duration of each simulation was based on the amount of traffic volume data I had from the first set of field data which was time-limited by the video tapes used to record the data. Travel time output files were not collected during the seeding period. All models were run using the multi-run setting, with a starting random seed of 1 and with a random seed increment of 1 for each run in the set of 10 . 


\subsection{Model Calibration}

I calibrated the models using travel time as the comparison between VISSIM and the field data. I collected travel time data from four intersections - the superstreet intersections in Chapel Hill and Wilmington, and two intersections along the US-17 superstreet corridor. Each intersection had twelve possible travel patterns (left, through, and right at each leg of the intersection), for a total of 48 movements that were driven. The purpose of the calibration was to test the mean percent difference in field collected travel time versus modeled travel time over each of the 48 movements. I achieved this by combining the travel times for each of the 48 movements from all three sites and calibrating the models together based on the mean percent difference to achieve a "global" calibration rather than calibrating them as individual sites. This was done to find the single set of VISSIM parameters that, for all the sites, was the best, rather than settling for different VISSIM parameters for different sites.

The main parameters adjusted in VISSIM were speed distribution and conflict areas. The speed distribution for each site was based on the free-flow speed data collected in the field. During the calibration process, I kept the same shape of the distribution curve, but changed the mean speed. The final speed distribution used for all three sites was a $25 \%$ reduction of the original free-flow speed data I collected in the field. The free-flow speed data were collected during the off-peak period on the arterial approaching the superstreet, but far enough away from the influence of the signals. Having to reduce the speeds to calibrate the model is not surprising because the models are capturing the peak periods so there is a higher volume of traffic, and vehicles travel slower through the intersection than on the open arterial.

Conflict areas were used for coding the right turn on red (RTOR) at all sites, and for the flashing yellow arrows utilized by NCDOT at Wilmington to allow permitted/protected lefts for the mainline left turn movements and at the u-turn crossovers. I used the video from Wilmington to calculate the average rear gap that vehicles accepted when making a u-turn 
and major left maneuver on a flashing yellow arrow, as well as a RTOR. This was the only site with proper video footage to collect these data, so I applied the RTOR gap values from the Wilmington site to the Chapel Hill and US-17 models. Table 4.1 lists the front and rear gap values used in VISSIM. At the time of data collection, the flashing yellow arrow was still a new concept in North Carolina, so I was unaware if vehicles were not accepting gaps as efficiently as expected because of the actual gap size, or because of unfamiliarity of the flashing yellow arrow. For future studies of superstreets, I recommend conducting a more thorough gap study at crossovers with flashing yellows and for RTOR in conjunction with VISSIM calibration.

TABLE 4.1 Gap Values Used for Coding Conflict Areas in VISSIM

\begin{tabular}{|c|c|c|c|c|c|c|}
\hline \multirow{2}{*}{ SITE } & \multicolumn{2}{|c|}{ RTOR } & \multicolumn{2}{c|}{$\begin{array}{c}\text { U-turn } \\
\text { (flashing yellow) }\end{array}$} & \multicolumn{2}{c|}{$\begin{array}{c}\text { Major left } \\
\text { (flashing yellow) }\end{array}$} \\
\cline { 2 - 7 } & $\begin{array}{c}\text { Front gap } \\
\text { (sec) }\end{array}$ & $\begin{array}{c}\text { Rear gap } \\
\text { (sec) }\end{array}$ & $\begin{array}{c}\text { Front gap } \\
\text { (sec) }\end{array}$ & $\begin{array}{c}\text { Rear gap } \\
\text { (sec) }\end{array}$ & $\begin{array}{c}\text { Front gap } \\
\text { (sec) }\end{array}$ & $\begin{array}{c}\text { Rear gap } \\
\text { (sec) }\end{array}$ \\
\hline Chapel Hill & 2.0 & 3.6 & N/A & N/A & N/A & N/A \\
Wilmington & 2.0 & 3.6 & 3.0 & 7.1 & 2.0 & 5.5 \\
US-17 & 2.5 & 3.6 & N/A & N/A & N/A & N/A \\
\hline
\end{tabular}

To calibrate the models I ran multiple sets of runs for each site as I adjusted parameters in VISSIM. Table 4.2 shows the parameters adjusted for each set of runs. "Set 1" is the earliest effort and "Set 5" is the latest effort. I did not follow any particular method when changing the parameters in each set; I simply ran a set of runs, checked the results, adjusted the parameters, and repeated until I found the final set of parameters. The order of conducting these sets of runs does not have an impact on the outcome of the final set of results. The models could be replicated by disregarding the adjustments I made in sets one through four, and directly inputting the parameters I used in the final set of runs (set five). The final set of parameters can be found in Appendix B. 


\section{TABLE 4.2 VISSIM Parameters Adjusted in Each Set of Runs During Calibration}

\begin{tabular}{|c|c|c|c|c|}
\hline SET 1 & SET 2 & SET 3 & SET 4 & SET 5 \\
\hline $\begin{array}{l}\text { - } \text { orig. } \\
\text { parameters } \\
\text { - no } \\
\text { adjustments }\end{array}$ & $\begin{array}{l}\text { - reduced orig. } \\
\text { speed dist. by } \\
20 \% \\
\text { - reduced } \\
\text { speed zones } \\
\text { for u-turns } \\
\text { - incr. SF for } \\
\text { conflict areas } \\
\text { for minor } \\
\text { RTOR }\end{array}$ & $\begin{array}{l}\text { - } \text { reduced orig. } \\
\text { speed dist. by } \\
25 \% \\
\text { - } \text { added reduced } \\
\text { speed zones } \\
\text { for UT } \\
\text { approaches } \\
\text { - } \text { added desired } \\
\text { speed } \\
\text { decisions for } \\
\text { minor roads } \\
\text { - reduced des. } \\
\text { speed zones } \\
\text { for all turns }\end{array}$ & $\begin{array}{l}\text { - updated } \\
\text { signal timing } \\
\text { offsets }\end{array}$ & $\begin{array}{l}\text { - adjusted gap } \\
\text { values for al } \\
\text { RTOR and } \\
\text { flashing } \\
\text { yellow } \\
\text { arrows }\end{array}$ \\
\hline
\end{tabular}

Table 4.3 shows the percent difference in the VISSIM travel time output compared to field data for each site, as well as the mean difference for all sites combined. The Lanvale Rd. intersection, part of the US-17 corridor, had consistently high differences in travel time and did not calibrate as well as the other models. This is a low-volume intersection, and the travel time data were collected at a different time than the other data from the corridor, and were therefore under a different time of day plan for the signal operations. In the model, I used signal plans for the same time of day for the entire corridor. The discrepancy in the signal timing between the model and when I collected the field data at Lanvale Rd. could be a reason for the large differences in travel time. The final calibration value was a mean percent difference of $-15.2 \%$ between the VISSIM output and field data. Fifteen percent is a generally accepted target for comparing model and observed travel times (23). 
TABLE 4.3 Percent Difference in Travel Time (VISSIM - field data) from Calibration

\begin{tabular}{|l|c|c|c|c|c|}
\hline SITE & SET 1 & SET 2 & SET 3 & SET 4 & SET 5 \\
\hline \hline Chapel Hill & $-16.9 \%$ & $-12.2 \%$ & $-9.5 \%$ & $-9.5 \%$ & $-9.2 \%$ \\
Wilmington & $-22.3 \%$ & $-22.5 \%$ & $-21.9 \%$ & $-21.9 \%$ & $-18.7 \%$ \\
US-17 (Walmart) & $-24.5 \%$ & $-16.9 \%$ & $-10.0 \%$ & $-9.6 \%$ & $-8.5 \%$ \\
US-17 (Lanvale Rd) & $-35.9 \%$ & $-31.7 \%$ & $-23.8 \%$ & $-23.4 \%$ & $-25.0 \%$ \\
\hline Mean difference & $\mathbf{- 2 3 . 7 \%}$ & $\mathbf{- 2 0 . 6 \%}$ & $\mathbf{- 1 6 . 0 \%}$ & $\mathbf{- 1 5 . 8 \%}$ & $\mathbf{- 1 5 . 2 \%}$ \\
\hline
\end{tabular}

\subsection{Model Validation}

With the calibration complete, I validated the models using the second set of field data. The second set of field data was collected in the same manner as the first, but at a different time of day. All parameters in the models were kept the same as they were in the final calibration set. The only changes made to the models were the signal timings, which were adjusted to the time of day plans corresponding to the time when the second data set was collected, and the vehicle inputs. The vehicle counts from the second field data set were grouped in 15minute flows. The models were run in sets of 10 runs each, keeping the same seeding time, simulation period, and random seed generation as in the calibration stage.

Table 4.4 lists the percent difference in travel time for each site and the overall mean percent difference. The final mean percent difference comparing the VISSIM travel time output to the field data was $-4.4 \%$. Since the mean percent differences are less that the percent differences from the calibration stage, all models are validated. Both the calibration and validation results can be found in Appendix C.

\section{TABLE 4.4 Percent Difference in Travel Time (VISSIM - field data) from Validation}

\begin{tabular}{|l|c|}
\hline SITE & SET 1 \\
\hline \hline Chapel Hill & $5.6 \%$ \\
Wilmington & $-10.5 \%$ \\
US-17 (Walmart) & $2.1 \%$ \\
US-17 (Lanvale Rd) & $-17.6 \%$ \\
\hline Mean percent difference & $\mathbf{- 4 . 4 \%}$ \\
\hline
\end{tabular}




\subsection{OPERATIONAL RESULTS}

This chapter describes the results from the operational analysis comparing superstreets to conventional intersections.

Using the calibrated and validated models of three of the four signalized superstreets in North Carolina, I set up an experiment to test the operational effects of superstreets compared to conventional intersections. Models of the equivalent conventional intersection at each site were also constructed in VISSIM. I ran both the superstreet and conventional models from each site at various demand levels and collected the travel time output to compare the superstreet against the conventional, as well as to find the capacity limits of the superstreet.

\subsection{Travel Time Comparison}

As discussed in the methodology chapter, I ran both the superstreet and conventional models from each site in VISSIM under varying demand levels. For each site I used the flow from the peak 15-minute period from the turning movement count field data as the baseline. It was important to use volume levels greater than and less than the peak to compare the two designs not only during periods with increased demand, but also during off-peak periods. The following demand levels were used in the comparison:

- Peak

- Peak minus $10 \%$

- Peak minus $20 \%$

- Peak minus $40 \%$

- Peak plus $10 \%$

- Peak plus $20 \%$

- Peak plus $40 \%$

I ran all models in sets of 10 runs for each demand level. A 15-minute seeding period was used to provide adequate time to fill the network with vehicles. The simulation period was 
one hour for all models. Travel time output files were not collected during the seeding period. All models were run using the multi-run setting, with a starting random seed of one and with a random seed increment of one for each run in the set of 10. I used Equation 5.1 (23) to determine if 10 runs were sufficient for producing the estimated mean travel time within $15 \%$ of the true mean at the $95 \%$ confidence level. Fifteen percent was chosen as the desired confidence level because that was used as the target for the calibration of the models.

\section{Equation $5.1 \quad \mathrm{CI}_{(1-\alpha) \%}=2 * \mathrm{t}_{(1-\alpha / 2), \mathrm{N}-1} \mathrm{~S} / \sqrt{ } \mathbf{N}$}

Where:

$\mathrm{CI}_{(1-\alpha) \%}=$ the $(1-\alpha) \%$ confidence interval for the true mean, where alpha equals the probability of the true mean not lying within the confidence interval

$\mathrm{T}_{(1-\alpha / 2), \mathrm{N}-1}=$ the $\mathrm{t}$ statistic for the probability of the two-sided error summing to alpha within $\mathrm{N}-1$ degrees of freedom

$\mathrm{N}=$ the number of repetitions

$\mathrm{S}=$ the standard deviation of the model results

The following shows an example calculation of the confidence interval for the WBL movement at the Chapel Hill superstreet for the peak demand level. The average travel time was 152 seconds with a standard deviation of 7.04 seconds.

$$
\begin{aligned}
\mathrm{CI}_{(1-\alpha) \%} & =2 * \mathrm{t}_{(1-\alpha / 2), \mathrm{N}-1} \mathrm{~S} / \sqrt{ } \mathrm{N} \\
& =2 *(2.262) *(7.044) / \sqrt{ } 10 \\
& =10.08 \mathrm{sec}
\end{aligned}
$$

$\mathrm{CI}$ as a percent of travel time $=\left[\left(\mathrm{CI}_{(1-\alpha) \%} / \mathrm{Avg} . \mathrm{TT}\right) * 100\right] / 2$

$$
\begin{aligned}
& =[(10.08 / 152) * 100] / 2 \\
& =3.31 \%
\end{aligned}
$$

The achieved confidence interval for the WBL movement at Chapel Hill during the peak period was within $3.31 \%$ of the true mean travel time. All models, both superstreet and 
conventional, from each site were well within the 15\% target. Table 5.1 shows the achieved confidence interval for the travel time results. The results were within $+/-2.4$ to $6.5 \%$ of the true mean travel time. Therefore, I did not make more VISSIM runs than the original ten for each scenario.

\subsection{Achieved Confidence Interval for Travel Time Results}

\begin{tabular}{|c|c|c|}
\hline \multirow{2}{*}{ Site } & \multicolumn{2}{|c|}{ Confidence Interval } \\
\cline { 2 - 3 } & Superstreet & Conventional \\
\hline \hline Chapel Hill & $2.4 \%$ & $3.2 \%$ \\
Wilmington & $2.5 \%$ & $5.9 \%$ \\
US-17 corridor & $3.6 \%$ & $6.5 \%$ \\
\hline
\end{tabular}

Certain geometric factors at the sites were influencing the travel time output enough at the higher demand levels that I made some changes to the original models. At the Chapel Hill site there is a lane drop after the adjacent conventional intersection just south of the superstreet. This lane drop was causing major congestion at the peak $+10 \%$ and higher demand levels, so vehicles were not entering the superstreet at the demand level expected. To get the full demand into the superstreet, I added an additional lane to alleviate the lane drop problem. This allowed the vehicles to enter the superstreet at the appropriate demand level, and thus allowed for a better analysis of the capabilities of the design without compromising the fair comparison. This modified geometry was used for the peak $+10 \%$ and peak $+20 \%$ levels for both the superstreet and conventional models. I kept the original geometry for all other demand levels because the upstream lane drop did not affect traffic flow into the superstreet, and I wanted to keep the existing conditions as much as possible for a more accurate assessment of the superstreet at that location.

The other major factor that affected the travel time results was the adjacent intersections. At the higher demand levels (peak+20\% and peak+40\%), these intersections were over capacity and failing, causing major delay and congestion to spill back to the superstreet locations. Using the data from these scenarios would not be a fair representation of the superstreet, so I 
did not include the peak $+40 \%$ scenario in the results. The US- 17 corridor does not have nearby adjacent signalized intersections, but at the peak+20\% level the conventional comparison reached its limit, and any higher demand level caused errors in the model output.

I collected travel time output for all twelve turning movements at each intersection. At each intersection the major road runs in the north/south direction, while the minor road runs east/west. Tables 5.2 through 5.7 give the volumes and travel times for each movement at each intersection I studied. The average travel time per vehicle for each movement was calculated and compared between the superstreet and conventional intersection. Figures 5.1 through 5.7 display the results from each intersection. A negative percent difference means the superstreet required less travel time than the conventional, while a positive percent difference means the superstreet required more travel time.

TABLE 5.2 Chapel Hill Volumes by Movement (vph)

\begin{tabular}{|c|c|c|c|c|c|c|}
\hline Movement & $\begin{array}{c}\text { Peak- } \\
\mathbf{4 0 \%}\end{array}$ & $\begin{array}{c}\text { Peak- } \\
\mathbf{2 0} \%\end{array}$ & $\begin{array}{c}\text { Peak- } \\
\mathbf{1 0 \%}\end{array}$ & Peak & Peak+10\% & Peak+20\% \\
\hline \hline WBL & 29 & 40 & 46 & 50 & 55 & 59 \\
\hline WBR & 94 & 121 & 137 & 153 & 167 & 183 \\
\hline WBT & 36 & 52 & 57 & 63 & 67 & 72 \\
\hline EBL & 22 & 30 & 34 & 39 & 43 & 47 \\
\hline EBR & 197 & 259 & 290 & 323 & 352 & 386 \\
\hline EBT & 30 & 41 & 46 & 50 & 55 & 62 \\
\hline NBL & 130 & 172 & 206 & 216 & 238 & 257 \\
\hline NBR & 31 & 41 & 46 & 51 & 55 & 59 \\
\hline NBT & 950 & 1270 & 1414 & 1590 & 1758 & 1905 \\
\hline SBL & 55 & 72 & 81 & 88 & 94 & 109 \\
\hline SBR & 35 & 48 & 53 & 59 & 65 & 71 \\
\hline SBT & 912 & 1227 & 1362 & 1527 & 1681 & 1824 \\
\hline Total & 2521 & 3371 & 3771 & 4208 & 4629 & 5033 \\
\hline
\end{tabular}


TABLE 5.3 Chapel Hill Travel Times by Movement (sec)

\begin{tabular}{|c|c|c|c|c|c|c|c|c|c|c|c|c|}
\hline \multirow{2}{*}{ Movement } & \multicolumn{2}{|c|}{ Peak-40\% } & \multicolumn{2}{|c|}{ Peak-20\% } & \multicolumn{2}{|c|}{ Peak-10\% } & \multicolumn{2}{|c|}{ Peak } & \multicolumn{2}{|c|}{ Peak $+10 \%$} & \multicolumn{2}{|c|}{ Peak $+20 \%$} \\
\hline & SS & Conv. & SS & Conv. & SS & Conv. & SS & Conv. & SS & Conv. & SS & Conv. \\
\hline WBL & 133 & 103 & 146 & 121 & 152 & 120 & 178 & 125 & 155 & 121 & 169 & 145 \\
\hline WBR & 52 & 46 & 60 & 49 & 65 & 51 & 69 & 53 & 66 & 59 & 75 & 70 \\
\hline WBT & 133 & 78 & 155 & 96 & 157 & 97 & 203 & 100 & 159 & 99 & 203 & 120 \\
\hline EBL & 152 & 96 & 161 & 115 & 163 & 111 & 191 & 108 & 168 & 104 & 178 & 125 \\
\hline EBR & 56 & 58 & 62 & 62 & 64 & 66 & 72 & 72 & 69 & 79 & 76 & 98 \\
\hline EBT & 137 & 73 & 148 & 89 & 156 & 89 & 178 & 86 & 158 & 84 & 167 & 103 \\
\hline NBL & 121 & 80 & 127 & 93 & 133 & 96 & 153 & 99 & 132 & 109 & 165 & 129 \\
\hline NBR & 31 & 34 & 31 & 37 & 31 & 38 & 31 & 37 & 32 & 43 & 32 & 45 \\
\hline NBT & 41 & 54 & 43 & 58 & 44 & 60 & 45 & 58 & 48 & 66 & 50 & 71 \\
\hline SBL & 130 & 69 & 137 & 116 & 136 & 91 & 122 & 97 & 143 & 101 & 145 & 129 \\
\hline SBR & 47 & 48 & 47 & 71 & 49 & 58 & 48 & 58 & 54 & 71 & 54 & 71 \\
\hline SBT & 50 & 55 & 53 & 76 & 55 & 63 & 56 & 66 & 62 & 80 & 63 & 83 \\
\hline $\begin{array}{c}\text { Wgt. Avg. } \\
\text { TT }\end{array}$ & 56 & 57 & 60 & 70 & 62 & 65 & 66 & 67 & 67 & 76 & 72 & 84 \\
\hline
\end{tabular}


TABLE 5.4 Wilmington Volumes by Movement (vph)

\begin{tabular}{|c|c|c|c|c|c|c|}
\hline Movement & $\begin{array}{c}\text { Peak- } \\
\mathbf{4 0} \%\end{array}$ & $\begin{array}{c}\text { Peak- } \\
\mathbf{2 0 \%}\end{array}$ & $\begin{array}{c}\text { Peak- } \\
\mathbf{1 0 \%}\end{array}$ & Peak & Peak+10\% & Peak+20\% \\
\hline WBL & 62 & 83 & 93 & 103 & 117 & 129 \\
\hline WBR & 66 & 90 & 104 & 115 & 124 & 134 \\
\hline WBT & 12 & 15 & 16 & 18 & 21 & 23 \\
\hline EBL & 26 & 36 & 40 & 45 & 51 & 56 \\
\hline EBR & 55 & 73 & 83 & 91 & 100 & 108 \\
\hline EBT & 6 & 7 & 8 & 9 & 10 & 11 \\
\hline NBL & 47 & 61 & 70 & 78 & 86 & 94 \\
\hline NBR & 54 & 73 & 81 & 88 & 97 & 106 \\
\hline NBT & 883 & 1184 & 1334 & 1484 & 1629 & 1775 \\
\hline SBL & 80 & 107 & 118 & 133 & 143 & 159 \\
\hline SBR & 48 & 64 & 74 & 81 & 86 & 95 \\
\hline SBT & 990 & 1318 & 1483 & 1649 & 1799 & 1962 \\
\hline Total & 2328 & 3113 & 3504 & 3893 & 4263 & 4652 \\
\hline
\end{tabular}


TABLE 5.5 Wilmington Travel Times by Movement (sec)

\begin{tabular}{|c|c|c|c|c|c|c|c|c|c|c|c|c|}
\hline \multirow{2}{*}{ Movement } & \multicolumn{2}{|c|}{ Peak-40\% } & \multicolumn{2}{|c|}{ Peak-20\% } & \multicolumn{2}{|c|}{ Peak-10\% } & \multicolumn{2}{|c|}{ Peak } & \multicolumn{2}{|c|}{ Peak+10\% } & \multicolumn{2}{|c|}{ Peak+20\% } \\
\hline & SS & Conv. & SS & Conv. & SS & Conv. & SS & Conv. & SS & Conv. & SS & Conv. \\
\hline WBL & 106 & 77 & 114 & 101 & 125 & 121 & 125 & 147 & 153 & 279 & 164 & 278 \\
\hline WBR & 41 & 41 & 43 & 48 & 46 & 53 & 47 & 64 & 50 & 111 & 51 & 110 \\
\hline WBT & 90 & 50 & 105 & 72 & 107 & 74 & 109 & 88 & 132 & 135 & 155 & 128 \\
\hline EBL & 110 & 69 & 121 & 85 & 129 & 94 & 134 & 92 & 152 & 111 & 171 & 108 \\
\hline EBR & 47 & 47 & 50 & 48 & 52 & 49 & 54 & 58 & 59 & 60 & 64 & 64 \\
\hline EBT & 97 & 57 & 110 & 73 & 117 & 68 & 114 & 71 & 143 & 77 & 159 & 76 \\
\hline NBL & 52 & 50 & 57 & 52 & 60 & 54 & 61 & 72 & 70 & 85 & 78 & 93 \\
\hline NBR & 39 & 39 & 41 & 40 & 41 & 41 & 42 & 41 & 41 & 42 & 42 & 44 \\
\hline NBT & 50 & 52 & 53 & 59 & 53 & 61 & 55 & 58 & 54 & 62 & 55 & 66 \\
\hline SBL & 48 & 45 & 55 & 50 & 57 & 51 & 62 & 63 & 67 & 67 & 73 & 73 \\
\hline SBR & 33 & 34 & 36 & 36 & 34 & 37 & 37 & 35 & 36 & 36 & 37 & 38 \\
\hline SBT & 49 & 54 & 53 & 59 & 51 & 62 & 55 & 53 & 53 & 54 & 53 & 55 \\
\hline $\begin{array}{c}\text { Wgt. Avg. } \\
\text { TT }\end{array}$ & 51 & 52 & 55 & 59 & 55 & 61 & 58 & 59 & 58 & 66 & 60 & 69 \\
\hline
\end{tabular}


TABLE 5.6 US-17 Volumes by Movement (vph)

\begin{tabular}{|c|c|c|c|c|c|c|c|}
\hline & Movement & Peak-40\% & Peak-20\% & Peak-10\% & Peak & Peak $+10 \%$ & Peak $+20 \%$ \\
\hline \multirow{13}{*}{ 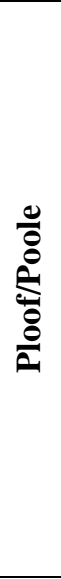 } & WBL & 12 & 16 & 18 & 20 & 22 & 24 \\
\hline & WBR & 13 & 16 & 18 & 20 & 22 & 24 \\
\hline & WBT & 5 & 7 & 8 & 9 & 10 & 11 \\
\hline & EBL & 39 & 53 & 60 & 66 & 75 & 80 \\
\hline & EBR & 236 & 311 & 350 & 391 & 434 & 469 \\
\hline & EBT & 5 & 8 & 9 & 11 & 11 & 13 \\
\hline & NBL & 189 & 254 & 283 & 319 & 357 & 379 \\
\hline & NBR & 23 & 31 & 33 & 37 & 42 & 47 \\
\hline & NBT & 1425 & 1898 & 2133 & 2358 & 2629 & 2834 \\
\hline & SBL & 14 & 17 & 20 & 22 & 23 & 26 \\
\hline & SBR & 38 & 54 & 59 & 65 & 72 & 79 \\
\hline & SBT & 859 & 1148 & 1294 & 1436 & 1571 & 1725 \\
\hline & Total & 2856 & 3812 & 4284 & 4753 & 5270 & 5710 \\
\hline \multirow{13}{*}{ 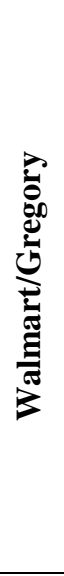 } & WBL & 40 & 54 & 60 & 66 & 73 & 78 \\
\hline & WBR & 209 & 278 & 310 & 345 & 381 & 413 \\
\hline & WBT & 6 & 8 & 9 & 11 & 11 & 12 \\
\hline & EBL & 11 & 14 & 17 & 18 & 20 & 21 \\
\hline & EBR & 12 & 17 & 18 & 20 & 23 & 26 \\
\hline & EBT & 5 & 7 & 7 & 9 & 10 & 10 \\
\hline & NBL & 13 & 17 & 19 & 20 & 23 & 24 \\
\hline & NBR & 42 & 56 & 65 & 71 & 79 & 85 \\
\hline & NBT & 1224 & 1632 & 1838 & 2029 & 2272 & 2446 \\
\hline & SBL & 193 & 258 & 291 & 321 & 361 & 386 \\
\hline & SBR & 24 & 31 & 34 & 38 & 45 & 47 \\
\hline & SBT & 977 & 1305 & 1466 & 1637 & 1772 & 1960 \\
\hline & Total & 2756 & 3677 & 4135 & 4585 & 5069 & 5507 \\
\hline \multirow{13}{*}{ 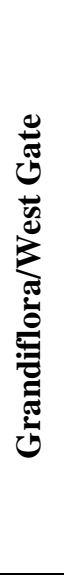 } & WBL & 44 & 55 & 64 & 71 & 78 & 84 \\
\hline & WBR & 238 & 317 & 352 & 391 & 431 & 473 \\
\hline & WBT & 5 & 8 & 8 & 10 & 10 & 11 \\
\hline & EBL & 42 & 57 & 67 & 74 & 82 & 89 \\
\hline & EBR & 234 & 312 & 345 & 387 & 424 & 466 \\
\hline & EBT & 6 & 8 & 9 & 10 & 11 & 11 \\
\hline & NBL & 18 & 24 & 26 & 28 & 24 & 33 \\
\hline & NBR & 60 & 80 & 90 & 101 & 86 & 121 \\
\hline & NBT & 1152 & 1546 & 1742 & 1934 & 2158 & 2323 \\
\hline & SBL & 13 & 16 & 18 & 20 & 22 & 23 \\
\hline & SBR & 40 & 52 & 59 & 64 & 70 & 77 \\
\hline & SBT & 975 & 1303 & 1462 & 1629 & 1782 & 1953 \\
\hline & Total & 2828 & 3777 & 4243 & 4718 & 5178 & 5663 \\
\hline
\end{tabular}


TABLE 5.6 (continued) US-17 Volumes by Movement (vph)

\begin{tabular}{|c|c|c|c|c|c|c|c|}
\hline & Movement & $\begin{array}{c}\text { Peak - } \\
40 \%\end{array}$ & $\begin{array}{c}\text { Peak - } \\
20 \%\end{array}$ & $\begin{array}{c}\text { Peak - } \\
10 \%\end{array}$ & Peak & $\begin{array}{c}\text { Peak + } \\
10 \%\end{array}$ & $\begin{array}{c}\text { Peak }+ \\
20 \%\end{array}$ \\
\hline \multirow{7}{*}{ 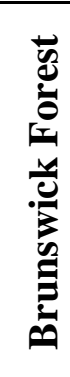 } & WBL & 40 & 53 & 60 & 68 & 74 & 81 \\
\hline & WBR & 235 & 315 & 351 & 389 & 430 & 467 \\
\hline & NBR & 45 & 58 & 64 & 71 & 78 & 86 \\
\hline & NBT & 1006 & 1340 & 1507 & 1686 & 1843 & 2016 \\
\hline & SBL & 194 & 261 & 288 & 318 & 350 & 382 \\
\hline & SBT & 1054 & 1407 & 1581 & 1762 & 1926 & 2119 \\
\hline & Total & 2573 & 3434 & 3851 & 4294 & 4701 & 5150 \\
\hline \multirow{13}{*}{ 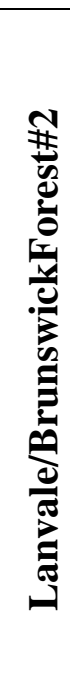 } & WBL & 42 & 57 & 64 & 72 & 77 & 84 \\
\hline & WBR & 208 & 271 & 306 & 340 & 372 & 410 \\
\hline & WBT & 6 & 8 & 11 & 11 & 12 & 12 \\
\hline & EBL & 12 & 17 & 19 & 21 & 24 & 26 \\
\hline & EBR & 11 & 14 & 16 & 18 & 19 & 21 \\
\hline & EBT & 6 & 8 & 9 & 10 & 11 & 12 \\
\hline & NBL & 13 & 16 & 19 & 21 & 22 & 25 \\
\hline & NBR & 43 & 57 & 62 & 68 & 75 & 80 \\
\hline & NBT & 766 & 1030 & 1155 & 1283 & 1413 & 1541 \\
\hline & SBL & 12 & 16 & 18 & 19 & 21 & 24 \\
\hline & SBR & 43 & 56 & 63 & 68 & 75 & 84 \\
\hline & SBT & 1036 & 1386 & 1562 & 1743 & 1909 & 2094 \\
\hline & Total & 2197 & 2936 & 3303 & 3673 & 4031 & 4412 \\
\hline
\end{tabular}


TABLE 5.7 US-17 Travel Times by Movement (sec)

\begin{tabular}{|c|c|c|c|c|c|c|c|c|c|c|c|c|c|}
\hline \multirow{2}{*}{ Int. } & \multirow{2}{*}{ Movement } & \multicolumn{2}{|c|}{ Peak-40\% } & \multicolumn{2}{|c|}{ Peak-20\% } & \multicolumn{2}{|c|}{ Peak-10\% } & \multicolumn{2}{|c|}{ Peak } & \multicolumn{2}{|c|}{ Peak+10\% } & \multicolumn{2}{|c|}{ Peak+20\% } \\
\hline & & SS & Conv. & SS & Conv. & SS & Conv. & SS & Conv. & SS & Conv. & SS & Conv. \\
\hline \multirow{13}{*}{$\begin{array}{l}\frac{0}{8} \\
\stackrel{0}{0} \\
\stackrel{0}{0} \\
\frac{0}{0}\end{array}$} & WBL & 125 & 71 & 128 & 82 & 139 & 991 & 138 & 991 & 147 & 123 & 131 & 123 \\
\hline & WBR & 37 & 40 & 44 & 47 & 48 & 50 & 52 & 60 & 59 & 67 & 62 & 66 \\
\hline & WBT & 125 & 68 & 120 & 79 & 134 & 78 & 132 & 78 & 135 & 87 & 121 & 85 \\
\hline & EBL & 104 & 66 & 119 & 75 & 133 & 79 & 137 & 78 & 141 & 140 & 163 & 205 \\
\hline & EBR & 37 & 38 & 44 & 48 & 48 & 56 & 56 & 63 & 66 & 143 & 80 & 217 \\
\hline & EBT & 106 & 63 & 125 & 77 & 140 & 71 & 139 & 74 & 139 & 143 & 171 & 212 \\
\hline & NBL & 73 & 58 & 62 & 68 & 62 & 71 & 65 & 75 & 66 & 87 & 79 & 91 \\
\hline & NBR & 26 & 26 & 26 & 27 & 26 & 28 & 27 & 29 & 27 & 30 & 27 & 32 \\
\hline & NBT & 21 & 22 & 21 & 25 & 22 & 28 & 22 & 33 & 22 & 37 & 23 & 39 \\
\hline & SBL & 69 & 82 & 79 & 88 & 90 & 93 & 87 & 95 & 86 & 129 & 81 & 137 \\
\hline & SBR & 26 & 28 & 27 & 29 & 27 & 29 & 28 & 31 & 28 & 35 & 29 & 46 \\
\hline & SBT & 24 & 30 & 26 & 34 & 26 & 35 & 28 & 39 & 29 & 60 & 30 & 91 \\
\hline & Wgt. Avg. TT & 29 & 30 & 30 & 34 & 31 & 37 & 32 & 41 & 34 & 58 & 37 & 77 \\
\hline \multirow{12}{*}{ 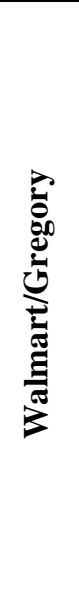 } & WBR & 51 & 51 & 62 & 68 & 73 & 87 & 81 & 113 & 107 & 115 & 111 & 132 \\
\hline & WBT & 123 & 62 & 126 & 75 & 140 & 83 & 153 & 100 & 182 & 101 & 180 & 110 \\
\hline & EBL & 113 & 74 & 119 & 87 & 142 & 87 & 149 & 93 & 152 & 117 & 175 & 124 \\
\hline & EBR & 33 & 37 & 38 & 37 & 40 & 39 & 41 & 41 & 43 & 50 & 50 & 49 \\
\hline & EBT & 102 & 67 & 112 & 68 & 138 & 73 & 131 & 66 & 136 & 75 & 152 & 73 \\
\hline & NBL & 92 & 82 & 81 & 90 & 81 & 93 & 84 & 105 & 91 & 144 & 94 & 138 \\
\hline & NBR & 35 & 37 & 38 & 40 & 37 & 51 & 38 & 64 & 40 & 80 & 46 & 84 \\
\hline & NBT & 39 & 43 & 44 & 50 & 43 & 65 & 44 & 85 & 47 & 111 & 57 & 120 \\
\hline & SBL & 62 & 72 & 72 & 106 & 83 & 124 & 87 & 170 & 103 & 365 & 86 & 421 \\
\hline & SBR & 24 & 24 & 24 & 24 & 25 & 25 & 25 & 25 & 25 & 31 & 25 & 40 \\
\hline & SBT & 35 & 36 & 36 & 37 & 37 & 38 & 38 & 40 & 38 & 49 & 39 & 59 \\
\hline & Wgt. Avg. TT & 42 & 44 & 46 & 51 & 48 & 61 & 50 & 76 & 55 & 107 & 59 & 119 \\
\hline
\end{tabular}


TABLE 5.7 (continued) US-17 Travel Times by Movement (sec)

\begin{tabular}{|c|c|c|c|c|c|c|c|c|c|c|c|c|c|}
\hline \multirow{2}{*}{ Int. } & \multirow{2}{*}{ Movement } & \multicolumn{2}{|c|}{ Peak-40\% } & \multicolumn{2}{|c|}{ Peak-20\% } & \multicolumn{2}{|c|}{ Peak-10\% } & \multicolumn{2}{|c|}{ Peak } & \multicolumn{2}{|c|}{ Peak $+10 \%$} & \multicolumn{2}{|c|}{ Peak $+20 \%$} \\
\hline & & SS & Conv. & SS & Conv. & SS & Conv. & SS & Conv. & SS & Conv. & SS & Conv. \\
\hline \multirow{13}{*}{ 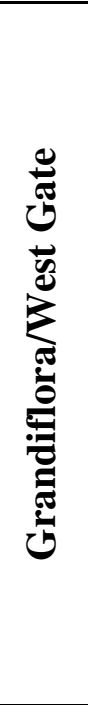 } & WBL & 157 & 77 & 155 & 75 & 162 & 119 & 167 & 151 & 174 & 221 & 170 & 386 \\
\hline & WBR & 42 & 45 & 50 & 51 & 55 & 66 & 61 & 90 & 69 & 140 & 77 & 357 \\
\hline & WBT & 124 & 58 & 135 & 55 & 137 & 71 & 146 & 76 & 159 & 101 & 149 & 368 \\
\hline & EBL & 131 & 75 & 153 & 73 & 174 & 128 & 162 & 163 & 182 & 255 & 190 & 391 \\
\hline & EBR & 46 & 47 & 52 & 49 & 54 & 59 & 58 & 64 & 63 & 71 & 68 & 73 \\
\hline & EBT & 120 & 55 & 137 & 44 & 158 & 64 & 157 & 58 & 163 & 76 & 169 & 73 \\
\hline & NBL & 89 & 93 & 79 & 76 & 75 & 94 & 80 & 97 & 79 & 178 & 93 & 194 \\
\hline & NBR & 35 & 38 & 36 & 38 & 38 & 38 & 39 & 40 & 38 & 120 & 40 & 117 \\
\hline & NBT & 41 & 50 & 44 & 49 & 45 & 49 & 48 & 63 & 48 & 187 & 54 & 193 \\
\hline & SBL & 67 & 90 & 74 & 74 & 82 & 114 & 76 & 112 & 77 & 123 & 70 & 111 \\
\hline & SBR & 30 & 31 & 30 & 34 & 31 & 32 & 31 & 32 & 32 & 33 & 32 & 44 \\
\hline & SBT & 41 & 45 & 42 & 56 & 44 & 48 & 44 & 49 & 45 & 56 & 47 & 74 \\
\hline & Wgt. Avg. TT & 45 & 49 & 48 & 52 & 50 & 53 & 53 & 63 & 55 & 126 & 59 & 158 \\
\hline \multirow{7}{*}{ 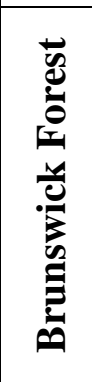 } & WBL & 131 & 83 & 128 & 72 & 130 & 89 & 133 & 86 & 148 & 123 & 147 & 149 \\
\hline & WBR & 40 & 38 & 45 & 43 & 44 & 50 & 47 & 56 & 57 & 132 & 61 & 165 \\
\hline & NBR & 32 & 32 & 33 & 33 & 34 & 35 & 34 & 34 & 33 & 41 & 35 & 44 \\
\hline & NBT & 34 & 38 & 35 & 39 & 36 & 51 & 38 & 53 & 39 & 107 & 40 & 126 \\
\hline & SBL & 60 & 53 & 68 & 52 & 53 & 65 & 57 & 72 & 78 & 75 & 75 & 75 \\
\hline & SBT & 32 & 34 & 33 & 36 & 33 & 36 & 33 & 39 & 34 & 41 & 34 & 43 \\
\hline & Wgt. Avg. TT & 37 & 38 & 39 & 39 & 38 & 46 & 40 & 49 & 43 & 79 & 44 & 90 \\
\hline
\end{tabular}


TABLE 5.7 (continued) US-17 Travel Times by Movement (sec)

\begin{tabular}{|c|c|c|c|c|c|c|c|c|c|c|c|c|c|}
\hline \multirow{2}{*}{ Int. } & \multirow{2}{*}{ Movement } & \multicolumn{2}{|c|}{ Peak-40\% } & \multicolumn{2}{|c|}{ Peak-20\% } & \multicolumn{2}{|c|}{ Peak-10\% } & \multicolumn{2}{|c|}{ Peak } & \multicolumn{2}{|c|}{ Peak+10\% } & \multicolumn{2}{|c|}{ Peak $+20 \%$} \\
\hline & & SS & Conv. & SS & Conv. & SS & Conv. & SS & Conv. & SS & Conv. & SS & Conv \\
\hline \multirow{13}{*}{ 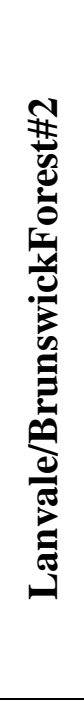 } & WBL & 132 & 71 & 128 & 70 & 128 & 82 & 136 & 83 & 145 & 88 & 163 & 104 \\
\hline & WBR & 45 & 47 & 50 & 52 & 50 & 59 & 55 & 64 & 66 & 100 & 75 & 140 \\
\hline & WBT & 127 & 59 & 116 & 56 & 114 & 71 & 121 & 68 & 129 & 76 & 153 & 103 \\
\hline & EBL & 124 & 77 & 137 & 81 & 127 & 111 & 138 & 105 & 159 & 123 & 160 & 141 \\
\hline & EBR & 50 & 50 & 51 & 51 & 52 & 55 & 53 & 59 & 57 & 57 & 57 & 57 \\
\hline & EBT & 106 & 57 & 122 & 59 & 106 & 74 & 113 & 74 & 142 & 69 & 139 & 65 \\
\hline & NBL & 107 & 84 & 95 & 81 & 97 & 106 & 100 & 109 & 102 & 101 & 109 & 113 \\
\hline & NBR & 39 & 40 & 40 & 40 & 41 & 41 & 41 & 42 & 41 & 42 & 42 & 48 \\
\hline & NBT & 51 & 54 & 53 & 57 & 56 & 59 & 56 & 61 & 58 & 91 & 60 & 121 \\
\hline & SBL & 63 & 75 & 71 & 74 & 60 & 98 & 63 & 100 & 85 & 83 & 84 & 97 \\
\hline & SBR & 40 & 37 & 40 & 38 & 41 & 39 & 41 & 41 & 41 & 43 & 43 & 42 \\
\hline & SBT & 49 & 52 & 49 & 56 & 50 & 57 & 50 & 59 & 51 & 63 & 53 & 61 \\
\hline & Wgt. Avg. TT & 52 & 52 & 53 & 56 & 54 & 59 & 56 & 61 & 58 & 77 & 61 & 91 \\
\hline
\end{tabular}




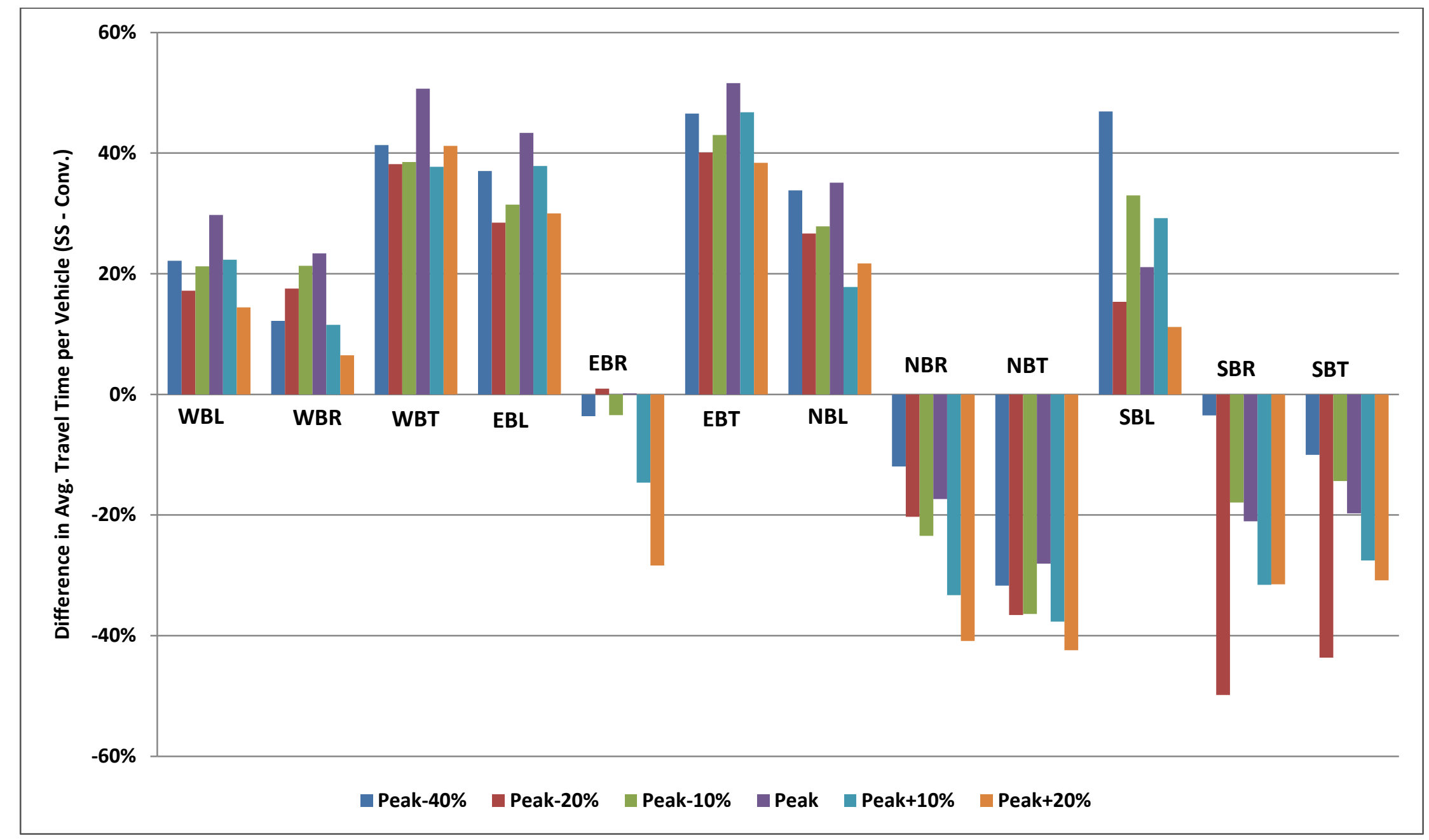

FIGURE 5.1 Comparison of travel times by movement - Chapel Hill. 


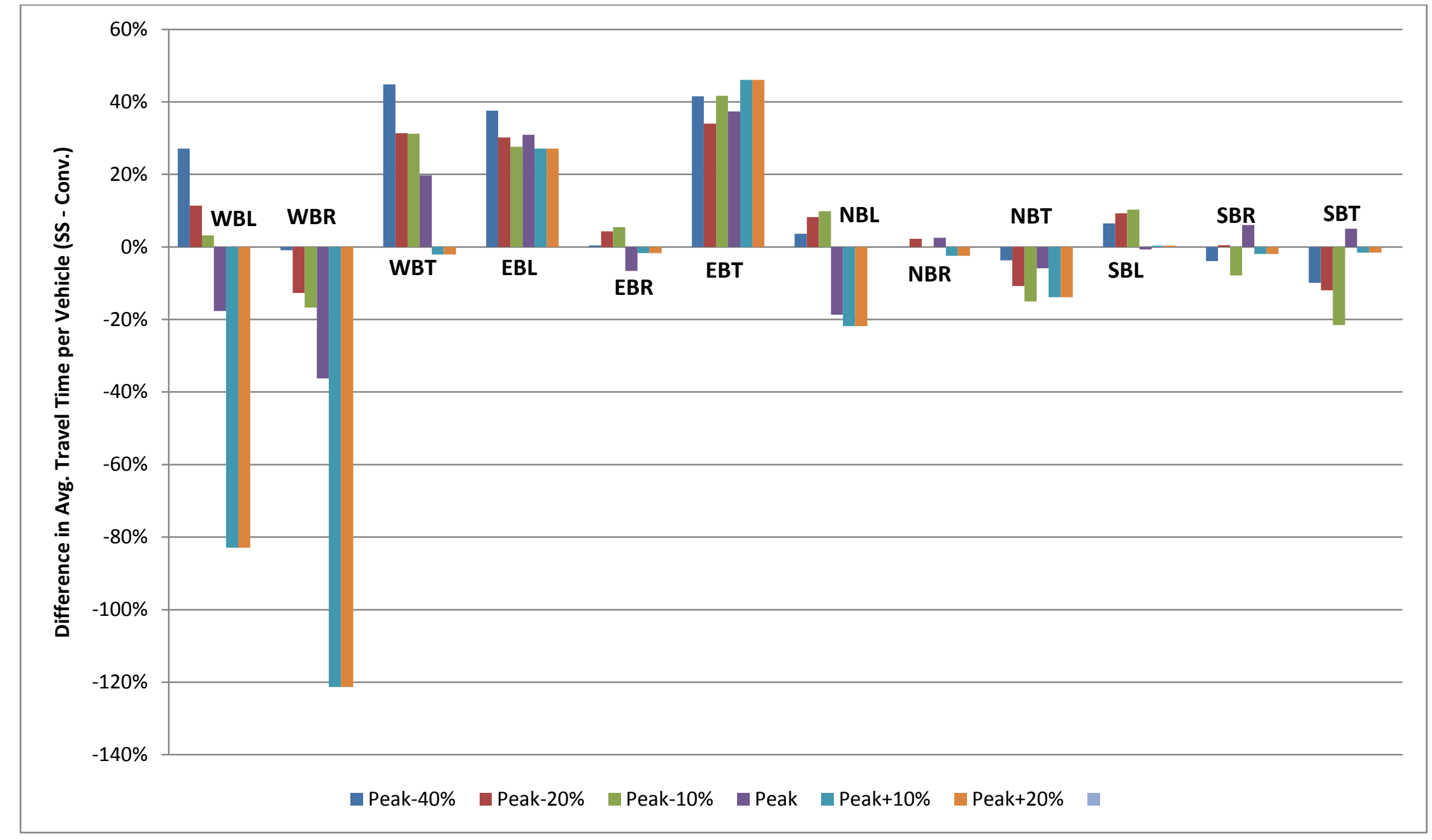

FIGURE 5.2 Comparison of travel times by movement - Wilmington. 


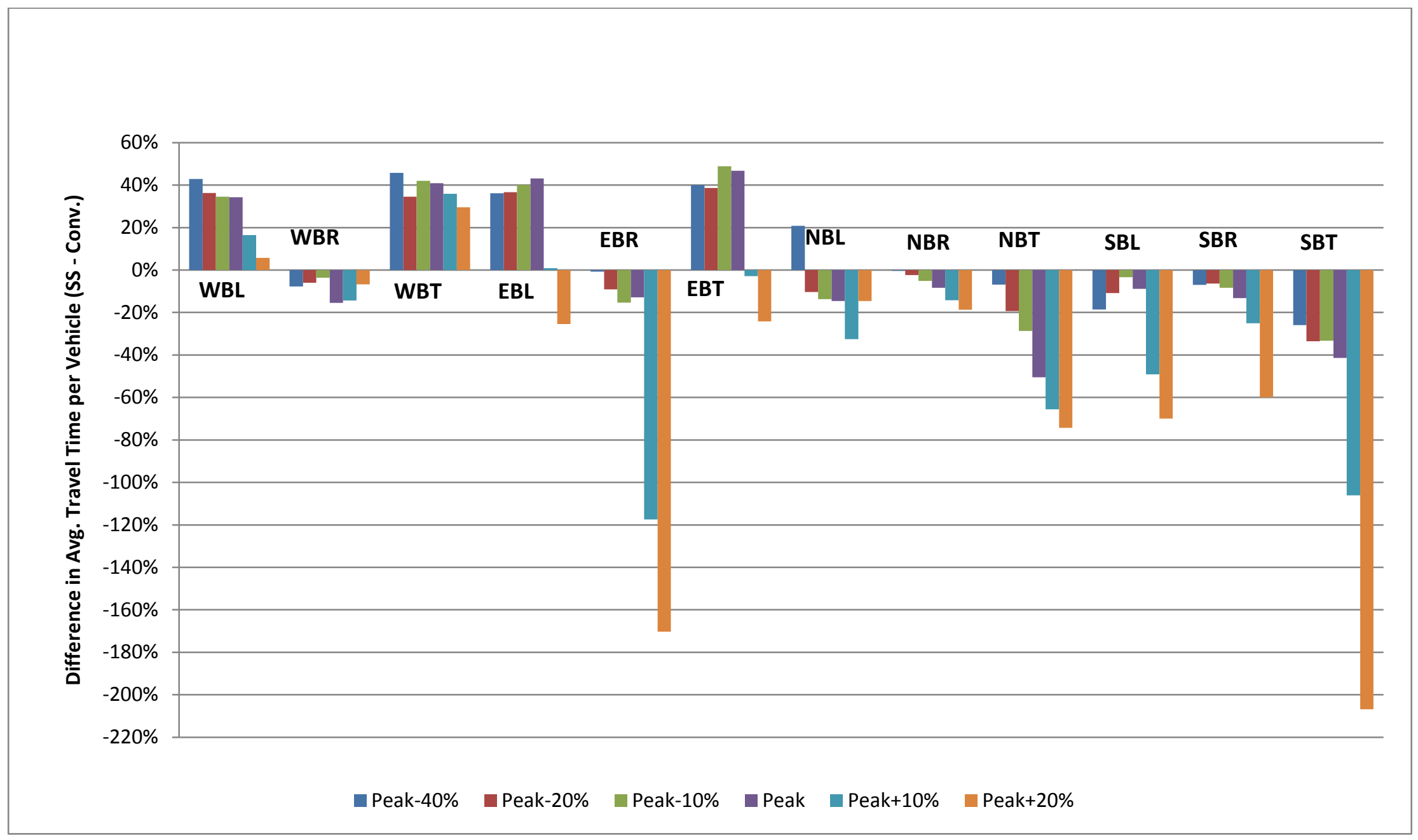

FIGURE 5.3 Comparison of travel times by movement - US-17 @ Ploof/Poole. 


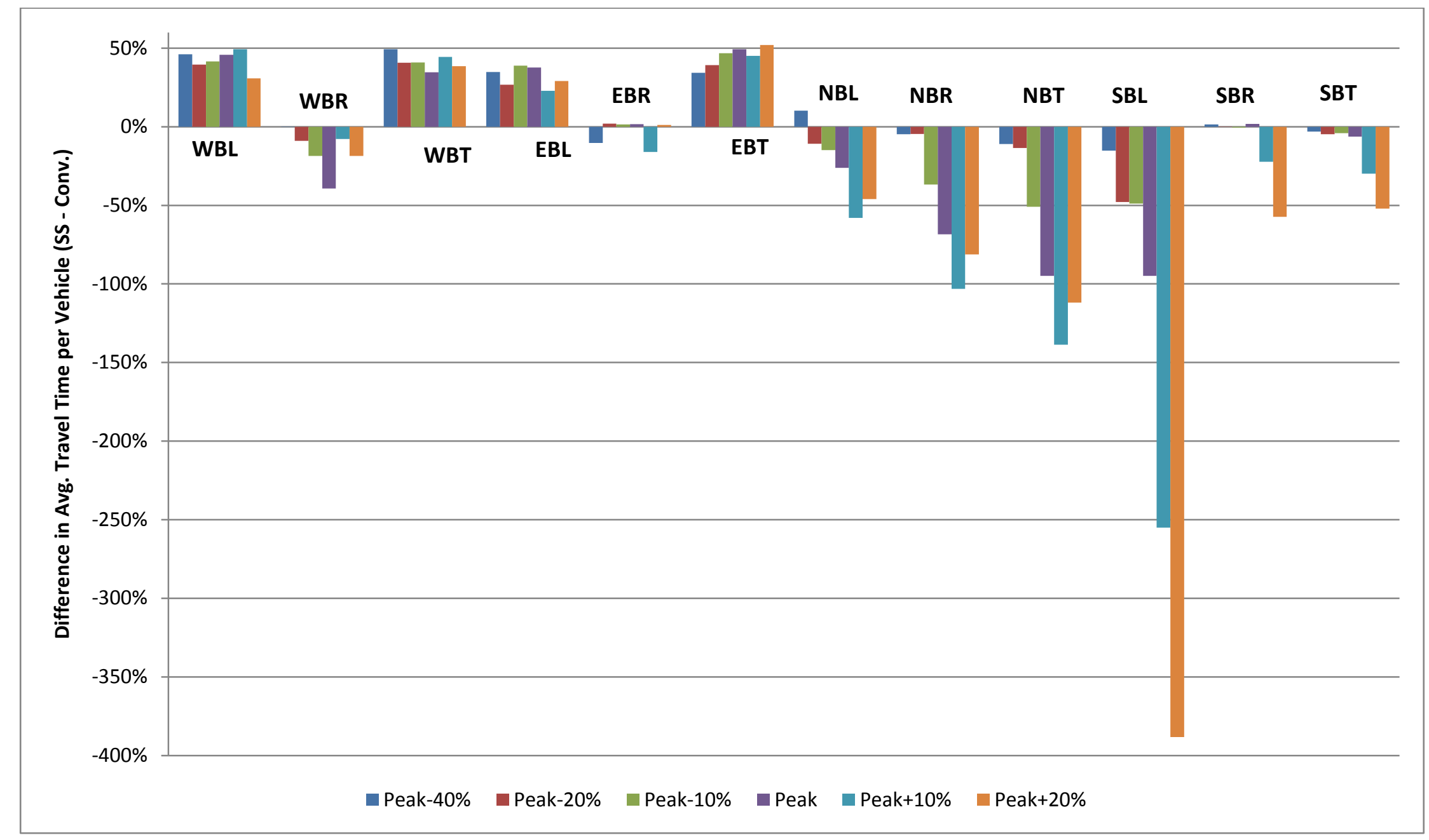

FIGURE 5.4 Comparison of travel times by movement - US-17 @ Walmart/Gregory. 


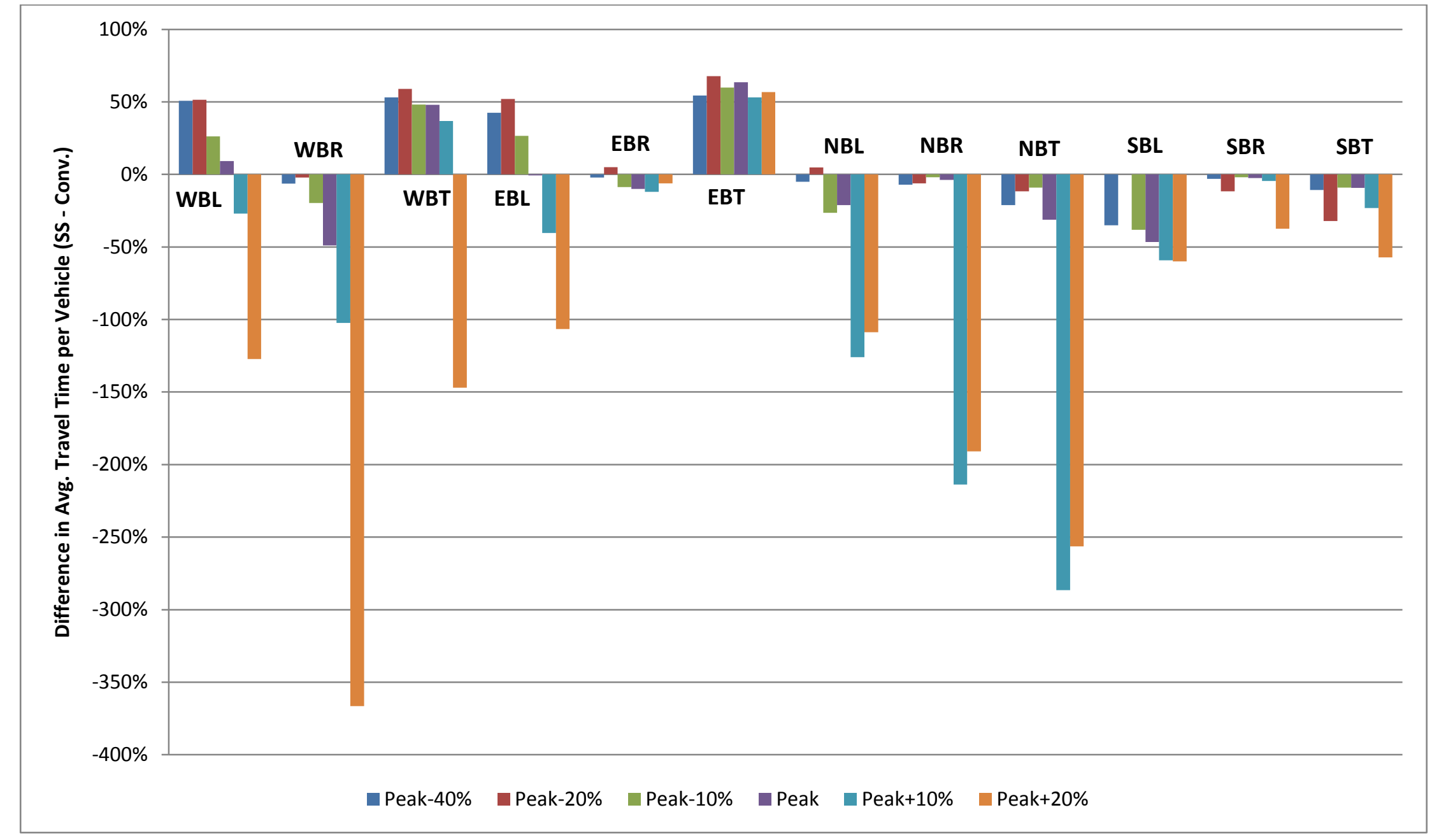

FIGURE 5.5 Comparison of travel times by movement - US-17 @ Grandiflora/West Gate. 


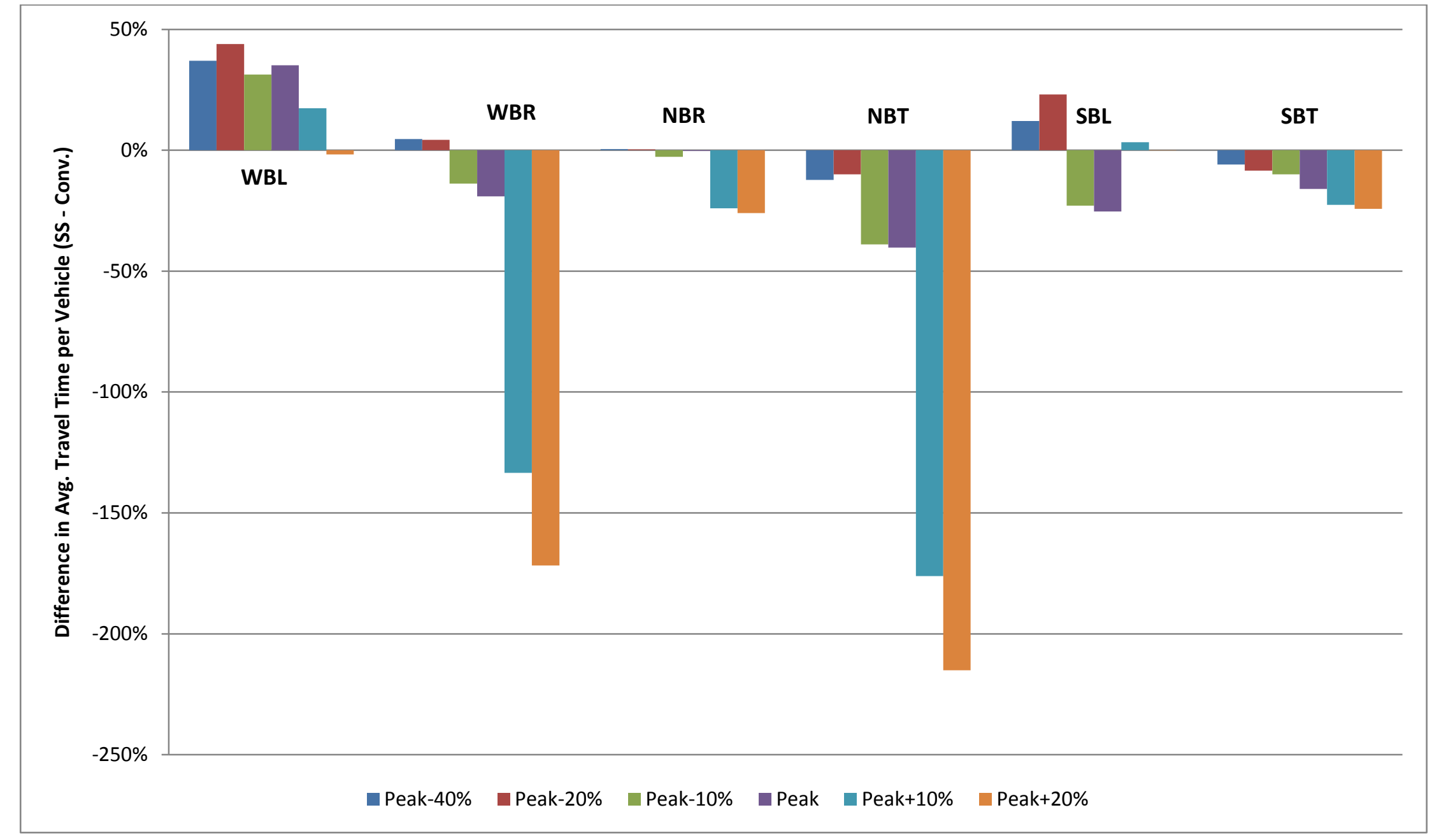

FIGURE 5.6 Comparison of travel times by movement - US-17 @ Brunswick Forest. 


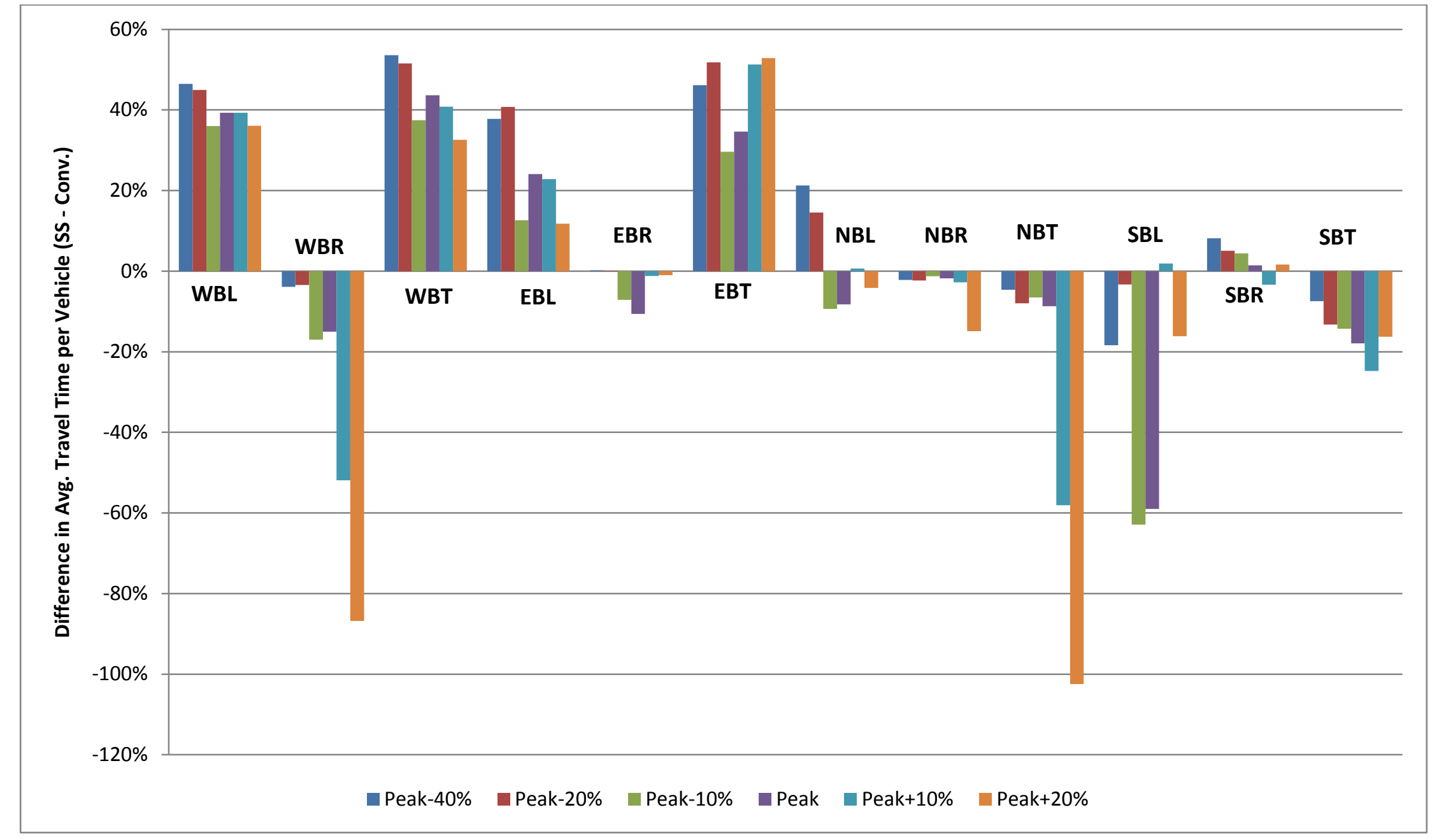

FIGURE 5.7 Comparison of travel times by movement - US-17 @ Lanvale Rd. 
I ran an ANOVA to determine if there was a statistically significant difference in the travel time results between the three sites, the designs (superstreet or conventional), and the demand levels. Table 5.8 lists the results of the ANOVA. At a 95\% confidence level the interactions between all three factors, and between combinations of the factors, were all statistically significant. This shows that location, the design choice, and the volume levels, all play a role and impact the travel times through the intersection. It is not surprising that the sites and demand levels had a significant impact on travel time. The important result from this is that the design choice - superstreet or conventional - did impact the travel time of vehicles traveling through the intersection, doing so at both isolated intersections and corridors.

TABLE 5.8 Analysis of Variance for Travel Time, Using Adjusted SS for Tests

\begin{tabular}{|l|c|c|c|c|c|c|}
\hline Source & DF & Seq SS & Adj SS & $\begin{array}{c}\text { Adj } \\
\text { MS }\end{array}$ & F & P \\
\hline \hline Site & 6 & 74785.4 & 74785.4 & 12464.2 & 1361.45 & 0.0000 \\
Demand & 5 & 96874.5 & 96874.5 & 19374.9 & 2116.29 & 0.0000 \\
Design & 1 & 48482.4 & 48482.4 & 48482.4 & 5295.66 & 0.0000 \\
Site*Demand & 30 & 28129 & 28129 & 937.6 & 102.42 & 0.0000 \\
Site*Design & 6 & 15860.5 & 15860.5 & 2643.4 & 288.74 & 0.0000 \\
Demand*Design & 5 & 44107.5 & 44107.5 & 8821.5 & 963.56 & 0.0000 \\
Site*Demand*Design & 30 & 24329.4 & 24329.4 & 811 & 88.58 & 0.0000 \\
\hline \hline Error & 756 & 6921.3 & 6921.3 & 9.2 & & \\
Total & 839 & 339490.1 & & & & \\
\hline \hline
\end{tabular}

\subsection{Travel Time Effects on the Intersection}

The simulations show that the superstreet reduces travel time for the major road through and left movements, and increases travel time for the minor road through and left movements. However, looking at the operation of the intersection as a whole, the superstreet outperforms the conventional design. Table 5.9 shows the percent difference in simulated average travel 
time per vehicle. The superstreet reduced travel time for the average vehicle traveling through the intersection at every location.

TABLE 5.9 Percent Difference in Simulated Average Travel Time Per Vehicle Between Superstreet and Conventional Intersections

\begin{tabular}{|l|c|c|c|c|c|c|}
\hline Intersection & Pk-40\% & Pk-20\% & Pk-10\% & Peak & Pk+10\% & Pk+20\% \\
\hline \hline $\begin{array}{l}\text { US-15/501 @ } \\
\text { Erwin / Europa }\end{array}$ & $-1.6 \%$ & $-16.2 \%$ & $-4.8 \%$ & $-1.6 \%$ & $-13.8 \%$ & $-16.8 \%$ \\
\hline $\begin{array}{l}\text { US-421 @ } \\
\text { Myrtle Gardens Dr. }\end{array}$ & $-2.2 \%$ & $-6.7 \%$ & $-12.7 \%$ & $-1.5 \%$ & $-11.9 \%$ & $-12.7 \%$ \\
\hline $\begin{array}{l}\text { US-17 corridor (avg. } \\
\text { for all intersections) }\end{array}$ & $-3.7 \%$ & $-7.7 \%$ & $-15.4 \%$ & $-26.5 \%$ & $-79.6 \%$ & $-100.2 \%$ \\
\hline US-17 @ Ploof / Poole & $-2.8 \%$ & $-15.1 \%$ & $-18.6 \%$ & $-27.8 \%$ & $-71.8 \%$ & $-106.3 \%$ \\
\hline $\begin{array}{l}\text { US-17 @ Walmart / } \\
\text { Gregory }\end{array}$ & $-3.9 \%$ & $-10.9 \%$ & $-27.8 \%$ & $-54.0 \%$ & $-89.6 \%$ & $-99.2 \%$ \\
\hline $\begin{array}{l}\text { US-17 @ Grandiflora / } \\
\text { West Gate }\end{array}$ & $-7.2 \%$ & $-8.3 \%$ & $-5.6 \%$ & $-19.2 \%$ & $-122.8 \%$ & $-146.6 \%$ \\
\hline $\begin{array}{l}\text { US-17 @ Brunswick } \\
\text { Forest Pkwy }\end{array}$ & $-2.6 \%$ & $-0.6 \%$ & $-20.2 \%$ & $-23.4 \%$ & $-80.8 \%$ & $-104.3 \%$ \\
\hline $\begin{array}{l}\text { US-17 @ Lanvale / } \\
\text { Brunswick Forest }\end{array}$ & $-1.7 \%$ & $-5.4 \%$ & $-8.2 \%$ & $-10.0 \%$ & $-32.9 \%$ & $-49.4 \%$ \\
\hline
\end{tabular}

Not only did the superstreet reduce travel time, but it also reduced travel time variability. Table 5.10 shows the standard deviation of the simulated travel times by movement for each site. The superstreet had less travel time variability than the conventional intersection at the Wilmington site and the US-17 corridor. The Chapel Hill simulations produced similar standard deviations for the two designs, with the superstreet slightly greater than the conventional. However, with the exception of the NBL, the arterial travel time variability was less for the superstreet than the conventional model. The lower travel time standard deviation means drivers experience less variability, and thus more reliability, when driving through superstreet intersections and corridors compared to the conventional equivalent. 
TABLE 5.10 Standard Deviation of Simulated Travel Time by movement (sec.)

\begin{tabular}{|c|c|c|c|c|c|c|c|}
\hline \multirow{2}{*}{ Movement } & \multicolumn{2}{c|}{ Chapel Hill } & \multicolumn{2}{c|}{ Wilmington } & \multicolumn{2}{c|}{ US-17 } \\
\cline { 3 - 8 } \multicolumn{2}{c|}{} & SS & Conv. & SS & Conv. & SS & Conv. \\
\hline \hline \multirow{3}{*}{} & WBL & 8.09 & 8.16 & 2.93 & 27.26 & 6.55 & 14.67 \\
\cline { 2 - 8 } & WBR & 2.34 & 2.10 & 1.35 & 9.24 & 2.84 & 7.65 \\
\cline { 2 - 8 } & WBT & 12.16 & 7.53 & 6.69 & 17.21 & 13.66 & 15.93 \\
\cline { 2 - 8 } & EBL & 6.67 & 6.40 & 6.92 & 10.40 & 6.08 & 22.22 \\
\cline { 2 - 8 } & EBR & 1.47 & 1.86 & 1.78 & 1.67 & 2.59 & 7.44 \\
\cline { 2 - 8 } & EBT & 5.10 & 4.82 & 9.58 & 12.27 & 11.84 & 14.72 \\
\hline \multirow{4}{*}{$:$} & NBL & 9.04 & 5.14 & 2.44 & 3.40 & 5.67 & 8.26 \\
\cline { 2 - 8 } & NBR & 1.00 & 1.32 & 0.86 & 0.74 & 0.85 & 2.22 \\
\cline { 2 - 8 } & NBT & 0.42 & 1.09 & 0.56 & 1.16 & 0.76 & 4.71 \\
\cline { 2 - 8 } & SBL & 3.34 & 8.91 & 2.31 & 3.68 & 5.21 & 13.31 \\
\cline { 2 - 8 } & SBR & 1.12 & 2.05 & 1.05 & 1.15 & 0.68 & 1.59 \\
\cline { 2 - 8 } & SBT & 0.51 & 0.86 & 0.62 & 0.71 & 0.31 & 2.30 \\
\hline Intersection Avg. & 4.27 & 4.19 & 3.09 & 7.41 & 4.75 & 9.59 \\
\hline
\end{tabular}

\subsection{Travel Time Effects on the Arterial}

At all sites the superstreet outperformed the conventional intersection for the major road through movements. This was expected because the superstreet benefits the arterial through movements due to the ability to have perfect progression in both directions. The superstreet major through travel times improved over the conventional by a greater amount at the higher volume levels. At both Wilmington and along the US-17 corridor, the major lefts also saw travel time improvements over the conventional design.

At Chapel Hill, the northbound through (NBT) remained consistent at each volume level, with improvements from $28 \%$ to $42 \%$. With the exception of the peak-20\% volumes, the southbound through (SBT) travel times savings steadily increased over the conventional with each increasing demand level. This was the only site where the major left turns experience more travel time than the conventional design. This superstreet intersection does not allow the direct major left turns at the main intersection. This is a modified design of the 
superstreet where the major left turns use the downstream directional u-turn crossover to make the left turn maneuver. The direct left turns were not built at this site because of a suspected weaving problem due to two roads merging together just upstream of the superstreet.

The Wilmington superstreet resulted in a similar situation to the Chapel Hill superstreet, with travel times improving more with each increase in traffic through the intersection for the NBT. The NBT travel time savings for the superstreet over the conventional ranged from 3\% to $14 \%$. The SBT improved steadily with increasing demand for the superstreet as well, except during the peak, peak $+10 \%$ and peak $+20 \%$ scenarios. The superstreet saw a minimal increase in travel time during these three cases, from $1.5 \%$ to $5.1 \%$.

The US-17 corridor saw similar effects as the Chapel Hill and Wilmington superstreets with travel time steadily improving as demand increased. At the peak $+10 \%$ and peak $+20 \%$ levels, the major through movements had large travel time savings over the conventional, reaching up to over $100 \%$ and even $200 \%$ in some cases. This is an indication that the conventional intersections were most likely overloaded and failing.

\subsection{Travel Time Effects on the Minor Road}

The minor road through and left turn movements were negatively impacted by the

superstreet. By the nature of the design, the minor road through and left turns have to travel an extra distance to a downstream u-turn, then back through the main intersection. The travel times for these movements were higher at the superstreet than the conventional intersections for all sites. The minor lefts were impacted less than the minor through movements at all sites.

Along the US-17 corridor, the minor left turn and through movements were affected more during the low-volume scenarios, with the travel time difference between the superstreet and conventional decreasing as the volumes increased. The percent differences ranged from a 30 to $40 \%$ increase at the lowest volumes (peak- $40 \%$ ), to a 9 to $18 \%$ decrease in travel time at 
the highest volumes (peak+20\%). At the highest demand level the superstreet travel times were lower than the conventional travel times for all movements.

At the Chapel Hill and Wilmington sites, the minor left turn and through movements were affected differently than they were along US-17. At Chapel Hill the minor left and through movements were negatively impacted the most during the peak period, with 30 to 50\% increases in travel time. The differences then decreased as the volume levels changed from the peak. The minor street movements were least negatively impacted by the superstreet during the highest demand level, at only a 14 to $30 \%$ difference from the conventional. At Wilmington the eastbound and westbound directions were affected differently. The WBT movement was affected in the same way as the minor movements at Chapel Hill with the largest difference at the peak demand. The opposite effect happened for the eastbound minor movements. The EBL and EBT were negatively impacted the least during the peak period, and more during the high volume and low volume scenarios. The WBL movement was different from the rest, with superstreet travel times higher than the conventional for the low volume scenarios, and lower than the conventional for the high volume scenarios.

\subsection{Capacity Check}

For a check on the capacity of each intersection, both superstreet and conventional, I applied the critical sum method. This method involves computing the sum of the critical lane volumes for each signal phase. This was not done to calculate the actual capacity of superstreets or the conventional intersections, but to compare the two designs to estimate how much more capacity one might get out of a superstreet than a conventional intersection. A signal-controlled intersection is generally considered to be in good operating condition if the critical sum is less than 1400 vphpl with a four-phase signal, and 1600 vphpl with a twophase signal. These values come from the base saturation flow rate of $1900 \mathrm{pc} / \mathrm{h} / \mathrm{ln}$ and multiplied by adjustment factors for heavy vehicles, left turns, right turns, and u-turns (20). Table 5.11 lists the critical sums for both the superstreet and conventional intersections for the high volume demand levels. The superstreet outperforms the conventional intersections 
at all sites, and is below the 1600 vphpl reference for two-phase signals at five of the intersections for all demand levels up to peak $+40 \%$. Based on this check, the superstreet design has a higher capacity than the conventional design.

TABLE 5.11 Critical Sums for Superstreet and Conventional Intersections

\begin{tabular}{|c|c|c|c|}
\hline \multirow{2}{*}{ Site } & \multirow{2}{*}{ Demand } & \multicolumn{2}{|c|}{ Critical Sum (vphpl) } \\
\hline & & Conv. & SS \\
\hline \multirow{4}{*}{ Chapel Hill } & Peak & 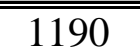 & 1020 \\
\hline & Peak+10\% & 1310 & 1120 \\
\hline & Peak+20\% & 1430 & 1220 \\
\hline & Peak $+40 \%$ & 1670 & 1430 \\
\hline \multirow{4}{*}{ Wilmington } & Peak & 1120 & 1100 \\
\hline & Peak+10\% & 1230 & 1210 \\
\hline & Peak+20\% & 1340 & 1320 \\
\hline & Peak $+40 \%$ & 1570 & 1540 \\
\hline \multirow{4}{*}{$\begin{array}{l}\text { Ploof/Poole } \\
\text { (US-17) }\end{array}$} & Peak & 1320 & 1410 \\
\hline & Peak+10\% & 1450 & 1560 \\
\hline & Peak+20\% & 1580 & 1700 \\
\hline & Peak $+40 \%$ & 1840 & 1980 \\
\hline \multirow{4}{*}{$\begin{array}{c}\text { Walmart/Gregory } \\
\text { (US-17) }\end{array}$} & Peak & 1750 & 1410 \\
\hline & Peak+10\% & 1930 & 1560 \\
\hline & Peak+20\% & 2100 & 1700 \\
\hline & Peak $+40 \%$ & 2450 & 1980 \\
\hline \multirow{4}{*}{$\begin{array}{c}\text { Grandiflora/West } \\
\text { Gate } \\
\text { (US-17) }\end{array}$} & Peak & 1310 & 1080 \\
\hline & Peak+10\% & 1520 & 1280 \\
\hline & Peak+20\% & 1570 & 1300 \\
\hline & Peak $+40 \%$ & 1830 & 1520 \\
\hline \multirow{4}{*}{$\begin{array}{c}\text { Brunswick Forest } \\
\text { (US-17) }\end{array}$} & Peak & 1140 & 1110 \\
\hline & Peak+10\% & 1250 & 1230 \\
\hline & Peak+20\% & 1360 & 1340 \\
\hline & Peak $+40 \%$ & 1590 & 1560 \\
\hline \multirow{5}{*}{$\begin{array}{l}\text { Lanvale Rd. } \\
\text { (US-17) }\end{array}$} & Peak & 1320 & 960 \\
\hline & Peak $+10 \%$ & 1450 & 1060 \\
\hline & Peak+20\% & 1580 & 1150 \\
\hline & Peak $+40 \%$ & 1840 & 1340 \\
\hline & Peak+60\% & 2100 & 1540 \\
\hline
\end{tabular}




\subsection{RESIDENT SURVEY METHODOLOGY}

One aspect of the superstreet design that has not been researched to this point is the effect on nearby residents. It is important to consider the opinions of those directly affected by the adjacent design because these residents can politically derail a superstreet proposal, and because these effects cannot be captured through traffic simulation or collision analyses. I conducted a residential survey to gather opinion data from the taxpayers, voters, and frequent users of the adjacent superstreet intersections and corridors. I chose to survey residents because they provide insight to the effects superstreets have on accessibility and property value. In addition, nearby residents are also frequent users of the facility who can provide insight on the navigability, travel time, and perceived delay associated with superstreets and the conventional intersections they replaced, especially concerning the side street movements. This chapter provides details on the methodology of the residential opinion survey.

\subsection{Identification and Selection of Sites}

The sites selected for the resident survey were taken from a list that included all operating superstreet intersections and corridors located in North Carolina. To get a full understanding of the public's opinion, both signalized and unsignalized sites were included in the list, encompassing both urban and rural areas. There were two major criteria used in the final site selection:

1. The superstreet must have been constructed within the past five years.

2. There must have been a comparable "before" scenario.

The reason for the first criterion was that residents might have difficulty remembering driving conditions of the previous intersection if the superstreet was constructed more than five years prior. The second criterion was imposed because it was important that the residents had something to compare to the superstreet. At a few sites there was no before 
scenario (i.e. no major intersection prior to the construction of the superstreet). For example, the superstreet corridor on US-17 in the town of Leland, NC was built because of a major boom in land development in the area. This site was eliminated from the survey list because there was little development along that stretch of US-17 prior to the superstreet, so opinions on the superstreet would be difficult to separate from opinions on the new development. After reducing the list based on the above criteria, the final list totaled ten sites including three signalized superstreets (one corridor and two intersections) and seven unsignalized superstreet intersections. Table 6.1 lists the sites selected for the survey.

TABLE 6.1 Sites Selected for Resident Survey

\begin{tabular}{|l|l|l|l|l|}
\hline Main Road & Cross street(s) & City & County & Type \\
\hline \hline US-15/501 & Europa Dr. / Erwin Rd. & Chapel Hill & Orange & Signalized \\
\hline US-17 & $\begin{array}{l}\text { Stephens Church Rd. } \\
\text { Scotts Hill Loop Rd. (corridor) } \\
\text { Sidbury Rd. }\end{array}$ & Wilmington & $\begin{array}{l}\text { New Hanover } \\
\text { Pender } \\
\text { Pender }\end{array}$ & Signalized \\
\hline US-17 & Lanvale Rd. & Lanvale & Brunswick & Signalized \\
\hline US-17 & Mt. Pisgah Rd. / Sellers Rd. & Supply & Brunswick & Unsignalized \\
\hline US-17 & Ocean Isle Beach Rd. & Shallotte & Brunswick & Unsignalized \\
\hline US-74/76 & Blacksmith Rd. & Bolton & Columbus & Unsignalized \\
\hline US-74 & Elmore Rd. & Laurinburg & Scotland & Unsignalized \\
\hline US-74 & Dicks Creek Rd. & Whittier & Jackson & Unsignalized \\
\hline NC-87 & Peanut Plant Rd & Elizabethtown & Bladen & Unsignalized \\
\hline NC-24 & Haw Branch Rd. & Richlands & Onslow & Unsignalized \\
\hline
\end{tabular}

\subsection{Data Collection}

Three options were considered to collect the resident opinion data: door-to-door interviews, survey by mail to households, or collection of license plate numbers and then survey by mail to vehicle owners. I concluded that mail-out surveys to households would reach the greatest number of people and be the most cost effective method to obtain a large sample size, so I used a four-wave mailing method. This technique involved sending mail four different times to each randomly-selected household in an approximate one-week interval. NCDOT 
personnel expect response rates for mail-out and mail-back surveys with just one mailing to be around ten percent (10\%), but with multiple mailings the response rate should be much larger.

I calculated the required sample size for the mailings using Equation 6.1 (22):

$$
\text { Equation 6.1 } \quad n=t^{2} \mathbf{p q} / \mathbf{d}^{2}
$$

Where:

$$
\begin{aligned}
& \mathrm{n}=\text { sample size needed, } \\
& \mathrm{t}=\text { constant corresponding to the desired level of confidence, } \alpha, \\
& \mathrm{p}=\text { proportion of units answering “yes", } \\
& \mathrm{q}=\text { proportion of units answering "no", and } \\
& \mathrm{d}=\text { percent error. }
\end{aligned}
$$

Expecting a strong split in opinions and assuming a 15/85 response split on a key question in the survey, I needed to receive 196 total responses to achieve a 5 percent error $(\mathrm{d}=0.05)$ at the 95 percent confidence level $(\mathrm{t}=1.96)$. The final sample size was 500, which was calculated based on these parameters and an expected $40 \%$ return rate.

I hired a local mailing service contractor to provide the addresses for households near the selected sites. All addresses were within a two-mile radius of the nearest superstreet location, and included both homeowners and renters. The list I received contained addresses for 2,000 households - 1,000 from the group of signalized sites and 1,000 from the group of unsignalized sites. Each group contained an equal number of addresses from each site within the group. The households receiving the survey were randomly selected using a random number generator to extract 250 names from each group for an even representation of both signalized and unsignalized superstreets. To ensure a good cross-section of the population, I provided instructions in the mailings to have the licensed driver (at least 16 years of age) within the household who would be celebrating the next birthday respond to the survey. 
The four mailings included an initial letter describing the study, the survey packet, a reminder letter, and a final survey packet. Figures 6.1 through 6.4 show copies of these mailings. The survey packet included a cover letter explaining the survey with instructions, the survey questions, and a return envelope with pre-paid postage. I mailed the first wave of mailings in mid-June, 2009. The second, third, and fourth wave of mailings followed approximately one week apart. As the surveys were mailed back, the results were recorded in a spreadsheet along with comments expressed by the residents. Addresses were tracked to determine who responded and when the response was received. The survey consisted of 12 questions, four of which I identified as key questions. These questions were about comparing the superstreet to the conventional intersection on perceived navigability, safety, travel time, and number of stopped vehicles. 
CURRENT RESIDENT

123 Main St.

Somewhere, NC 12345

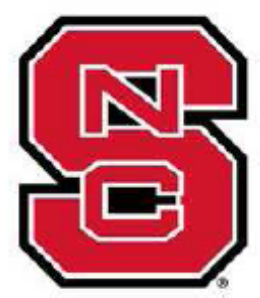

\section{Greetings,}

North Carolina State University is conducting research sponsored by the North Carolina Department of Transportation to evaluate the effects of superstreets. A superstreet is an intersection design that prohibits direct left-turn and through movements from the side streets. Instead, the left turns from the side streets are made by turning right onto the main road then making a u-turn using a one-way median opening, as shown by the dotted line in the diagram below; through movements across the main road are done in a similar manner, as shown by the dashed line in the diagram.

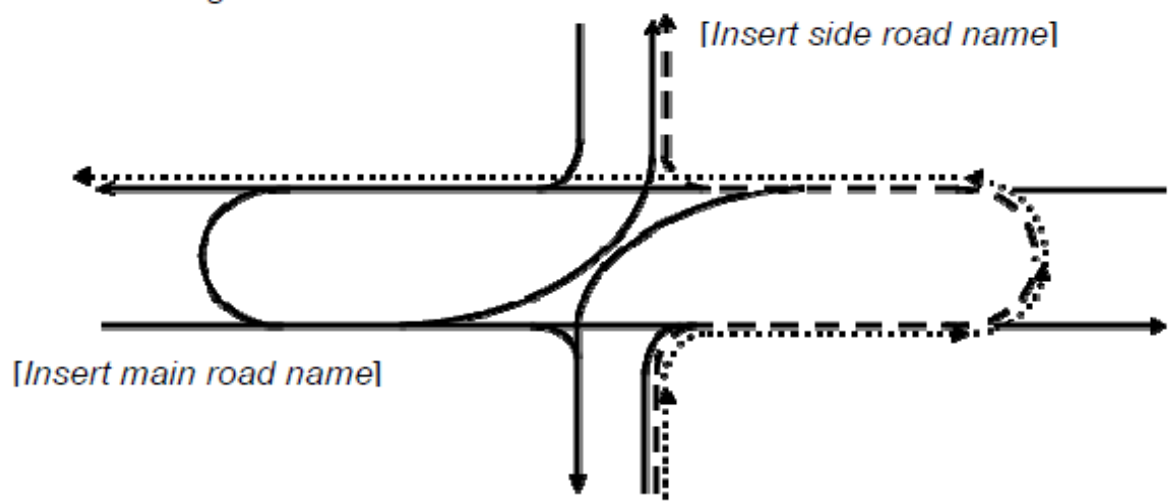

Figure 1. Basic superstreet design

We are gathering opinions from residents that live near a superstreet to better understand how well the design is working. A superstreet is located near you at the intersection of [insert road name] and [insert road name]. A short, one-page questionnaire will be arriving in the mail shortly, and will include a return envelope with pre-paid postage for your convenience. You have been selected to represent your neighbors in this survey - your opinion is of great value.

Please help us by taking a few minutes to participate in this study by completing and returning the survey form when you receive it. All participants and responses will remain anonymous. If you have any questions please contact the study director, Dr. Joseph Hummer at (919) 5157733 or hummer@ncsu.edu.

Thank you!

\section{FIGURE 6.1 Initial letter for the resident survey.}




\section{CURRENT RESIDENT \\ 123 Main St. \\ City, NC 12345}

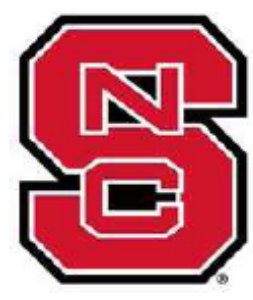

Greetings,

North Carolina State University is conducting research sponsored by the North Carolina Department of Transportation to evaluate the effects of superstreets. A superstreet is an intersection design that prohibits direct left-turn and through movements from the side streets. Instead, the left turns from the side streets are made by turning right onto the main road then making a u-turn using a one-way median opening, as shown by the dotted line in the diagram below; through movements across the main road are done in a similar manner, as shown by the dashed line in the diagram.

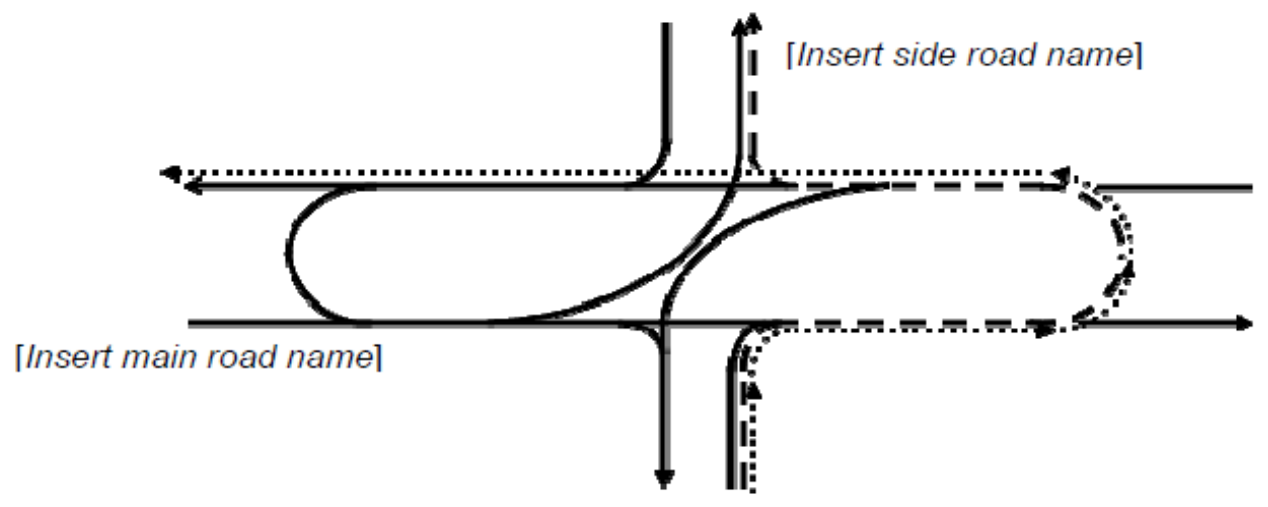

As you may recall from our previous letter, we are gathering opinions from nearby residents to better understand how well the design is working. A superstreet is located near you at the intersection of [insert road name] and [insert road name]. To ensure we have a good crosssection of the population, please help us by having the licensed driver - at least 16 years of age - within the household who will be celebrating the next birthday answer the following brief survey questions found on the back of this letter.

When you are finished please place this survey in the mail using the enclosed envelope and pre-paid postage. If you have any questions contact the study director, Dr. Joseph Hummer at (919) 515-7733 or hummer@ncsu.edu. All participants and responses will remain anonymous.

Thank you for your help with this important research!

FIGURE 6.2 Cover letter that accompanied the resident survey packet. 


\section{RESIDENT SURVEY}

1. How long have you, personally, lived near this intersection?
$\square$ Less than 1 year
$\square 1-3$ years
$\square 4-10$ years
More than 10 years

2. How often do you, personally, drive this section of road?
$\square$ Daily
$\square$ Weekly
$\square$ Monthly
Few times a year

3. How does navigation through the superstreet compare to a typical intersection?
$\square$ Easier/less confusing
$\square$ The same
$\square$ More difficult/more confusing

4. Had you heard about the superstreet concept before it was built at your location?

$\square$ Yes $\quad \square$ No

If yes, what was your opinion on the superstreet concept before it was build at your location?

$\square$ Positive opinion $\quad \square$ Neutral opinion $\quad \square$ Negative opinion

$\square$ Did not know enough about superstreets to form an opinion

5. Did you live here and have your driver's license prior to the construction of the superstreet? If no, skip ahead to question 10. If yes, proceed with survey.

$\square$ Yes $\quad \square$ No (skip to question 10)

6. How do you, personally, feel the superstreet has affected your ability to safely navigate the roadway compared to the previous roadway design?

$\square$ Positively $\quad \square$ Negatively $\quad \square$ Same

7. How do you, personally, feel the superstreet has affected property values in your area?

$\square$ Positively $\quad \square$ Negatively $\quad \square$ Same $\quad \square$ Don't know - I rent

8. How was travel time through this section of roadway affected during the construction period?

$\square$ Less travel time $\quad \square$ No change $\quad \square$ More travel time

9. What differences, if any, have you, personally, experienced in travel time since the opening of the superstreet?

$\square$ Less travel time $\quad \square$ No change $\quad \square$ More travel time

10. What differences, if any, have you, personally, noticed in the number of stopped vehicles waiting to make a safe maneuver since the opening of the superstreet?

$\square$ More stopped vehicles $\square$ No change $\square$ Fewer stopped vehicles

11. Please select your age range:
$\square 16-29$
$\square$ 30-49
$50-65$
66 or above

12. Please select your gender:
$\square$ Male
$\square$ Female

In the space below, please provide any additional thoughts you may have regarding superstreets. This may include comments related to topics covered in this questionnaire or you may address topics not covered in this survey.

Please place this form in the enclosed envelope and mail it back to us. Thank you!

\section{FIGURE 6.3 Resident survey.}




\section{CURRENT RESIDENT \\ 123 Main St. \\ City, NC 12345}

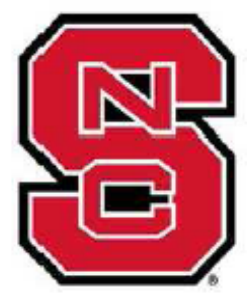

Greetings,

By now you should have received notice of a research study North Carolina State University is doing for the North Carolina Department of Transportation on the effects of superstreets. To remind you, a superstreet is an intersection design that prohibits direct left-turn and through movements from the side streets. Instead, the left turns from the side streets are made by turning right onto the main road then making a u-turn using a one-way median opening, as shown by the dotted line in the diagram below; through movements across the main road are done in a similar manner, as shown by the dashed line in the diagram.

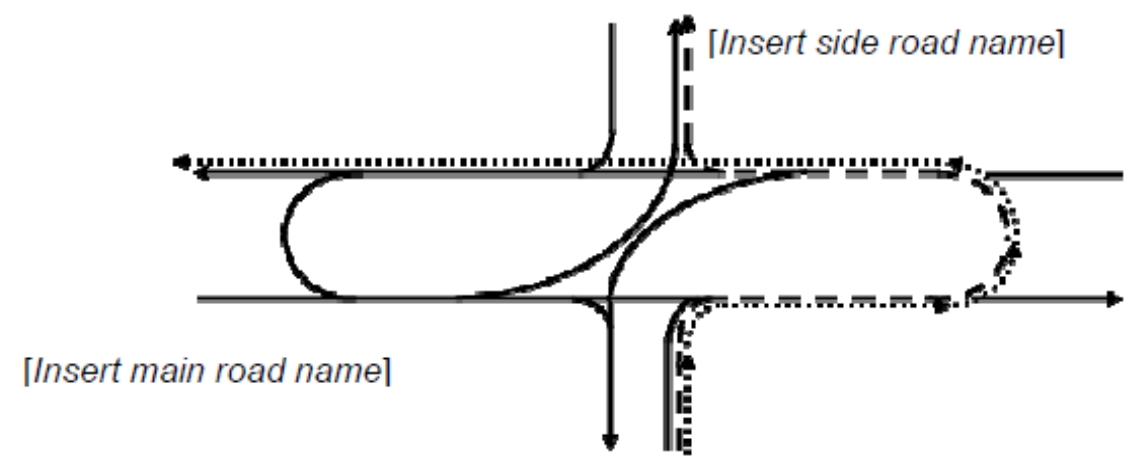

Figure 1. Basic superstreet design

Our records show that you have not returned our survey. We would like to remind you that you have been selected to represent your neighbors in the study, and your opinion is very important in helping us understand how well the design is working. If in fact you have returned the survey, we thank you for your participation!

For your convenience, we will be mailing you another survey packet. Please take the time to fill out the short questionnaire. As a reminder, a superstreet is located near you at the intersection of [insert road name] and [insert road name]. All participants and responses will remain anonymous. If you have any questions please contact the study director, Dr. Joseph Hummer at (919) 515-7733 or hummer@ncsu.edu.

Thank you for your help with this important research!

FIGURE 6.4 Reminder letter for the resident survey. 


\subsection{RESIDENT SURVEY RESULTS}

\subsection{Results}

Approximately two months after the initial letters were mailed I received 145 surveys back from the 500 selected households, for a 29\% response rate. The three signalized sites yielded 92 responses and the eight unsignalized sites combined for 53 responses. Table 7.1 lists the number of responses received from each site. Table 7.2 provides the results for each question. It is important to note that not all of question responses total $100 \%$ in Table 7.2 because not all respondents answered every question. It is also likely that those who responded to the survey had strong opinions either for or against the superstreet design.

TABLE 7.1 Number of Responses From Each Survey Site

\begin{tabular}{|l|l|c|c|c|}
\hline Site & City & State & \multicolumn{1}{|c|}{ Type } & $\begin{array}{c}\text { \# of } \\
\text { Responses }\end{array}$ \\
\hline \hline US 15-501 \& Europa Dr. / Erwin Rd. & Chapel Hill & NC & signalized & 37 \\
\hline US 17 \& Scotts Hill Loop Rd. / Sidbury Rd. & Wilmington & NC & signalized & 38 \\
\hline US 17 \& Lanvale Rd. & Leland & NC & signalized & 17 \\
\hline US 17 \& Mt. Pisgah Rd. / Sellers Rd. & Supply & NC & unsignalized & 10 \\
\hline US 17 \& Ocean Isle Beach Rd. & Shallotte & NC & unsignalized & 9 \\
\hline US 74-76 \& Blacksmith Rd. & Bolton & NC & unsignalized & 8 \\
\hline US 74 \& Elmore Rd. & Laurinburg & NC & unsignalized & 3 \\
\hline US 74 \& Dicks Creek Rd. & Whittier & NC & unsignalized & 6 \\
\hline NC 87 \& Peanut Plant Rd. & Elizabethtown & NC & unsignalized & 10 \\
\hline NC 24 \& Haw Branch Rd. & Richlands & NC & unsignalized & 7 \\
\hline TOTAL: & & & & $\mathbf{1 4 5}$ \\
\hline
\end{tabular}


TABLE 7.2 Resident Survey Results by Question

\begin{tabular}{|c|c|c|c|c|}
\hline Question & Response & Signalized & Unsignalized & All \\
\hline \multirow{4}{*}{$\begin{array}{l}\text { 1. How long have you, personally, } \\
\text { lived near this intersection? }\end{array}$} & Less than 1 year & $3 \%$ & $4 \%$ & $3 \%$ \\
\hline & $\overline{1}-\underline{3}$ years - & $22 \%$ & $\overline{8} \%$ & $17 \overline{\%}$ \\
\hline & $4-10$ years & $43 \%$ & $17 \%$ & $34 \%$ \\
\hline & $\overline{\text { More than }} \overline{10}$ years & $32 \%$ & $\overline{68} \%$ & $45 \overline{\%}$ \\
\hline \multirow{4}{*}{$\begin{array}{l}\text { 2. How often do you, personally, } \\
\text { drive this section of road? }\end{array}$} & Daily & $57 \%$ & $42 \%$ & $51 \%$ \\
\hline & Weekly & $26 \%$ & $42 \%$ & $32 \%$ \\
\hline & Monthly & $10 \%$ & $8 \%$ & $9 \%$ \\
\hline & Few times a year & $8 \%$ & $6 \%$ & $7 \%$ \\
\hline \multirow{3}{*}{$\begin{array}{l}\text { 3. How doe s navigation through the } \\
\text { superstreet compare to a typical } \\
\text { intersection? }\end{array}$} & Easier/less confusing . & $33 \%$ & $38 \%$ & $35 \%$ \\
\hline & The same & $\underline{17} \%$. & $21 \%$ & $\underline{19} \%$ \\
\hline & More difficult/more confusing & $41 \%$ & $32 \%$ & $38 \%$ \\
\hline \multirow{2}{*}{$\begin{array}{l}\text { 4. Had you heard about the } \\
\text { superstreet concept before it was } \\
\text { built at your location? }\end{array}$} & Yes & $34 \%$ & $45 \%$ & $38 \%$ \\
\hline & No & $\overline{66 \%}$ & & \\
\hline \multirow{4}{*}{$\begin{array}{l}\text { 4a. If yes, what was your opinion on } \\
\text { the superstreet concept before it was } \\
\text { built at your location? }\end{array}$} & Pos itive opi nion & $26 \%$ & $50 \%$ & $36 \%$ \\
\hline & Neutral opi nion & $23 \%$ & $17 \%$ & $20 \%$ \\
\hline & Negative opi nion & $29 \%$ & $21 \%$ & $26 \%$ \\
\hline & Did not know enough & $\overline{23} \%$ & $12 \overline{\%}$ & $\overline{18} \%$ \\
\hline \multirow{3}{*}{$\begin{array}{l}\text { 5. Did you live here and have your } \\
\text { driver's license prior to the } \\
\text { construction of the superstreet? If no, } \\
\text { skip ahead to question } 10 \text {. If yes, } \\
\text { proceed with survey. }\end{array}$} & Yes & $92 \%$ & $91 \%$ & $92 \%$ \\
\hline & --- & & - & 一 \\
\hline & No (skip to question 10) & $8 \%$ & $6 \%$ & $7 \%$ \\
\hline \multirow{4}{*}{$\begin{array}{l}\text { 6. How do you, personally, feel the } \\
\text { superstreet has affected your ability } \\
\text { to safely navigate the roadway } \\
\text { compared to the previous roadway } \\
\text { design? }\end{array}$} & Pos itively & $49 \%$ & $56 \%$ & $52 \%$ \\
\hline & Negatively & $22 \%$ & $23 \%$ & $23 \%$ \\
\hline & --- & & & - \\
\hline & Same & $28 \%$ & $17 \%$ & $24 \%$ \\
\hline \multirow{4}{*}{$\begin{array}{l}\text { 7. How do you, personally, feel the } \\
\text { superstreet has affected property } \\
\text { values in your area? }\end{array}$} & Pos itively & $9 \%$ & $15 \%$ & $11 \%$ \\
\hline & Negatively & $12 \%$ & $8 \%$ & $-11 \%$ \\
\hline & Same -- & $\underline{56} \%$ & $58 \%$ & $\underline{57 \%}$ \\
\hline & Don't know - I rent & $20 \%$ & $10 \%$ & $17 \%$ \\
\hline \multirow{3}{*}{$\begin{array}{l}\text { 8. How was travel time through this } \\
\text { section of roadway affected during } \\
\text { the construction period? }\end{array}$} & Less travel time & $1 \%$ & $4 \%$ & $2 \%$ \\
\hline & No change & $24 \%$ & $-44 \%$ & $\underline{31} \%$ \\
\hline & More travel time & $74 \%$ & $48 \%$ & $65 \%$ \\
\hline
\end{tabular}


TABLE 7.2 (continued) Resident Survey Results by Question

\begin{tabular}{|l|l|c|c|c|}
\hline Question & Response & Signalized & Unsignalized & All \\
\hline \hline $\begin{array}{l}\text { 9. What differences, if } \\
\text { any, have you, personally, } \\
\text { experienced in travel time } \\
\text { since the opening of the } \\
\text { superstreet? }\end{array}$ & Less travel time & $18 \%$ & $10 \%$ & $15 \%$ \\
\cline { 2 - 5 } & No change & $32 \%$ & $52 \%$ & $39 \%$ \\
\cline { 2 - 5 } $\begin{array}{l}\text { 10. What differences, if } \\
\text { any, have you, personally, } \\
\text { noticed in the number of } \\
\text { stopped vehicles waiting } \\
\text { to make a safe maneuver } \\
\text { since the opening of the } \\
\text { superstreet? }\end{array}$ & More stopped vehicles & $45 \%$ & $28 \%$ & $44 \%$ \\
\cline { 2 - 5 } & Fewer stopped vehicles & $36 \%$ & $38 \%$ & $37 \%$ \\
\hline \multirow{2}{*}{$\begin{array}{l}\text { 11. Please select your age } \\
\text { range: }\end{array}$} & $16-29$ & $11 \%$ & $26 \%$ & $20 \%$ \\
\cline { 2 - 5 } & $30-40$ & $26 \%$ & $32 \%$ & $28 \%$ \\
\cline { 2 - 5 } & $50-65$ & $36 \%$ & $43 \%$ & $39 \%$ \\
\cline { 2 - 5 } & 66 or above & $27 \%$ & $21 \%$ & $25 \%$ \\
\hline \multirow{2}{*}{$\begin{array}{l}\text { 12. Please select your } \\
\text { gender: }\end{array}$} & Male & $52 \%$ & $42 \%$ & $49 \%$ \\
\cline { 2 - 5 } & Female & $57 \%$ & $50 \%$ \\
\hline
\end{tabular}

Most respondents had lived near the superstreet intersection for a long-enough time to remember the previous intersection design. Overall, the responses from males and females were evenly split. The slight difference in male/female responses between signalized and unsignalized sites was not large enough to be statistically significant. I also received a relatively even split for the age range of respondents, with the 16-29 age group being the only exception. The results confirm there was no over-representation of any particular age group or gender.

I tested the accuracy provided by the final sample size using Equation 6.1 for simple random sampling of proportional data. Assuming a 95\% confidence level, the achieved percent error ranged from $6 \%$ to just over $8 \%$ for the four key questions in the survey. This is only slightly greater than the goal of staying within $5 \%$ of the mean, and still within an acceptable range for the results to show meaningful differences if they existed. Table 7.3 shows the percent 
error (d) achieved and the sample size that I would need to achieve results within 5\% of the mean.

\section{TABLE 7.3 Value of d Achieved for the Key Questions}

\begin{tabular}{|l|c|c|c|c|}
\hline & Q.3 & Q. 6 & Q. 9 & Q. 10 \\
\hline \hline alpha & 0.05 & 0.05 & 0.05 & 0.05 \\
actual n & 145 & 133 & 133 & 145 \\
achieved d & 7.90 & 8.49 & 6.11 & 7.99 \\
$n$ needed for $d=$ & & & & \\
5\% & 362 & 383 & 199 & 371 \\
\hline
\end{tabular}

\subsection{Analysis}

I identified four key questions from the survey - questions three, six, nine, and ten - on navigation, safety, travel time, and the number of stopped vehicles, respectively. Overall, thirty-five percent (35\%) of the total respondents found navigation through a superstreet easier and less confusing compared to a typical intersection, while thirty-eight percent (38\%) found it more difficult and more confusing. Over half of the respondents (52\%) reported that the superstreet has a positive effect on their ability to safely navigate through the intersection, while twenty-three percent (23\%) reported a negative effect. Fifteen percent $(15 \%)$ of the respondents reported less travel time negotiating the superstreet, while forty-four percent (44\%) reported experiencing an increase in travel time. I analyzed the key questions further by comparing responses from signalized and unsignalized superstreet sites.

\subsubsection{Signalized vs. Unsignalized}

I performed a two-tailed Z-test for proportions at the 95\% confidence level for the four key survey questions to compare the responses from the signalized and unsignalized sites. Table 7.4 shows the results of the tests. It should be noted that not all of the responses in the table sum to $100 \%$ because some respondents chose not to answer all of the questions. The only key question with significant proportional differences between signalized and unsignalized 
sites was question nine on travel time: just over half of the residents near unsignalized superstreets report no change in travel time, compared to $32 \%$ reporting no change at signalized superstreets.

TABLE 7.4 Two-tailed Z-test for Proportions Results Comparing Signalized to Unsignalized Survey Responses at a 95\% Confidence Level

\begin{tabular}{|c|c|c|c|c|}
\hline \multirow{2}{*}{ Key Question } & \multirow{2}{*}{ Answer } & \multicolumn{2}{|c|}{ Response } & \multirow{2}{*}{$\begin{array}{l}\text { Significant } \\
\text { difference? }\end{array}$} \\
\hline & & Signalized & Unsignalized & \\
\hline \multirow{3}{*}{$\begin{array}{l}\# 3 \text { - How does navigation } \\
\text { through the superstreet } \\
\text { compare to a typical } \\
\text { intersection? }\end{array}$} & easier & $33 \%$ & $38 \%$ & no \\
\hline & same & $17 \%$ & $21 \%$ & no \\
\hline & $\begin{array}{l}\text { more } \\
\text { difficult }\end{array}$ & $41 \%$ & $32 \%$ & no \\
\hline \multirow{3}{*}{$\begin{array}{l}\# 6 \text { - How do you, personally, } \\
\text { feel the superstreet has affected } \\
\text { your ability to safely navigate } \\
\text { the roadway compared to the } \\
\text { previous roadway design? }\end{array}$} & positively & $49 \%$ & $56 \%$ & no \\
\hline & negatively & $22 \%$ & $23 \%$ & no \\
\hline & same & $28 \%$ & $17 \%$ & no \\
\hline \multirow{3}{*}{$\begin{array}{l}\# 9 \text { - What differences, if any, } \\
\text { have you, personally, } \\
\text { experienced in travel time since } \\
\text { the opening of the superstreet? }\end{array}$} & less TT & $18 \%$ & $10 \%$ & no \\
\hline & no change & $32 \%$ & $52 \%$ & yes \\
\hline & more TT & $51 \%$ & $33 \%$ & no \\
\hline \multirow{3}{*}{$\begin{array}{l}\text { \#10 - What differences, if any, } \\
\text { have you, personally, noticed } \\
\text { in the number of stopped } \\
\text { vehicles waiting to make a safe } \\
\text { maneuver since the opening of } \\
\text { the superstreet? }\end{array}$} & more stopped & $45 \%$ & $28 \%$ & no \\
\hline & no change & $16 \%$ & $26 \%$ & no \\
\hline & $\begin{array}{l}\text { fewer } \\
\text { stopped }\end{array}$ & $36 \%$ & $38 \%$ & no \\
\hline
\end{tabular}

A reason for a high percentage of responses for increased travel time is likely due to the survey responses coming mostly from the neighborhoods located off of the side streets. More complaints regarding travel time came from the signalized superstreets as opposed to the unsignalized superstreets. One of the purposes of signalized superstreets is to improve progression for the major street through movement, and as a result minor road left turn and through traffic is required to make extra maneuvers. It is possible that motorists perceive this as an increase in travel time because of the added movement. There were many comments 
from the surveyed residents expressing how they feel they have to go out of their way to make a left or through movement from the side road. One of the sites with multiple complaints was the US 15-501 site in Chapel Hill, NC where there is no direct left turn from the major road to the minor road.

Although not significant, another large difference in responses between the signalized and unsignalized groups was for the number of stopped vehicles (Question 10). More residents near the signalized sites (45\%) felt there were more stopped vehicles than near the unsignalized sites (28\%). I received multiple complaints of non-compliance for the "no turn on red" signs and illegal left turns on red at the u-turn crossovers at two of the signalized sites, US-17 at Scotts Hill Loop Road and US-17 at Lanvale Road. Under North Carolina law it is illegal to make a left turn on red; therefore, drivers likely feel they are delayed unnecessarily at signalized u-turn intersections if there are acceptable gaps in the approaching traffic.

\subsubsection{Signalized Sites}

I separately analyzed the answers provided for each question for both signalized and unsignalized sites. As before, a two-tailed Z-test for proportions was conducted at the 95\% confidence level on the same four key questions.

Table 7.5 shows the results for the signalized sites. The responses show that navigation through a superstreet is not significantly easier or harder than a typical intersection (Question 3). However, residents felt the superstreet design positively affected their ability to safely navigate the intersection, with the results showing a significant difference between "positive" responses (49\%) and "negative" responses (22\%), and between "positive" and "the same" responses (28\%). 
TABLE 7.5 Two-tailed Z-test for Proportions Comparing Key Survey Question Responses for Signalized Sites at a 95\% Confidence Level.

\begin{tabular}{|c|c|c|c|c|c|}
\hline \multirow[b]{2}{*}{ Key Question } & \multicolumn{4}{|c|}{ Comparison } & \multirow{2}{*}{$\begin{array}{l}\text { Significant } \\
\text { difference? }\end{array}$} \\
\hline & Response & $\begin{array}{c}\% \\
\text { response }\end{array}$ & Response & $\begin{array}{c}\% \\
\text { response }\end{array}$ & \\
\hline \multirow{3}{*}{$\begin{array}{l}\# 3 \text { - How does navigation } \\
\text { through the superstreet } \\
\text { compare to a typical } \\
\text { intersection? }\end{array}$} & easier & $33 \%$ & more difficult & $41 \%$ & no \\
\hline & easier & $33 \%$ & the same & $17 \%$ & yes \\
\hline & the same & $17 \%$ & more difficult & $41 \%$ & yes \\
\hline \multirow{3}{*}{$\begin{array}{l}\# 6 \text { - How do you, personally, } \\
\text { feel the superstreet has } \\
\text { affected your ability to safely } \\
\text { navigate the roadway } \\
\text { compared to the previous } \\
\text { roadway design? }\end{array}$} & positively & $49 \%$ & negatively & $22 \%$ & yes \\
\hline & positively & $49 \%$ & the same & $28 \%$ & yes \\
\hline & the same & $28 \%$ & negatively & $22 \%$ & no \\
\hline \multirow{3}{*}{$\begin{array}{l}\text { \#9 - What differences, if any, } \\
\text { have you, personally, } \\
\text { experienced in travel time } \\
\text { since the opening of the } \\
\text { superstreet? }\end{array}$} & less TT & $18 \%$ & more TT & $51 \%$ & yes \\
\hline & less TT & $18 \%$ & no change & $32 \%$ & yes \\
\hline & no change & $32 \%$ & more TT & $51 \%$ & yes \\
\hline \multirow{3}{*}{$\begin{array}{l}\# 10 \text { - What differences, if } \\
\text { any, have you, personally, } \\
\text { noticed in the number of } \\
\text { stopped vehicles waiting to } \\
\text { make a safe maneuver since } \\
\text { the opening of the } \\
\text { superstreet? }\end{array}$} & $\begin{array}{l}\text { more } \\
\text { stopped }\end{array}$ & $45 \%$ & fewer stopped & $36 \%$ & no \\
\hline & $\begin{array}{l}\text { more } \\
\text { stopped }\end{array}$ & $45 \%$ & no change & $16 \%$ & yes \\
\hline & no change & $16 \%$ & fewer stopped & $36 \%$ & yes \\
\hline
\end{tabular}

Only $18 \%$ of residents reported a reduction in travel time (question nine), while 51\% reported an increase, and 32\% reported no change. There were statistically significant differences between all these answers. As previously discussed, the reason for the higher responses for increased travel time or no change in travel time is likely because these were surveys of residents who live along the side streets.

\subsubsection{Unsignalized Sites}

Table 7.6 displays the results for the two-tailed Z-tests for proportions for responses from unsignalized sites. Similar to the signalized superstreets, the results for question six regarding safe navigation through the superstreet showed significant differences between 
positive (56\%) and negative (23\%), as well as positive and the same (17\%). Unsignalized superstreets are generally installed as a safety countermeasure, and while this survey is not a safety analysis, the results are clear that nearby residents at least have a feeling of increased safety while traversing the unsignalized superstreet compared to the previous intersection design.

TABLE 7.6 Two-tailed Z-test for Proportions Comparing Key Survey Question Responses for Unsignalized Sites at a 95\% Confidence Level.

\begin{tabular}{|c|c|c|c|c|c|}
\hline \multirow[b]{2}{*}{ KEY QUESTIONS } & \multicolumn{4}{|c|}{ Comparison between response choices } & \multirow{2}{*}{$\begin{array}{l}\text { Significant } \\
\text { difference? }\end{array}$} \\
\hline & Response & $\begin{array}{c}\% \\
\text { response }\end{array}$ & Response & $\begin{array}{c}\% \\
\text { response }\end{array}$ & \\
\hline \multirow{3}{*}{$\begin{array}{l}\text { \#3 - How does navigation } \\
\text { through the superstreet } \\
\text { compare to a typical } \\
\text { intersection? }\end{array}$} & easier & $38 \%$ & $\begin{array}{c}\text { more } \\
\text { difficult }\end{array}$ & $32 \%$ & no \\
\hline & easier & $38 \%$ & the same & $21 \%$ & no \\
\hline & the same & $21 \%$ & $\begin{array}{c}\text { more } \\
\text { difficult }\end{array}$ & $32 \%$ & no \\
\hline \multirow{3}{*}{$\begin{array}{l}\text { \#6 - How do you, personally, } \\
\text { feel the superstreet has } \\
\text { affected your ability to safely } \\
\text { navigate the roadway } \\
\text { compared to the previous } \\
\text { roadway design? }\end{array}$} & positively & $56 \%$ & negative & $23 \%$ & yes \\
\hline & positively & $56 \%$ & the same & $17 \%$ & yes \\
\hline & the same & $17 \%$ & negative & $23 \%$ & no \\
\hline \multirow{3}{*}{$\begin{array}{l}\text { \#9 - What differences, if any, } \\
\text { have you, personally, } \\
\text { experienced in travel time } \\
\text { since the opening of the } \\
\text { superstreet? }\end{array}$} & less TT & $10 \%$ & more TT & $33 \%$ & yes \\
\hline & less TT & $10 \%$ & no change & $52 \%$ & yes \\
\hline & no change & $52 \%$ & more TT & $33 \%$ & no \\
\hline \multirow{3}{*}{$\begin{array}{l}\# 10 \text { - What differences, if any, } \\
\text { have you, personally, noticed } \\
\text { in the number of stopped } \\
\text { vehicles waiting to make a safe } \\
\text { maneuver since the opening of } \\
\text { the superstreet? }\end{array}$} & $\begin{array}{c}\text { more } \\
\text { stopped }\end{array}$ & $28 \%$ & $\begin{array}{c}\text { fewer } \\
\text { stopped }\end{array}$ & $38 \%$ & no \\
\hline & $\begin{array}{c}\text { more } \\
\text { stopped }\end{array}$ & $28 \%$ & no change & $26 \%$ & no \\
\hline & no change & $26 \%$ & $\begin{array}{c}\text { fewer } \\
\text { stopped }\end{array}$ & $38 \%$ & no \\
\hline
\end{tabular}




\subsection{CONCLUSIONS}

\subsection{Research Results}

This project investigated the operational effects of superstreets compared to conventional intersections. I calibrated and validated models of three existing signalized superstreets in VISSIM and compared them to the equivalent conventional intersection using travel time as the measure of effectiveness. All three superstreets, which included two isolated intersections and one five-intersection corridor, performed better than the corresponding conventional intersections when comparing the average travel times per vehicle. The largest travel time savings occurred at the peak, peak+10\%, and peak+20\% demand levels.

With the superstreet reducing overall travel time through the intersection at peak periods and higher, it means that it can buy an agency more years after the conventional intersection hits capacity before a major upgrade is funded. Using the critical sum as a capacity check, the superstreet was able to provide more capacity beyond what the conventional intersection could provide when it reached high demand levels in these three cases. When agencies are looking to make intersection improvements along their corridors, the superstreet can give them more capacity and at the same time reduce travel time, therefore adding more years to the intersections' useful lives before having to make additional improvements, and thus saving money.

The three superstreets modeled were all different from each other. The Chapel Hill site is a single, isolated superstreet that does not allow direct left turns from the major road to the minor road. The Wilmington site is also a single, isolated superstreet but it did allow direct left turns from the major road, and it also allowed permitted and protected movements at the left turn and u-turn crossovers. The Leland superstreet is as example of corridor application, with five adjacent signalized superstreet intersections. At all three of these sites the superstreet required less travel time for the average vehicle than the conventional intersection. This proves that the superstreet design could work well as both an isolated 
intersection and a corridor. The corridor, however, had a greater reduction in travel time over the conventional compared to the single superstreet intersection locations. The superstreet design allows for perfect progression through the arterial by creating a one-way pair and requiring only two-phase signals. Theory suggests, and these results confirm, that the more superstreet intersections that are back-to-back along a corridor, the better the progression will be relative to a conventional corridor. The Chapel Hill and Wilmington sites both have adjacent conventional intersections, which limits the progression capabilities of the superstreet.

Broken down by movement, the major road through and left movements were positively impacted by the superstreet design, having lower travel times than the conventional comparison intersections. The minor road left and through movements were negatively impacted, with the travel time higher than for the superstreet than the conventional. The minor road left and through movements have to travel an extra distance to a downstream crossover, and in doing so pass through two extra signals. The minor movements were affected more during the low volume, off-peak periods than the peak periods. Along the US17 corridor the difference in travel time steadily decreased as the demand increased. The minor left and minor through travel times were only 9-18\% higher than the conventional during the peak periods.

The Highway Capacity Manual defines an arterial as "a signalized street that primarily serves through-traffic and that secondarily provides access to abutting properties, with signal spacing of 2.0 miles or less” (24). The positive affect the superstreet has on the arterial through and left movements should prevail over any negative impacts to the minor road movements in many corridors. By definition, the superstreet is helping serve the purpose of the arterial by effectively and efficiently moving vehicles along the corridor.

From the residential survey, residents living near superstreets, both signalized and unsignalized, have mixed reactions in regard to the ease of navigation through superstreets compared to typical intersections, but they generally agree that the design helps them travel 
more safely through the intersection. The difference between unsignalized and signalized sites in relation to travel time and the number of stopped vehicles is likely due in part to the nature of the traffic control device (signal versus stop sign), and also to the inability of vehicles at signalized sites to make a legal left turn on red in NC.

The scope of this survey was limited. By surveying residents living near superstreets, the results reflect mostly those drivers coming to and from the side streets, rather than the majority of through travelers. The responses showing increased travel time or no change in travel time are likely a reflection of those making the additional movements of a right turn then u-turn to move in and/or out of the minor roads.

\subsection{Recommendations}

Agencies should consider superstreets as a viable option for upgrading arterials that look like the three cases studied here. These intersections should be where low volume, two-lane roads meet a high-volume, divided, four-, six-, or eight-lane arterial. Building a superstreet instead of upgrading the conventional intersection can save money over the long run because the increasing traffic along the arterial will outgrow the conventional design before it outgrows the superstreet.

I recommend building superstreets as a corridor rather than a single, isolated intersection where possible. While a single superstreet intersection will improve travel time and reduce congestion, the design works better as a corridor treatment since that allows for perfect progression in both directions at any speed and signal spacing. I also recommend building them along developing corridors as a preventative measure to increase capacity and reduce congestion before it actually happens, as was the case with the US-17 superstreet corridor in Leland, NC.

The superstreet is best suited for divided arterials with a high through and left turn volumes on the major road. The arterial left turn volume per lane should be greater than $80 \%$ of the minor road traffic per lane that moves during the same signal phase. Superstreets are not the 
optimal choice for minor roads with high left turn and through volumes. The minor road total volume should typically be less than $20 \%$ of the total intersection volume. Another useful rule of thumb, based on Kramer's definition of an arterial receiving at least 2/3 of the green time (11), is that the minor street two-way demand should be less than about 22,000 vehicles per day. The median width should be between 40 and 70 feet to accommodate large trucks. If the median is not wide enough, or there is not enough right-of-way to widen, loons can be built across from the median crossovers for wide-turning vehicles (13).

Multiple residents from each signalized site commented on the disregard for the no left turn on red rule at the u-turn crossovers. With the number of superstreets in North Carolina likely to increase in future years, I recommend evaluating the possibility of changing this rule so a vehicle could make a left turn on red when entering a one-way street (which is essentially what they are doing when completing the u-turn maneuver). This is allowed in other states at similar locations.

Agencies should be proactive in education and public awareness of the benefits of superstreets. I suggest showing aerial video of an actual intersection or corridor before and after superstreet implementation to help viewers understand how a superstreet functions compared to a conventional intersection. Simulations are an excellent tool for analyzing designs but may not provide the best visualization for the general public. Instead, a video showing an actual before and after construction from an aerial vantage point may be more convincing. It is also important to understand any perceived negative aspects of the design and mitigate them. As with any intersection treatment, it is important to understand the circumstances where the superstreet will be most beneficial. Superstreets reroute minor street left turn and through movements, and if the demand for those movements is high, superstreets may not be the optimum design choice. Superstreets are a promising solution for congested arterials, and agencies should seriously consider them for operational and safety improvements. 


\subsection{Future Research Needs}

For any future research on the operational effects of superstreets, I have suggestions to consider when collecting data at existing superstreets. Lane utilization studies should be done when collecting data from crossovers. From field observations I noted an uneven distribution of vehicles at the two-lane crossovers. I did not do a full lane utilization study, but was able to look back at the videos and pull data from the Walmart intersection on US-17 where there was an approximate 80/20 split in the lane use. At the rest of the two-lane crossovers I made assumptions on the lane utilization based on qualitative observations.

Another recommendation when collecting field data is to do a gap study where there are permitted/protected movements at crossovers, as well as for right turn on red (RTOR). I was able to use the video footage I had to collect some gap data, but for future studies of superstreets, I recommend conducting a full-scale gap study in conjunction with VISSIM calibration.

There are many other studies that could be done to assess the operational impact of superstreets that were not within the scope of this research project. Some of these research topics include investigating the impacts:

- Of allowing left turns on red,

- Of not allowing right turns on red,

- On operations with and without the direct left turn from the arterial to the minor road,

- Of different distances to the u-turn crossovers and signal spacing,

- Of driveways along the arterial,

- On emissions and fuel savings, and

- On pedestrians and bicycles. 
There is research currently being done on the safety impact of superstreets. This work is expected to be published soon. There is also more research beyond operational and safety analyses that can be done to assess the impact of the superstreet design. A benefit/cost analysis and a decision support guideline would help provide assistance to DOTs and other agencies considering the superstreet design.

Superstreets have the ability to be flexible with crossover distances and driveways along the arterial because the road essentially acts a one-way pair. Studies should be done to investigate the impact of crossover distances and driveway locations on different signal options, such as allowing permissive movements at the crossovers. When studying these effects, I recommend modeling them using data from existing superstreets and their adjacent intersections. Using data from existing superstreets and modifying the geometry or signals will allow for a good understanding of the effects of these changes on actual intersections. 


\section{REFERENCES}

1. Al-Maseid, HR, "Capacity of U-Turns at Median Openings," ITE Journal, Vol. 69, No. 6, June 1999.

2. Liu, P., J. Lu, F, Hu, and G. Sokolow, "Capacity of U-Turn Movement at Median Openings on Multilane Highways," Journal of Transportation Engineering, ASCE, April 2008, Pages 147-154.

3. Maki, R.E. “Directional Crossovers: Michigan’s Preferred Left Turn Strategy”. Presented at the $75^{\text {th }}$ Annual Meeting of the Transportation Research Board, 1996.

4. Dorothy, P.W., T.L. Maleck and S.E. Nolf, "Operational Aspects of the Michigan Design for Divided Highways,” Transportation Research Record 1579, TRB, Washington, DC, 1997.

5. Hummer, J.E. and J.L. Boone, "The Travel Efficiency of Unconventional Arterial Intersection Designs," Transportation Research Record 1500, TRB, 1995, Pages 153-161

6. Bared, J.G. and E.I. Kaisar, "Median U-Turn Design as an Alternative Treatment for Left Turns at Signalized Intersections,” ITE Journal, Vol. 72, No. 2, February 2002.

7. Henderson, S.M. and N. Stamatiadis, "Use of Median U-Turns to Improve Traffic Flow Along Urban Arterials," Journal of the Transportation Research Forum, Volume 40, Number 2, Spring 2001.

8. Thakkar, J., V. Reddy, M. Hadi, and F. Vargas, "A Methodology to Evaluate the Impacts of Prohibiting Median Opening Movements," $4^{\text {th }}$ Annual Access Management Conference, Transportation Research Board, Portland, Oregon, August 2000.

9. Access Management Manual, Transportation Research Board, Washington, D.C., 2003.

10. Eisele, W.L., and W.E. Frawley, "A Methodology for Determining Economic Impacts of Raised Medians: Final Project Results,” Texas Transportation Institute and The Texas A\&M University, College Station, Texas, 2000.

11. Kramer, R.P., "New Combinations of Old Techniques to Rejuvenate Jammed Suburban Arterials," Strategies to Alleviate Traffic Congestion, Proceedings of the 1987 National Conference, ITE, Washington, DC, 1988. 
12. Hummer, J.E., "Unconventional Left Turn Alternatives for Urban and Suburban Arterials: Part One," ITE Journal, Volume 68, Number 9, September 1998.

13. Hughes, Warren, R. Jagannathan, D. Sengupta, and J.E. Hummer, Alternative Intersections/Interchanges: Informational Report (AIIR), Publication No. FHWA-HRT09-060, FHWA, Washington, DC, 2010.

14. Kim, T., P.K. Edara, and J.G. Bared, "Operational and Safety Performance of a NonTraditional Intersection Design: The Superstreet," Transportation Research Board $86^{\text {th }}$ Annual Meeting Compendium of Papers CD-ROM, TRB, Washington, DC, 2007.

15. Reid, J.D. and J.E. Hummer, “Analyzing System Travel Time in Arterial Corridors with Unconventional Designs Using Microscopic Simulation.” Paper 991519, presented at $78^{\text {th }}$ Annual Meeting, Transportation Research Board, Washington, DC, 1998.

16. Hummer, Joseph E., and Jonathan D. Reid. "Unconventional Left-Turn Alternatives for Urban and Suburban Arterials: An Update." Transportation Research E-Circular, Number E-C019, December 2000.

17. Reid, J.D. and J.E. Hummer, "Travel Time Comparison Between Seven Unconventional Arterial Intersection Designs,” Transportation Research Record 1751, Transportation Research Board, National Research Council, Washington, DC, 2001.

18. Lu, J., and P. Liu, "Operational Evaluation of Right Turns Followed by U-turns (4-Lane Arterial) as an Alternative to Direct Left Turns.” Report Submitted to the Florida Department of Transportation, Tallahassee, FL. March 2005.

19. Hummer, J.E., B. Schroeder, J. Moon, and R. Jagannathan, "Recent Superstreet Implementation and Research.” Third Urban Streets Symposium. Transportation Research Board. Seattle, WA, June 2007.

20. Asokan, Anand, J. Bared, R. Jagannathan, W. Hughes, F. Cicu, and P.F. Illotta, “Alternative Intersections Selection Tool - AIST," Transportation Research Board $89^{\text {th }}$ Annual Meeting Compendium of Papers CD-ROM, TRB, Washington, DC, 2010.

21. Personal communication from D. Eyler to R. Haley, 22 Sept. 2008.

22. Manual of Transportation Engineering Studies, Institute of Transportation Engineers, Washington, DC, 2000.

23. California Department of Transportation Guidelines for Applying Traffic Microsimulation Modeling Software, Dowling Associates, Inc., September 2002. 
24. TRB, Highway Capacity Manual, National Research Council, Washington, DC, 2000. 
APPENDICES 
APPENDIX A:

Field Data from Superstreets 
- Travel times - Chapel Hill

\begin{tabular}{|l|c|c|c|c|c|c|}
\hline \multicolumn{1}{|c|}{ Scenario } & $\begin{array}{c}\# \\
\text { runs }\end{array}$ & $\begin{array}{c}\text { Distance } \\
\text { (mi) }\end{array}$ & $\begin{array}{c}\text { Avg. \# } \\
\text { Stops }\end{array}$ & $\begin{array}{c}\text { Avg } \\
\text { Speed } \\
\text { (mph) }\end{array}$ & $\begin{array}{c}\text { Avg. Travel } \\
\text { Time (min) }\end{array}$ & $\begin{array}{c}\text { St.Dev. } \\
\text { Travel } \\
\text { Time }\end{array}$ \\
\hline \hline Minor left (EB) & 6 & 0.73 & 2 & 19.6 & 2.38 & 0.634 \\
Minor left (WB) & 6 & 0.64 & 2 & 15.0 & 2.63 & 0.599 \\
Minor right (EB) & 4 & 0.30 & 1 & 11.7 & 1.57 & 0.357 \\
Minor right (WB) & 4 & 0.27 & 1 & 12.2 & 1.42 & 0.417 \\
Minor thru (EB) & 5 & 0.58 & 3 & 15.2 & 2.36 & 0.513 \\
Minor thru (WB) & 6 & 0.40 & 2 & 15.7 & 1.72 & 0.743 \\
Major left (NB) & 5 & 0.34 & 2 & 12.5 & 1.75 & 0.423 \\
Major left (SB) & 6 & 0.28 & 1 & 19.2 & 0.94 & 0.279 \\
Major right (NB) & 4 & 0.31 & 0 & 26.0 & 0.78 & 0.306 \\
Major right (SB) & 4 & 0.26 & 1 & 22.4 & 0.71 & 0.130 \\
Major thru (NB) & 4 & 0.49 & 0 & 38.2 & 0.78 & 0.122 \\
Major thru (SB) & 4 & 0.53 & 1 & 36.8 & 0.92 & 0.297 \\
\hline
\end{tabular}

- Travel times - Wilmington

\begin{tabular}{|l|c|c|c|c|c|c|}
\hline \multicolumn{1}{|c|}{ Scenario } & $\begin{array}{c}\# \\
\text { runs }\end{array}$ & $\begin{array}{c}\text { Distance } \\
\text { (mi) }\end{array}$ & $\begin{array}{c}\text { Avg. \# } \\
\text { Stops }\end{array}$ & $\begin{array}{c}\text { Avg } \\
\text { Speed } \\
\text { (mph) }\end{array}$ & $\begin{array}{c}\text { St.Dev. } \\
\text { Avg. Travel } \\
\text { Time (min) }\end{array}$ & $\begin{array}{c}\text { Travel } \\
\text { Time }\end{array}$ \\
\hline \hline Minor left (EB) & 4 & 0.67 & 2 & 18.5 & 2.76 & 1.560 \\
Minor left (WB) & 4 & 0.63 & 3 & 13.3 & 3.12 & 1.012 \\
Minor right (EB) & 3 & 0.40 & 2 & 18.3 & 1.34 & 0.367 \\
Minor right (WB) & 3 & 0.32 & 1 & 19.7 & 1.12 & 0.433 \\
Minor thru (EB) & 5 & 0.51 & 3 & 12.9 & 2.64 & 0.959 \\
Minor thru (WB) & 4 & 0.51 & 2 & 12.4 & 2.55 & 0.436 \\
Major left (NB) & 5 & 0.73 & 1 & 23.0 & 2.15 & 0.974 \\
Major left (SB) & 4 & 0.63 & 1 & 16.4 & 2.47 & 0.643 \\
Major right (NB) & 3 & 0.34 & 0 & 30.5 & 0.67 & 0.058 \\
Major right (SB) & 3 & 0.34 & 0 & 32.1 & 0.65 & 0.089 \\
Major thru (NB) & 4 & 0.54 & 0 & 40.6 & 0.81 & 0.108 \\
Major thru (SB) & 4 & 0.49 & 0 & 44.3 & 0.82 & 0.320 \\
\hline
\end{tabular}


- Travel times - Walmart/Gregory (US-17)

\begin{tabular}{|l|c|c|c|c|c|c|}
\hline \multicolumn{1}{|c|}{ Scenario } & $\begin{array}{c}\# \\
\text { runs }\end{array}$ & $\begin{array}{c}\text { Distance } \\
\text { (mi) }\end{array}$ & $\begin{array}{c}\text { Avg. \# } \\
\text { Stops }\end{array}$ & $\begin{array}{c}\text { Avg } \\
\text { Speed } \\
\text { (mph) }\end{array}$ & $\begin{array}{c}\text { Avg. Travel } \\
\text { Time (min) }\end{array}$ & $\begin{array}{c}\text { St.Dev. } \\
\text { Travel } \\
\text { Time }\end{array}$ \\
\hline \hline Minor left (EB) & 5 & 0.54 & 3 & 13.4 & 2.45 & 0.41 \\
Minor left (WB) & 5 & 0.57 & 2 & 18.1 & 2.00 & 0.54 \\
Minor right (EB) & 5 & 0.29 & 2 & 15.5 & 1.38 & 0.97 \\
Minor right (WB) & 6 & 0.22 & 1 & 17.2 & 0.89 & 0.39 \\
Minor thru (EB) & 6 & 0.44 & 2 & 12.7 & 2.25 & 0.76 \\
Minor thru (WB) & 4 & 0.34 & 2 & 11.3 & 2.09 & 0.85 \\
Major left (NB) & 6 & 0.31 & 1 & 17.9 & 1.17 & 0.43 \\
Major left (SB) & 6 & 0.25 & 1 & 12.8 & 1.26 & 0.32 \\
Major right (NB) & 4 & 0.33 & 0 & 31.5 & 0.64 & 0.07 \\
Major right (SB) & 5 & 0.21 & 0 & 31.9 & 0.40 & 0.02 \\
Major thru (NB) & 5 & 0.44 & 0 & 33.0 & 0.81 & 0.13 \\
Major thru (SB) & 5 & 0.43 & 0 & 43.8 & 0.58 & 0.02 \\
\hline
\end{tabular}

- Travel times - Lanvale/Brunswick Forest (US-17)

\begin{tabular}{|l|c|c|c|c|c|c|}
\hline \multicolumn{1}{|c|}{ Scenario } & $\begin{array}{c}\# \\
\text { runs }\end{array}$ & $\begin{array}{c}\text { Distance } \\
\text { (mi) }\end{array}$ & $\begin{array}{c}\text { Avg. \# } \\
\text { Stops }\end{array}$ & $\begin{array}{c}\text { Avg } \\
\text { Speed } \\
\text { (mph) }\end{array}$ & $\begin{array}{c}\text { Avg. Travel } \\
\text { Time (min) }\end{array}$ & $\begin{array}{c}\text { St.Dev. } \\
\text { Travel } \\
\text { Time }\end{array}$ \\
\hline \hline Minor left (EB) & 6 & 0.79 & 2 & 18.6 & 2.61 & 0.45 \\
Minor left (WB) & 1 & 0.64 & 2 & 19.9 & 1.93 & - \\
Minor right (EB) & 2 & 0.42 & 1 & 26.3 & 1.03 & 0.39 \\
Minor right (WB) & 2 & 0.38 & 1 & 18.0 & 1.27 & 0.07 \\
Minor thru (EB) & 2 & 0.50 & 2 & 14.6 & 2.08 & 0.39 \\
Minor thru (WB) & 2 & 0.51 & 3 & 11.1 & 2.77 & 0.16 \\
Major left (NB) & 5 & 0.43 & 1 & 17.6 & 1.58 & 0.39 \\
Major left (SB) & 2 & 0.47 & 1 & 16.7 & 1.69 & 0.01 \\
Major right (NB) & 2 & 0.33 & 1 & 26.8 & 0.73 & 0.07 \\
Major right (SB) & 2 & 0.48 & 0 & 40.8 & 0.71 & 0.04 \\
Major thru (SB) & 4 & 0.68 & 0 & 54.1 & 0.75 & 0.02 \\
\hline
\end{tabular}


- Turning movement counts - Chapel Hill: Data set \#1 collected on 10/27/09

\begin{tabular}{|c|c|c|c|c|c|c|c|c|c|c|}
\hline \multirow{2}{*}{$\begin{array}{r}\text { Time: } \\
\text { Movement }\end{array}$} & \multicolumn{2}{|c|}{ 7:30 - 7:45am } & \multicolumn{2}{|c|}{ 7:45 - 8:00am } & \multicolumn{2}{|c|}{ 8:00 - 8:15am } & \multicolumn{2}{|c|}{ 8:15-8:30am } & \multicolumn{2}{|c|}{ 8:30 - 8:45am } \\
\hline & cars & trucks & cars & trucks & cars & trucks & cars & trucks & cars & trucks \\
\hline NBT & 312 & 11 & 408 & 7 & 381 & 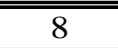 & 321 & 8 & 321 & 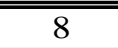 \\
\hline NBR & 8 & 1 & 11 & 0 & 9 & 1 & 9 & 0 & 11 & 0 \\
\hline NBL & 31 & 2 & 54 & 0 & 53 & 2 & 63 & 5 & 47 & 1 \\
\hline SBT & 313 & 7 & 377 & 10 & 298 & 12 & 365 & 5 & 324 & 11 \\
\hline SBR & 5 & 0 & 14 & 0 & 25 & 0 & 11 & 0 & 7 & 0 \\
\hline SBL & 16 & 0 & 21 & 0 & 30 & 0 & 27 & 0 & 26 & 0 \\
\hline EBT & 3 & 1 & 14 & 0 & 24 & 0 & 6 & 0 & 7 & 0 \\
\hline EBR & 67 & 0 & 87 & 1 & 74 & 0 & 138 & 2 & 105 & 0 \\
\hline EBL & 9 & 0 & 3 & 0 & 9 & 0 & 5 & 0 & 8 & 1 \\
\hline WBT & 2 & 1 & 12 & 0 & 14 & 0 & 28 & 0 & 15 & 0 \\
\hline WBR & 37 & 2 & 22 & 0 & 30 & 0 & 28 & 0 & 33 & 0 \\
\hline WBL & 8 & 1 & 7 & 0 & 7 & 0 & 7 & 0 & 7 & 0 \\
\hline
\end{tabular}

- Turning movement counts - Chapel Hill: Data set \#2 collected on 10/27/09

\begin{tabular}{|c|c|c|c|c|c|c|c|c|c|c|}
\hline Time: & $11: 30$ & 1:45am & $11: 45$ & 2:00pm & $12: 00$ & 2:15pm & $12: 15$ & $2: 30 \mathrm{pm}$ & $12: 30$ & 2:45pm \\
\hline Movement & cars & trucks & cars & trucks & cars & trucks & cars & trucks & cars & trucks \\
\hline NBT & 308 & 6 & 334 & 6 & 336 & 9 & 358 & 7 & 392 & 8 \\
\hline NBL & 38 & 4 & 43 & 0 & 39 & 0 & 51 & 0 & 66 & 0 \\
\hline SBT & 343 & 4 & 320 & 12 & 314 & 6 & 290 & 6 & 363 & 7 \\
\hline SBR & 18 & 0 & 12 & 2 & 16 & 0 & 11 & 0 & 12 & 0 \\
\hline EBR & 44 & 2 & 49 & 0 & 55 & 0 & 54 & 0 & 57 & 1 \\
\hline EBL & 9 & 0 & 8 & 1 & 8 & 0 & 9 & 1 & 7 & 0 \\
\hline WBT & 11 & 1 & 14 & 2 & 8 & 0 & 17 & 0 & 14 & 0 \\
\hline WBR & 36 & 0 & 29 & 0 & 38 & 1 & 41 & 0 & 29 & 0 \\
\hline WBL & 13 & 0 & 8 & 1 & 13 & 1 & 19 & 0 & 15 & 0 \\
\hline
\end{tabular}


- Turning movement counts - Wilmington: Data set \#1 collected on 7/17/09

\begin{tabular}{|l|c|c|c|c|c|c|c|c|c|c|}
\hline Time : & $\mathbf{1 2 : 0 0}-\mathbf{1 2 : 1 5} \mathbf{p m}$ & \multicolumn{1}{|c|}{$\mathbf{1 2 : 1 5}-\mathbf{1 2} \mathbf{3 0} \mathbf{p m}$} & \multicolumn{2}{|c|}{$\mathbf{1 2 : 3 0}-\mathbf{1 2 : 4 5} \mathbf{p m}$} & \multicolumn{2}{|c|}{$\mathbf{1 2 : 4 5}-\mathbf{1 : 0 0 m}$} & \multicolumn{2}{|c|}{$\mathbf{1 : 0 0}-\mathbf{1 : 1 5} \mathbf{p m}$} \\
\hline Movement & cars & trucks & cars & trucks & cars & trucks & cars & trucks & cars & trucks \\
\hline \hline NBT & 360 & 4 & 330 & 8 & 372 & 3 & 325 & 5 & 321 & 3 \\
\hline NBR & 27 & 0 & 11 & 1 & 21 & 0 & 23 & 0 & 18 & 0 \\
\hline NBL & 23 & 1 & 22 & 0 & 16 & 0 & 18 & 0 & 19 & 0 \\
\hline SBT & 358 & 3 & 412 & 5 & 391 & 2 & 387 & 3 & 382 & 4 \\
\hline SBR & 16 & 0 & 16 & 0 & 17 & 0 & 20 & 1 & 28 & 0 \\
\hline SBL & 35 & 1 & 32 & 1 & 42 & 0 & 33 & 2 & 35 & 0 \\
\hline EBT & 2 & 0 & 4 & 0 & 2 & 0 & 3 & 0 & 2 & 0 \\
\hline EBR & 21 & 0 & 14 & 0 & 13 & 0 & 24 & 0 & 32 & 0 \\
\hline EBL & 18 & 0 & 8 & 0 & 7 & 0 & 13 & 0 & 16 & 0 \\
\hline WBT & 2 & 0 & 4 & 0 & 2 & 0 & 2 & 0 & 4 & 0 \\
\hline WBR & 13 & 0 & 38 & 0 & 17 & 1 & 23 & 0 & 26 & 0 \\
\hline WBL & 18 & 0 & 23 & 0 & 27 & 0 & 38 & 0 & 32 & 1 \\
\hline
\end{tabular}

- Turning movement counts - Wilmington: Data set \#2 collected on 7/18/09

\begin{tabular}{|c|c|c|c|c|c|c|c|c|c|c|}
\hline Time: & $10: 30$ & 0:45am & $10: 45$ & 1:00am & 11:00 & 1:15am & 11:15 & 1:30am & $11: 30$ & 1:45am \\
\hline Movement & cars & trucks & cars & trucks & cars & trucks & cars & trucks & cars & trucks \\
\hline NBT & 333 & 2 & 341 & 4 & 334 & 3 & 403 & 3 & 324 & 5 \\
\hline NBR & 20 & 0 & 21 & 0 & 25 & 0 & 31 & 0 & 17 & 0 \\
\hline NBL & 17 & 0 & 14 & 0 & 17 & 0 & 11 & 0 & 18 & 0 \\
\hline SBT & 393 & 4 & 371 & 4 & 412 & 3 & 427 & 2 & 461 & 0 \\
\hline SBR & 19 & 0 & 18 & 0 & 9 & 0 & 13 & 0 & 17 & 0 \\
\hline SBL & 37 & 0 & 33 & 0 & 29 & 0 & 21 & 0 & 33 & 1 \\
\hline EBT & 0 & 0 & 0 & 0 & 1 & 0 & 2 & 0 & 3 & 0 \\
\hline EBR & 20 & 1 & 18 & 0 & 23 & 0 & 18 & 0 & 19 & 0 \\
\hline EBL & 17 & 0 & 10 & 0 & 7 & 0 & 4 & 0 & 12 & 0 \\
\hline WBT & 5 & 0 & 9 & 0 & 4 & 0 & 3 & 0 & 1 & 0 \\
\hline WBR & 20 & 0 & 16 & 0 & 31 & 0 & 32 & 0 & 46 & 0 \\
\hline WBL & 22 & 0 & 23 & 0 & 25 & 1 & 24 & 0 & 26 & 0 \\
\hline
\end{tabular}


- Turning movement counts - Walmart/Gregory (US-17): Data set \#1 collected on 7/17/09

\begin{tabular}{|l|c|c|c|c|c|c|c|c|c|c|c|c|}
\hline Time: & $\mathbf{7 : 3 0}-\mathbf{7 : 4 5}$ & \multicolumn{2}{|c|}{$\mathbf{7 : 4 5}-\mathbf{8 : 0 0}$} & \multicolumn{2}{|c|}{$\mathbf{8 : 0 0}-\mathbf{8 : 1 5}$} & \multicolumn{2}{|c|}{$\mathbf{8 : 1 5}-\mathbf{8 : 3 0}$} & \multicolumn{2}{|c|}{$\mathbf{8 : 3 0 - 8 : 4 5}$} & \multicolumn{2}{|c|}{$\mathbf{8 : 4 5}-\mathbf{9 : 0 0}$} \\
\hline Movement & cars & trucks & cars & trucks & cars & trucks & cars & trucks & cars & trucks & cars & trucks \\
\hline \hline NBT & 278 & 8 & 270 & 8 & 245 & 8 & 222 & 5 & 218 & 9 & 232 & 9 \\
\hline NBR & 13 & 0 & 9 & 0 & 12 & 0 & 14 & 0 & 6 & 0 & 7 & 0 \\
\hline NBL & 4 & 0 & 6 & 0 & 5 & 0 & 3 & 0 & 2 & 0 & 3 & 0 \\
\hline SBT & 148 & 9 & 188 & 14 & 175 & 18 & 189 & 16 & 167 & 20 & 135 & 13 \\
\hline SBR & 5 & 2 & 13 & 0 & 8 & 3 & 7 & 0 & 10 & 1 & 6 & 1 \\
\hline SBL & 25 & 1 & 36 & 0 & 31 & 0 & 45 & 1 & 43 & 0 & 52 & 2 \\
\hline EBT & 0 & 0 & 2 & 0 & 3 & 0 & 1 & 0 & 1 & 0 & 3 & 0 \\
\hline EBR & 0 & 0 & 3 & 0 & 4 & 0 & 3 & 1 & 7 & 0 & 1 & 0 \\
\hline EBL & 3 & 0 & 5 & 2 & 4 & 0 & 1 & 3 & 3 & 2 & 4 & 1 \\
\hline WBT & 0 & 0 & 0 & 0 & 0 & 0 & 0 & 0 & 0 & 0 & 0 & 0 \\
\hline WBR & 45 & 0 & 47 & 1 & 58 & 0 & 55 & 1 & 50 & 1 & 48 & 1 \\
\hline WBL & 5 & 0 & 5 & 0 & 6 & 0 & 4 & 0 & 5 & 0 & 5 & 0 \\
\hline
\end{tabular}

- Turning movement counts - Walmart/Gregory (US-17): Data set \#2 collected on 7/18/09

\begin{tabular}{|l|c|c|c|c|c|c|c|c|c|c|c|c|}
\hline \multicolumn{1}{r|}{ Time: } & $\mathbf{1 : 4 5}-\mathbf{2 : 0 0}$ & \multicolumn{2}{c|}{$\mathbf{2 : 0 0}-\mathbf{2 : 1 5}$} & \multicolumn{2}{c|}{$\mathbf{2 : 1 5}-\mathbf{2 : 3 0}$} & \multicolumn{2}{c|}{$\mathbf{2 : 3 0}-\mathbf{2 : 4 5}$} & \multicolumn{2}{|c|}{$\mathbf{2 : 4 5}-\mathbf{3 : 0 0}$} & \multicolumn{2}{|c|}{$\mathbf{3 : 0 0}-\mathbf{3 : 1 5}$} \\
\hline Movement & cars & trucks & cars & trucks & cars & trucks & cars & trucks & cars & trucks & cars & trucks \\
\hline \hline NBT & 209 & 2 & 250 & 4 & 210 & 5 & 188 & 4 & 225 & 5 & 165 & 4 \\
\hline NBR & 16 & 0 & 15 & 0 & 15 & 0 & 11 & 0 & 14 & 0 & 12 & 0 \\
\hline NBL & 2 & 0 & 0 & 0 & 1 & 0 & 1 & 0 & 0 & 0 & 2 & 0 \\
\hline SBT & 412 & 2 & 477 & 0 & 428 & 3 & 417 & 2 & 461 & 0 & 393 & 2 \\
\hline SBR & 1 & 0 & 4 & 0 & 6 & 0 & 1 & 0 & 4 & 0 & 1 & 0 \\
\hline SBL & 76 & 0 & 90 & 1 & 93 & 0 & 96 & 0 & 85 & 0 & 65 & 0 \\
\hline EBT & 0 & 0 & 0 & 0 & 0 & 0 & 0 & 0 & 1 & 0 & 0 & 0 \\
\hline EBR & 1 & 0 & 1 & 0 & 8 & 0 & 3 & 0 & 2 & 0 & 3 & 0 \\
\hline EBL & 1 & 0 & 5 & 0 & 3 & 0 & 0 & 0 & 0 & 0 & 2 & 0 \\
\hline WBT & 1 & 0 & 2 & 0 & 2 & 0 & 0 & 0 & 0 & 0 & 0 & 0 \\
\hline WBR & 107 & 0 & 86 & 0 & 92 & 0 & 97 & 0 & 106 & 1 & 85 & 0 \\
\hline WBL & 41 & 0 & 32 & 0 & 28 & 0 & 16 & 0 & 15 & 0 & 22 & 0 \\
\hline
\end{tabular}


- Turning movement counts - Lanvale/Brunswick Forest (US-17): Data set \#1 collected on 7/17/09

\begin{tabular}{|l|c|c|c|c|c|c|c|c|c|c|c|c|}
\hline \multicolumn{1}{r|}{ Time: } & $\mathbf{5 : 0 0}-\mathbf{5 : 1 5}$ & \multicolumn{2}{c|}{$\mathbf{5 : 1 5}-\mathbf{5 : 3 0}$} & \multicolumn{2}{c|}{$\mathbf{5 : 3 0}-\mathbf{5 : 4 5}$} & \multicolumn{2}{c|}{$\mathbf{5 : 4 5}-\mathbf{6 : 0 0}$} & \multicolumn{2}{c|}{$\mathbf{6 : 0 0}-\mathbf{6 : 1 5}$} & \multicolumn{2}{c|}{$\mathbf{6 : 1 5}-\mathbf{6 : 3 0}$} \\
\hline Movement & cars & trucks & cars & trucks & cars & trucks & cars & trucks & cars & trucks & cars & trucks \\
\hline \hline NBT & 209 & 2 & 239 & 3 & 200 & 4 & 202 & 4 & 193 & 7 & 191 & 2 \\
\hline NBR & 0 & 0 & 0 & 0 & 1 & 0 & 1 & 0 & 0 & 0 & 0 & 0 \\
\hline NBL & 27 & 0 & 24 & 0 & 29 & 0 & 16 & 1 & 19 & 0 & 24 & 1 \\
\hline SBT & 310 & 6 & 372 & 5 & 320 & 6 & 315 & 8 & 305 & 6 & 259 & 2 \\
\hline SBR & 23 & 0 & 32 & 0 & 33 & 0 & 28 & 0 & 36 & 0 & 21 & 0 \\
\hline SBL & 1 & 0 & 1 & 0 & 0 & 0 & 0 & 0 & 1 & 0 & 1 & 0 \\
\hline EBT & 0 & 0 & 0 & 0 & 0 & 0 & 1 & 0 & 1 & 0 & 0 & 0 \\
\hline EBR & 13 & 2 & 19 & 0 & 21 & 0 & 20 & 0 & 12 & 0 & 31 & 0 \\
\hline EBL & 25 & 1 & 22 & 1 & 18 & 0 & 28 & 0 & 20 & 0 & 14 & 0 \\
\hline WBT & 0 & 0 & 0 & 0 & 0 & 0 & 1 & 0 & 0 & 0 & 0 & 0 \\
\hline WBR & 0 & 0 & 1 & 0 & 1 & 0 & 1 & 0 & 1 & 0 & 0 & 0 \\
\hline WBL & 0 & 0 & 0 & 0 & 0 & 0 & 0 & 0 & 1 & 0 & 0 & 0 \\
\hline
\end{tabular}




\section{- Spot speed data}

\begin{tabular}{|l|c|c|c|c|c|}
\hline Site & No. Obs. & Mean & St. Dev. & Median & Mode \\
\hline \hline Chapel Hill & 359 & 50.2 & 4.50 & 50.3 & 49.4 \\
\hline Wilmington & 291 & 51.8 & 4.85 & 51.4 & 46.2 \\
\hline US-17 & 153 & 57.4 & 4.40 & 58.0 & 59.3 \\
\hline Lanvale Rd. & 308 & 61.7 & 4.23 & 61.3 & 62.6 \\
\hline
\end{tabular}

- Speed distribution curve - Chapel Hill

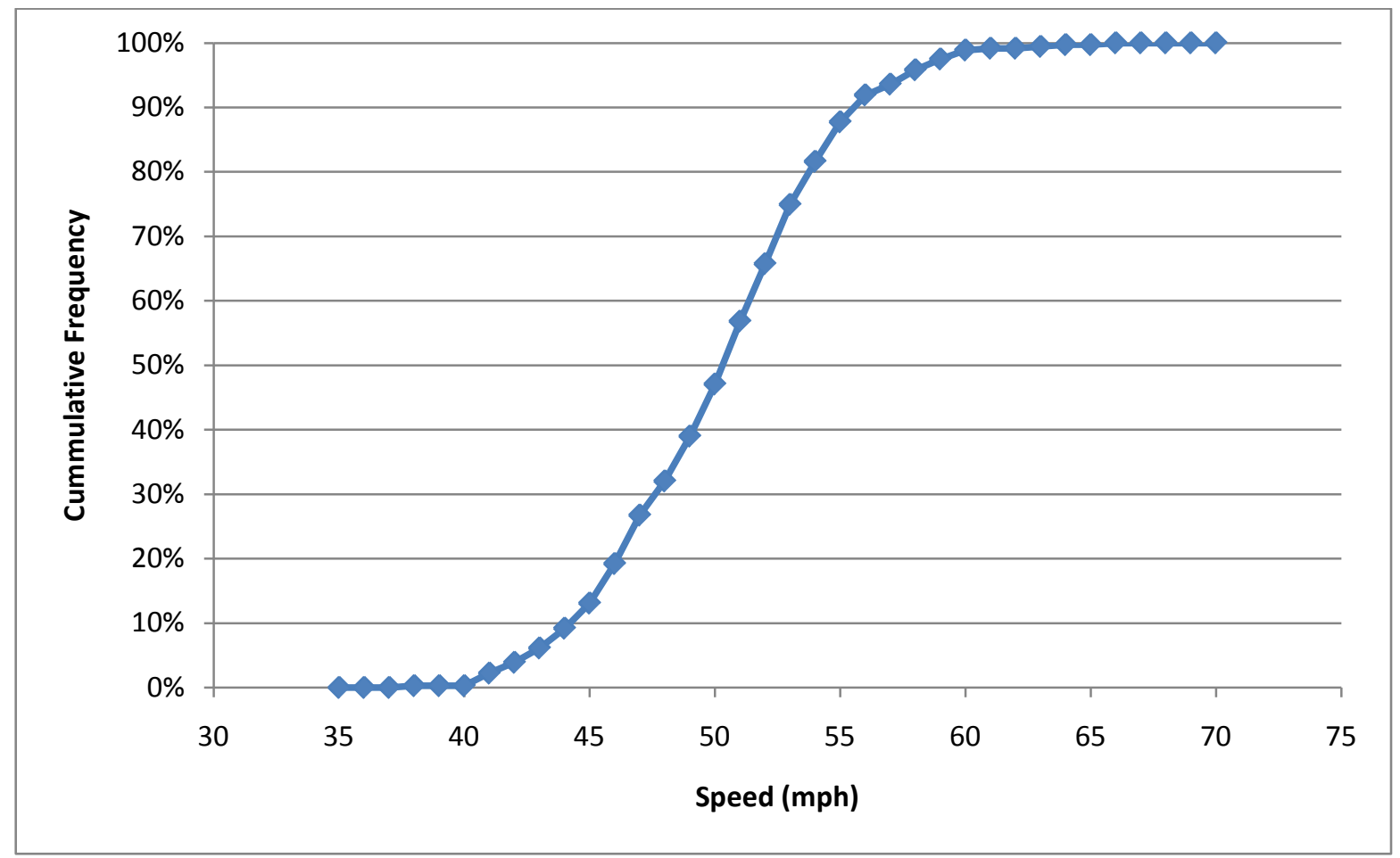


- Speed distribution curve - Wilmington

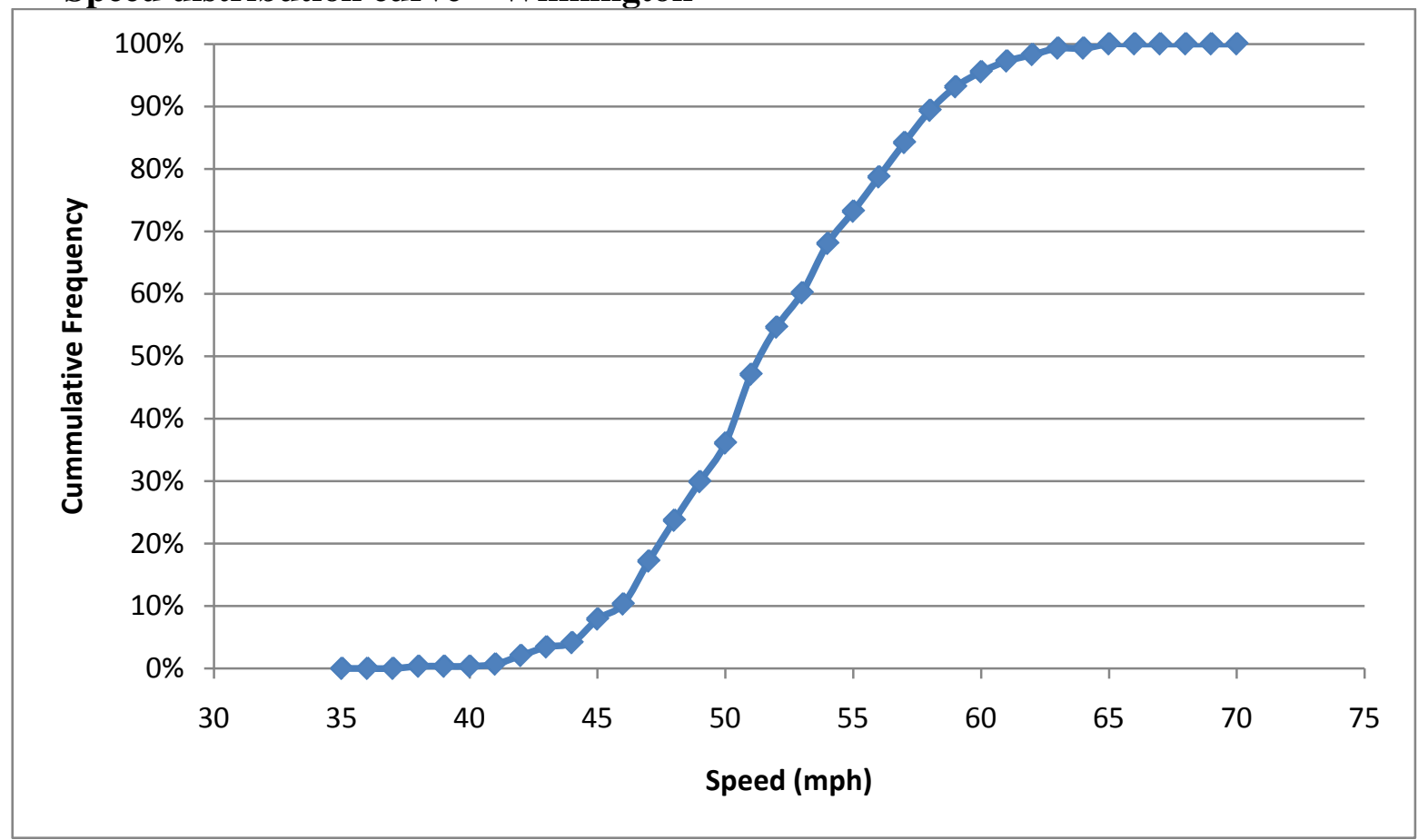

- $\quad$ Speed distribution curve - US-17

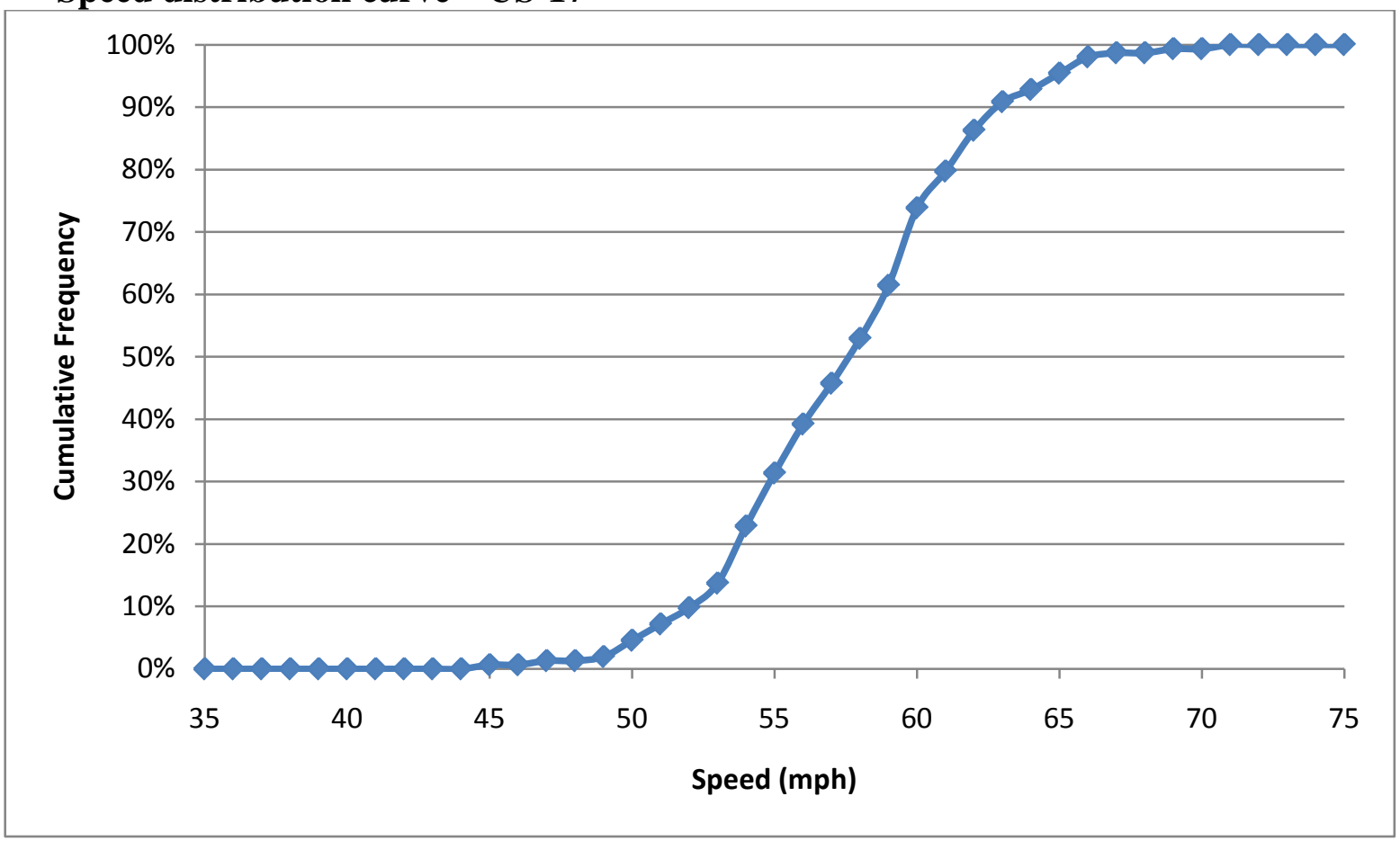


- Speed distribution curve - Lanvale Rd.

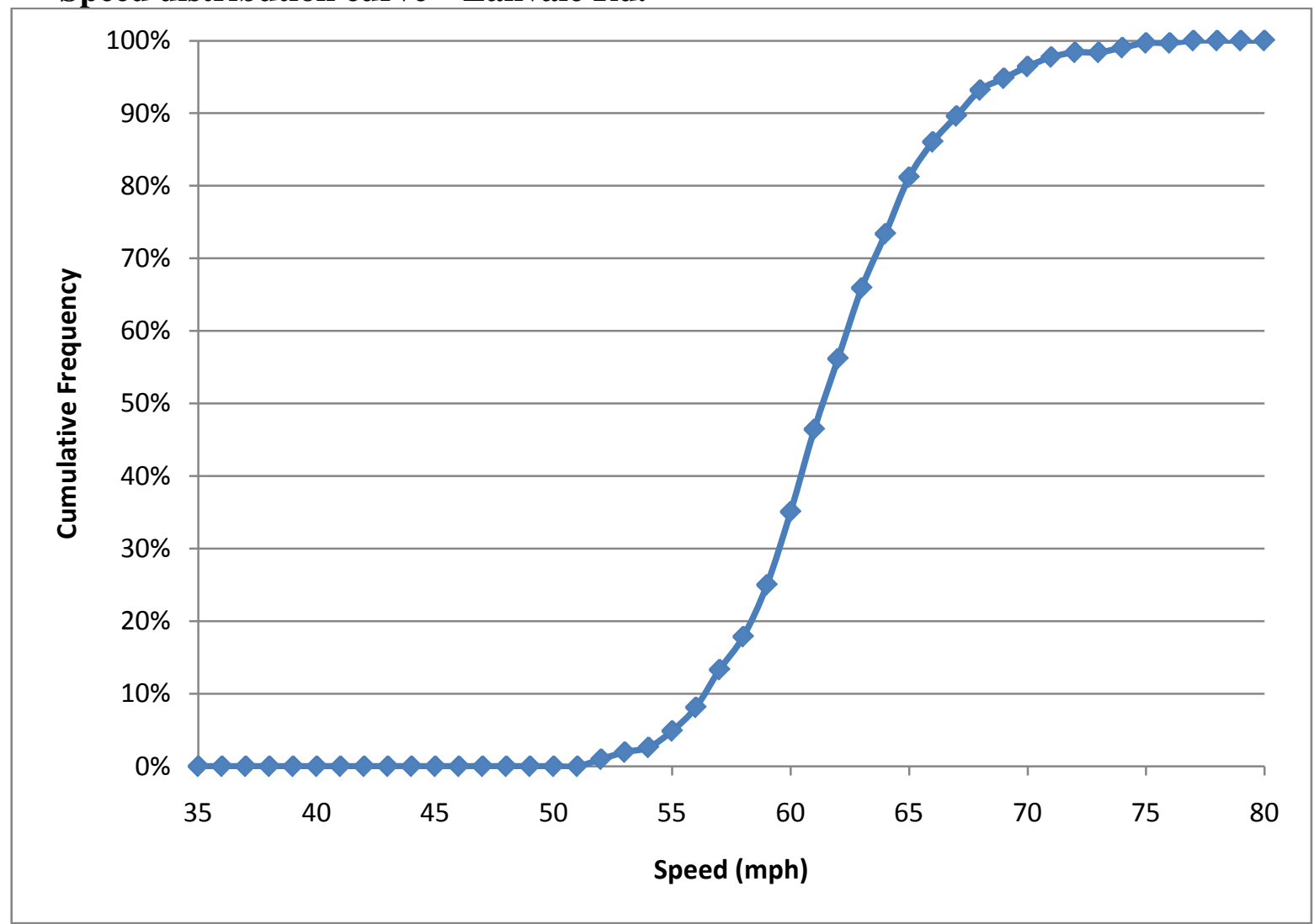


APPENDIX B:

VISSIM Calibration Inputs 
- Vehicle inputs for US-15/501 superstreet in Chapel Hill (vph)

\begin{tabular}{|r|c|c|c|c|c|c|}
\hline \multirow{2}{*}{ INPUT } & \multicolumn{5}{l|}{ SIMULATION PERIOD (sec) } \\
\cline { 2 - 7 } & $0-900$ & $900-1800$ & $1800-2700$ & $2700-3600$ & $3600-4500$ & $4500-5400$ \\
\hline \hline NB input (TOTAL)* & 1460 & 1460 & 1920 & 1816 & 1624 & 1552 \\
\hline $15-501$ NB & 876 & 876 & 1152 & 1090 & 974 & 931 \\
\hline Franklin NB & 292 & 292 & 384 & 363 & 325 & 310 \\
\hline Ephesus Church (WBR) & 292 & 292 & 384 & 363 & 325 & 310 \\
\hline SB input (TOTAL)* & 1364 & 1364 & 1688 & 1460 & 1632 & 1472 \\
\hline 15-501 SB & 1091 & 1091 & 1350 & 1168 & 1306 & 1178 \\
\hline Sage (EBR) & 136 & 136 & 169 & 146 & 163 & 147 \\
\hline Old Durham (WBL) & 136 & 136 & 169 & 146 & 163 & 147 \\
\hline EB input & 320 & 320 & 420 & 428 & 604 & 484 \\
\hline WB input & 204 & 204 & 164 & 204 & 252 & 220 \\
\hline
\end{tabular}

* NB assumptions: 60\% US-15/501, 20\% Franklin St, 20\% Ephesus Church Rd.

* SB assumptions: 80\% US-15/501, 10\% Sage Rd, 10\% Old Durham Rd.

- Vehicle inputs for US-421 superstreet in Wilmington (vph)

\begin{tabular}{|r|c|c|c|c|c|c|}
\hline \multirow{2}{*}{\multicolumn{1}{|c|}{ INPUT }} & \multicolumn{6}{|c|}{ SIMULATION PERIOD (sec) } \\
\cline { 2 - 7 } & $0-900$ & $900-1800$ & $1800-2700$ & $2700-3600$ & $3600-4500$ & $4500-5400$ \\
\hline \hline NB input (TOTAL)* & 1660 & 1660 & 1488 & 1648 & 1484 & 1444 \\
\hline 421NB & 1245 & 1245 & 1116 & 1236 & 1113 & 1083 \\
\hline Sanders & 415 & 415 & 372 & 412 & 371 & 361 \\
\hline SB input (TOTAL)* & 1652 & 1652 & 1864 & 1808 & 1784 & 1796 \\
\hline College Rd SB & 1156 & 1156 & 1305 & 1266 & 1249 & 1257 \\
\hline Piner (WBL) & 165 & 165 & 186 & 181 & 178 & 180 \\
\hline US-421 (EBR) & 330 & 330 & 373 & 362 & 357 & 359 \\
\hline EB input & 164 & 164 & 104 & 88 & 160 & 200 \\
\hline WB input & 132 & 132 & 260 & 188 & 252 & 252 \\
\hline
\end{tabular}

* NB assumptions: 75\% US-421, 25\% Sanders Dr.

* SB assumptions: 70\% College Rd, 10 \% Piner Rd, 15\% US-421 
- Vehicle inputs for US-17 superstreet corridor in Leland (vph)

\begin{tabular}{|l|c|c|c|c|c|c|c|}
\hline \multirow{2}{*}{ INPUT } & \multicolumn{6}{|l}{ SIMULATION PERIOD (sec) } \\
\cline { 2 - 9 } & $0-900$ & $\begin{array}{c}900- \\
1800\end{array}$ & $\begin{array}{c}1800- \\
2700\end{array}$ & $\begin{array}{c}2700- \\
3600\end{array}$ & $\begin{array}{c}3600- \\
4500\end{array}$ & $\begin{array}{c}4500- \\
5400\end{array}$ & $\begin{array}{c}5400- \\
6300\end{array}$ \\
\hline \hline NB (US-17) & 1212 & 1212 & 1172 & 1080 & 976 & 940 & 1004 \\
\hline SB (US-17) & 1360 & 1360 & 1640 & 1436 & 1404 & 1392 & 1132 \\
\hline WB (Ploof) & 12 & 12 & 48 & 44 & 36 & 52 & 36 \\
\hline EB (Poole) & 200 & 200 & 212 & 256 & 240 & 224 & 216 \\
\hline WB (Walmart) & 200 & 200 & 212 & 256 & 240 & 224 & 216 \\
\hline EB (Gregory) & 12 & 12 & 48 & 44 & 36 & 52 & 36 \\
\hline WB (West Gate) & 200 & 200 & 212 & 256 & 240 & 224 & 216 \\
\hline EB (Grandiflora) & 200 & 200 & 212 & 256 & 240 & 224 & 216 \\
\hline WB (Brunswick Forest Pkwy) & 164 & 164 & 168 & 156 & 196 & 132 & 180 \\
\hline EB (Lanvale) & 164 & 164 & 168 & 156 & 196 & 132 & 180 \\
\hline WB (Brunswick Forest Dr.) & 0 & 0 & 4 & 4 & 8 & 8 & 0 \\
\hline
\end{tabular}


- Speed distributions

\begin{tabular}{|l|c|c|}
\hline \multirow{2}{*}{ Name } & \multicolumn{2}{|c|}{ Input speed points } \\
\cline { 2 - 3 } & Speed & \% \\
\hline \hline ChapelHill_mod3. & 27.8 & 0.00 \\
(reduced original speeds by 25\%) & 30.8 & 0.02 \\
\hline & 33.0 & 0.09 \\
\hline & 36.0 & 0.32 \\
\hline & 37.5 & 0.47 \\
\hline MyrtleGrove_mod2. & 39.8 & 0.75 \\
\hline (reduced original speeds by 25\%) & 41.3 & 0.88 \\
\hline & 43.5 & 0.96 \\
\hline & 48.0 & 1.00 \\
\hline & 30.3 & 0.00 \\
& 36.8 & 0.11 \\
\hline & 49.2 & 0.30 \\
\hline Leland_mod3 & 42.4 & 0.60 \\
\hline (reduced original speeds by 25\%) & 45.6 & 0.85 \\
\hline & 48.0 & 0.95 \\
\hline & 51.9 & 1.00 \\
\hline & 33.0 & 0.00 \\
\hline & 41.3 & 0.10 \\
\hline & 44.3 & 0.31 \\
\hline & 46.5 & 0.61 \\
\hline & 48.8 & 0.86 \\
\hline & 53.3 & 1.00 \\
\hline
\end{tabular}

- Conflict area parameters - Chapel Hill

\begin{tabular}{|c|c|c|c|c|c|c|c|}
\hline Who yields? & Font Gap & Rear Gap & SF & $\begin{array}{c}\text { Add'l stop } \\
\text { dist. }\end{array}$ & $\begin{array}{c}\text { Obsv. Adj. } \\
\text { Routes }\end{array}$ & $\begin{array}{c}\text { Anticipate } \\
\text { routes }\end{array}$ & $\begin{array}{c}\text { Avoid } \\
\text { blocking }\end{array}$ \\
\hline \hline EBR to SBT & 2 & 3.6 & 10 & 10 & $\mathrm{X}$ & 1 & 1 \\
EBR to SBT & 2 & 3.6 & 10 & 10 & $\mathrm{X}$ & 1 & 1 \\
WBR to NBT & 2 & 3.6 & 10 & 8 & $\mathrm{X}$ & 1 & 1 \\
WBR to NBT & 2 & 3.6 & 10 & 6 & $\mathrm{X}$ & 1 & 1 \\
\hline
\end{tabular}


- Conflict area parameters - Wilmington

\begin{tabular}{|c|c|c|c|c|c|c|c|}
\hline Who yields? & Font Gap & Rear Gap & SF & $\begin{array}{c}\text { Add'l stop } \\
\text { dist. }\end{array}$ & $\begin{array}{c}\text { Obsv. Adj. } \\
\text { Routes }\end{array}$ & $\begin{array}{c}\text { Anticipate } \\
\text { routes }\end{array}$ & $\begin{array}{c}\text { Avoid } \\
\text { blocking }\end{array}$ \\
\hline \hline EBR to SBT & 2.0 & 3.6 & 12 & 5 & $\mathrm{X}$ & 1 & 1 \\
EBR to SBT & 2.0 & 3.6 & 12 & 5 & $\mathrm{X}$ & 1 & 1 \\
NBL to SBT & 2.0 & 5.5 & 15 & 23 & $\mathrm{X}$ & 1 & 1 \\
NBR to SBL & 2.0 & 3.6 & 12 & 5 & $\mathrm{X}$ & 1 & 1 \\
NUT to SBT & 3.0 & 7.1 & 15 & 23 & $\mathrm{X}$ & 1 & 1 \\
SBL to NBT & 2.0 & 5.5 & 15 & 23 & $\mathrm{X}$ & 1 & 1 \\
SBR to NBL & 2.0 & 3.6 & 12 & 5 & $\mathrm{X}$ & 1 & 1 \\
SUT to NBT & 3.0 & 7.1 & 15 & 20 & $\mathrm{X}$ & 1 & 1 \\
WBR to NBT & 2.0 & 3.6 & 12 & 5 & $\mathrm{X}$ & 1 & 1 \\
\hline
\end{tabular}

- Conflict area parameters - US-17

\begin{tabular}{|c|c|c|c|c|c|c|c|}
\hline Who yields? & $\begin{array}{c}\text { Font } \\
\text { Gap }\end{array}$ & $\begin{array}{c}\text { Rear } \\
\text { Gap }\end{array}$ & SF & $\begin{array}{c}\text { stop } \\
\text { dist. }\end{array}$ & $\begin{array}{c}\text { Obsv. Adj. } \\
\text { Routes }\end{array}$ & $\begin{array}{c}\text { Anticipat } \\
\text { e routes }\end{array}$ & $\begin{array}{c}\text { Avoid } \\
\text { blocking }\end{array}$ \\
\hline \hline P/P: EBR to SBT & 2.5 & 3.6 & 10 & 8 & $\mathrm{X}$ & 1 & 1 \\
P/P: EBR to SBT & 2.5 & 3.6 & 10 & 8 & $\mathrm{X}$ & 1 & 1 \\
P/P: NBR to SBL & 2.5 & 3.6 & 10 & 8 & $\mathrm{X}$ & 1 & 1 \\
P/P: SBR to NBL & 2.5 & 3.6 & 10 & 8 & $\mathrm{X}$ & 1 & 1 \\
P/P: WBR to NBT & 2.5 & 3.6 & 10 & 8 & $\mathrm{X}$ & 1 & 1 \\
W/G: EBR to SBT & 2.5 & 3.6 & 10 & 8 & $\mathrm{X}$ & 1 & 1 \\
W/G: NBR to SBL & 2.5 & 3.6 & 10 & 8 & $\mathrm{X}$ & 1 & 1 \\
W/G: SBR to NBL & 2.5 & 3.6 & 10 & 8 & $\mathrm{X}$ & 1 & 1 \\
W/G: WBR to NBT & 2.5 & 3.6 & 10 & 8 & $\mathrm{X}$ & 1 & 1 \\
W/G: WBR to NBT & 2.5 & 3.6 & 10 & 8 & $\mathrm{X}$ & 1 & 1 \\
G/WG: EBR to SBT & 2.5 & 3.6 & 10 & 8 & $\mathrm{X}$ & 1 & 1 \\
G/WG: NBR to SBL & 2.5 & 3.6 & 10 & 8 & $\mathrm{X}$ & 1 & 1 \\
G/WG: SBR to NBL & 2.5 & 3.6 & 10 & 8 & $\mathrm{X}$ & 1 & 1 \\
G/WG: WBR to NBT & 2.5 & 3.6 & 10 & 8 & $\mathrm{X}$ & 1 & 1 \\
BF: NBR to SBL & 2.5 & 3.6 & 10 & 8 & $\mathrm{X}$ & 1 & 1 \\
BF: WBR to NBT & 2.5 & 3.6 & 10 & 8 & $\mathrm{X}$ & 1 & 1 \\
L/BF: EBR to SBT & 2.5 & 3.6 & 10 & 8 & $\mathrm{X}$ & 1 & 1 \\
L/BF: NBR to SBL & 2.5 & 3.6 & 10 & 8 & $\mathrm{X}$ & 1 & 1 \\
L/BF: SBR to NBL & 2.5 & 3.6 & 10 & 8 & $\mathrm{X}$ & 1 & 1 \\
L/BF: WBR to NBT & 2.5 & 3.6 & 10 & 8 & $\mathrm{X}$ & 1 & 1 \\
L/BF: WBR to NBT & 2.5 & 3.6 & 10 & 8 & $\mathrm{X}$ & 1 & 1 \\
\hline
\end{tabular}


- Reduced speed areas - Chapel Hill

\begin{tabular}{|l|l|c|c|}
\hline No. & Name & $\begin{array}{c}\text { Speed Dist car } \\
\text { (min, max) }\end{array}$ & $\begin{array}{c}\text { Speed Dist } \\
\text { HGV } \\
\text { (min, max) }\end{array}$ \\
\hline \hline 1 & NBR & $2(15,20)$ & $2(15,20)$ \\
2 & NBR(2) & $2(15,20)$ & $2(15,20)$ \\
3 & WBR_outer & $2(15,20)$ & $2(15,20)$ \\
4 & WBR_inner & $2(15,20)$ & $2(15,20)$ \\
5 & NUT_inner approach & $2(15,20)$ & $2(15,20)$ \\
6 & NUT_outer approach & $2(15,20)$ & $2(15,20)$ \\
7 & SBR & $2(15,20)$ & $2(15,20)$ \\
8 & EBR_inner & $2(15,20)$ & $2(15,20)$ \\
9 & EBR_outer & $2(15,20)$ & $2(15,20)$ \\
10 & SUT_inner approach & $2(15,20)$ & $2(15,20)$ \\
11 & SUT_outer approach & $2(15,20)$ & $2(15,20)$ \\
12 & NUT_inner & $4(9,14)$ & $4(9,14)$ \\
13 & NUT_outer & $4(9,14)$ & $4(9,14)$ \\
14 & SUT_inner & $4(9,14)$ & $4(9,14)$ \\
15 & SUT_outer & $4(9,14)$ & $4(9,14)$ \\
16 & NUT_inner approach1 & $2(15,20)$ & $2(15,20)$ \\
17 & NUT_outer approach1 & $2(15,20)$ & $2(15,20)$ \\
\hline
\end{tabular}


- Reduced speed areas - Wilmington

\begin{tabular}{|l|l|c|c|}
\hline No. & Name & $\begin{array}{c}\text { Speed Dist car } \\
\text { (min, max) }\end{array}$ & $\begin{array}{c}\text { Speed Dist } \\
\text { HGV } \\
\text { (min, max) }\end{array}$ \\
\hline \hline 1 & NBR & $3(15,20)$ & $3(15,20)$ \\
2 & NBL & $3(15,20)$ & $3(15,20)$ \\
3 & SBR & $3(15,20)$ & $3(15,20)$ \\
4 & SBL & $3(15,20)$ & $3(15,20)$ \\
5 & North UT & $4(9,14)$ & $4(9,14)$ \\
6 & South UT & $4(9,14)$ & $4(9,14)$ \\
7 & WBR & $3(15,20)$ & $3(15,20)$ \\
8 & WBR-2 & $3(15,20)$ & $3(15,20)$ \\
9 & EBR & $3(15,20)$ & $3(15,20)$ \\
10 & EBR-2 & $3(15,20)$ & $3(15,20)$ \\
11 & Piner-WBL & $3(15,20)$ & $3(15,20)$ \\
12 & North UT $(1)$ & $3(15,20)$ & $3(15,20)$ \\
13 & WBR approach & $3(15,20)$ & $3(15,20)$ \\
14 & WBR-2 approach & $3(15,20)$ & $3(15,20)$ \\
15 & SBR approach & $3(15,20)$ & $3(15,20)$ \\
16 & SBL approach & $3(15,20)$ & $3(15,20)$ \\
17 & NBL approach & $3(15,20)$ & $3(15,20)$ \\
18 & NBR approach & $3(15,20)$ & $3(15,20)$ \\
19 & EBR approach & $3(15,20)$ & $3(15,20)$ \\
20 & EBR-2 approach & $3(15,20)$ & $3(15,20)$ \\
21 & South UT approach & $3(15,20)$ & $3(15,20)$ \\
\hline
\end{tabular}


- $\quad$ Reduced speed areas - US-17

\begin{tabular}{|l|l|c|c|}
\hline No. & Name & $\begin{array}{c}\text { Speed Dist car } \\
\text { (min, max) }\end{array}$ & $\begin{array}{c}\text { Speed Dist } \\
\text { HGV } \\
\text { (min, max) }\end{array}$ \\
\hline \hline 1 & P/P WBR & $3(15,20)$ & $3(15,20)$ \\
2 & /P NBR & $3(15,20)$ & $3(15,20)$ \\
3 & P/P SBL & $3(15,20)$ & $3(15,20)$ \\
4 & P/P NBL & $3(15,20)$ & $3(15,20)$ \\
5 & P/P NBL & $3(15,20)$ & $3(15,20)$ \\
6 & P/P SBR & $3(15,20)$ & $3(15,20)$ \\
7 & P/P EBR & $3(15,20)$ & $3(15,20)$ \\
8 & P/P EBR & $3(15,20)$ & $3(15,20)$ \\
9 & P/P EBR & $3(15,20)$ & $3(15,20)$ \\
10 & P/P NUT & $3(15,20)$ & $3(15,20)$ \\
11 & P/P SUT approach2 & $3(15,20)$ & $3(15,20)$ \\
12 & P/P SUT approach2 & $3(15,20)$ & $3(15,20)$ \\
13 & W/G NUT & $3(15,20)$ & $3(15,20)$ \\
14 & W/G SBR & $3(15,20)$ & $3(15,20)$ \\
15 & W/G SBL & $3(15,20)$ & $3(15,20)$ \\
16 & W/G SBL & $3(15,20)$ & $3(15,20)$ \\
17 & W/G NBL & $3(15,20)$ & $3(15,20)$ \\
18 & W/G WBR & $3(15,20)$ & $3(15,20)$ \\
19 & W/G WBR & $3(15,20)$ & $3(15,20)$ \\
20 & W/G NBR & $3(15,20)$ & $3(15,20)$ \\
21 & W/G EBR & $3(15,20)$ & $3(15,20)$ \\
22 & W/G SUT approach & $3(15,20)$ & $3(15,20)$ \\
23 & G/WG NUT approach & $3(15,20)$ & $3(15,20)$ \\
24 & G/WG NUT approach & $3(15,20)$ & $3(15,20)$ \\
25 & G/WG WBR & $3(15,20)$ & $3(15,20)$ \\
26 & G/WG WBR & $3(15,20)$ & $3(15,20)$ \\
27 & G/WG SBL & $3(15,20)$ & $3(15,20)$ \\
28 & G/WG NBR & $3(15,20)$ & $3(15,20)$ \\
29 & G/WG NBL & $3(15,20)$ & $3(15,20)$ \\
30 & G/WG SBR & $3(15,20)$ & $3(15,20)$ \\
31 & G/WG EBR & $3(15,20)$ & $3(15,20)$ \\
32 & G/WG EBR & $3(15,20)$ & $3(15,20)$ \\
33 & G/WG SUT approach & $3(15,20)$ & $3(15,20)$ \\
34 & G/WG SUT approach & $3(15,20)$ & $3(15,20)$ \\
35 & BF NUT approach & $3(15,20)$ & $3(15,20)$ \\
36 & BF SBL & $3(15,20)$ & $3(15,20)$ \\
& & & \\
\hline
\end{tabular}

\begin{tabular}{|l|l|c|c|}
\hline No. & Name & $\begin{array}{c}\text { Speed Dist car } \\
\text { (min, max) }\end{array}$ & $\begin{array}{c}\text { Speed Dist } \\
\text { HGV } \\
\text { (min, max) }\end{array}$ \\
\hline \hline 37 & BF SBL & $3(15,20)$ & $3(15,20)$ \\
38 & BF WBR & $3(15,20)$ & $3(15,20)$ \\
39 & BF WBR & $3(15,20)$ & $3(15,20)$ \\
40 & BF NBR & $3(15,20)$ & $3(15,20)$ \\
41 & L/BF NUT approach & $3(15,20)$ & $3(15,20)$ \\
42 & L/BF NUT approach & $3(15,20)$ & $3(15,20)$ \\
43 & L/BF WBR & $3(15,20)$ & $3(15,20)$ \\
44 & L/BF WBR & $3(15,20)$ & $3(15,20)$ \\
45 & L/BF WBR & $3(15,20)$ & $3(15,20)$ \\
46 & L/BF SBL & $3(15,20)$ & $3(15,20)$ \\
47 & L/BF SBL & $3(15,20)$ & $3(15,20)$ \\
48 & L/BF NBR & $3(15,20)$ & $3(15,20)$ \\
49 & L/BF NBL & $3(15,20)$ & $3(15,20)$ \\
50 & L/BF SBR & $3(15,20)$ & $3(15,20)$ \\
51 & L/BF EBR & $3(15,20)$ & $3(15,20)$ \\
52 & L/BF SUT approach & $3(15,20)$ & $3(15,20)$ \\
53 & W/G SBR approach & $3(15,20)$ & $3(15,20)$ \\
54 & W/G NBR approach & $3(15,20)$ & $3(15,20)$ \\
55 & G/WG NBR approach & $3(15,20)$ & $3(15,20)$ \\
56 & L/BF SBR approach & $3(15,20)$ & $3(15,20)$ \\
57 & L/BF SUT & $6(9,14)$ & $6(9,14)$ \\
58 & L/BF NUT & $6(9,14)$ & $6(9,14)$ \\
59 & L/BF NUT & $6(9,14)$ & $6(9,14)$ \\
60 & BF NUT & $6(9,14)$ & $6(9,14)$ \\
61 & G/WG SUT & $6(9,14)$ & $6(9,14)$ \\
62 & G/WG SUT & $6(9,14)$ & $6(9,14)$ \\
63 & G/WG NUT & $6(9,14)$ & $6(9,14)$ \\
64 & G/WG NUT & $6(9,14)$ & $6(9,14)$ \\
65 & W/G SUT & $6(9,14)$ & $6(9,14)$ \\
66 & W/G SBL approach & $3(15,20)$ & $3(15,20)$ \\
67 & W/G SBL approach & $3(15,20)$ & $3(15,20)$ \\
68 & P/P SUT approach & $3(15,20)$ & $3(15,20)$ \\
69 & P/P SUT approach & $3(15,20)$ & $3(15,20)$ \\
70 & P/P SUT & $6(9,14)$ & $6(9,14)$ \\
71 & P/P SUT & $6(9,14)$ & $6(9,14)$ \\
72 & P/P SBL approach & $3(15,20)$ & $3(15,20)$ \\
\hline
\end{tabular}


- Desired speed decisions - Chapel Hill

\begin{tabular}{|c|l|c|c|}
\hline No. & Name & $\begin{array}{c}\text { Speed Dist car } \\
\text { (min, max) }\end{array}$ & $\begin{array}{c}\text { Speed Dist HGV } \\
(\mathbf{m i n}, \mathbf{m a x})\end{array}$ \\
\hline \hline 1 & Europa WB & $7(20,30)$ & $7(20,30)$ \\
2 & Europa EB & $7(20,30)$ & $7(20,30)$ \\
3 & Europa WBR & $6(29.6,51.2)$ & $6(29.6,51.2)$ \\
4 & Europa WBR & $6(29.6,51.2)$ & $6(29.6,51.2)$ \\
5 & Erwin WB & $50(29.8,36.0)$ & $50(29.8,36.0)$ \\
6 & Erwin EB & $50(29.8,36.0)$ & $50(29.8,36.0)$ \\
7 & Erwin EBR & $6(29.6,51.2)$ & $6(29.6,51.2)$ \\
8 & Erwin EBR & $6(29.6,51.2)$ & $6(29.6,51.2)$ \\
9 & NUT approach & $8(25,35)$ & $8(25,35)$ \\
10 & NUT approach & $8(25,35)$ & $8(25,35)$ \\
11 & $15-501 S B$ after NUT & $6(29.6,51.2)$ & $6(29.6,51.2)$ \\
12 & 15-501SB after NUT & $6(29.6,51.2)$ & $6(29.6,51.2)$ \\
13 & SUT approach & $8(25,35)$ & $8(25,35)$ \\
14 & 15-501NB after SUT & $6(29.6,51.2)$ & $6(29.6,51.2)$ \\
15 & 15-501NB after SUT & $6(29.6,51.2)$ & $6(29.6,51.2)$ \\
16 & NBR lane & $8(25,35)$ & $8(25,35)$ \\
\hline
\end{tabular}


- Desired speed decisions - Wilmington

\begin{tabular}{|c|c|c|c|}
\hline No. & Name & $\begin{array}{c}\text { Speed Dist car } \\
(\mathrm{min}, \mathrm{max})\end{array}$ & $\begin{array}{c}\text { Speed Dist HGV } \\
\text { (min, max) }\end{array}$ \\
\hline 1 & Myrtle Gardens WB & $30(18.6,21.7)$ & $30(18.6,21.7)$ \\
\hline 2 & Myrtle Gardens WB & $30(18.6,21.7)$ & $30(18.6,21.7)$ \\
\hline 3 & Service Rd EB & $7(25,33)$ & $7(25,33)$ \\
\hline 4 & Piner WB & $60(36,42.3)$ & $60(36,42.3)$ \\
\hline 5 & Sanders EB & $60(36,42.3)$ & $60(36,42.3)$ \\
\hline 6 & MyrtleGardens WBR & MG_mod2(30.3, 51.9) & MG_mod2(30.3, 51.9) \\
\hline 7 & MyrtleGardens WBR & MG_mod2(30.3, 51.9) & MG_mod2(30.3, 51.9) \\
\hline 8 & Piner WBL & MG_mod2(30.3, 51.9) & MG_mod2(30.3, 51.9) \\
\hline 9 & Piner WBL & MG_mod2(30.3, 51.9) & MG_mod2(30.3, 51.9) \\
\hline 10 & Service Rd EBR & MG_mod2(30.3, 51.9) & MG_mod2(30.3, 51.9) \\
\hline 11 & Service Rd EBR & MG_mod2(30.3, 51.9) & MG_mod2(30.3, 51.9) \\
\hline 12 & Sanders EBL & MG_mod2(30.3, 51.9) & MG_mod2(30.3, 51.9) \\
\hline 13 & Sanders EBL & MG_mod2(30.3, 51.9) & MG_mod2(30.3, 51.9) \\
\hline 14 & NUT approach & $8(25,35)$ & $8(25,35)$ \\
\hline 15 & NBL approach & $8(25,35)$ & $8(25,35)$ \\
\hline 16 & SBL approach & $8(25,35)$ & $8(25,35)$ \\
\hline 17 & SUT approach & $8(25,35)$ & $8(25,35)$ \\
\hline 18 & MyrtleGardens EB & $30(18.6,21.7)$ & $30(18.6,21.7)$ \\
\hline 19 & Service Rd WB & $7(25,33)$ & $7(25,33)$ \\
\hline 20 & US 421 after NUT & MG_mod2 $(30.3,51.9)$ & MG_mod2(30.3, 51.9) \\
\hline 21 & US 421 after NUT & MG_mod2(30.3, 51.9) & MG_mod2(30.3, 51.9) \\
\hline 22 & US 421 after NUT & MG_mod2(30.3, 51.9) & MG_mod2(30.3, 51.9) \\
\hline 23 & US 421 after SUT & MG_mod2(30.3, 51.9) & MG_mod2(30.3, 51.9) \\
\hline 24 & US 421 after SUT & MG_mod2(30.3, 51.9) & MG_mod2(30.3, 51.9) \\
\hline
\end{tabular}


- Desired speed decision - US-17

\begin{tabular}{|c|c|c|c|}
\hline No. & Name & $\begin{array}{l}\text { Spe ed Dist car } \\
(\min , \max ) \\
\end{array}$ & $\begin{array}{c}\text { Spe ed Dist HGV } \\
(\min , \max ) \\
\end{array}$ \\
\hline 1 & Ploof WB & $50(29.8,36.0)$ & $50(29.8,36.0)$ \\
\hline 2 & Poole EB & $50(29.8,36.0)$ & $50(29.8,36.0)$ \\
\hline 3 & Poole EB & $50(29.8,36.0)$ & $50(29.8,36.0)$ \\
\hline 4 & Gregory EB & $9(25,35)$ & $9(25,35)$ \\
\hline 5 & Grandiflora EB & $50(29.8,36.0)$ & $50(29.8,36.0)$ \\
\hline 6 & Grandiflora EB & $50(29.8,36.0)$ & $50(29.8,36.0)$ \\
\hline 7 & WestGate WB & $50(29.8,36.0)$ & $50(29.8,36.0)$ \\
\hline 8 & WestGate WB & $50(29.8,36.0)$ & $50(29.8,36.0)$ \\
\hline 9 & BrunswickForest WB & $50(29.8,36.0)$ & $50(29.8,36.0)$ \\
\hline 10 & BrunswickForest WB & $50(29.8,36.0)$ & $50(29.8,36.0)$ \\
\hline 11 & BF\#2 WB & $40(24.9,28.0)$ & $40(24.9,28.0)$ \\
\hline 12 & BF\#2 WB & $40(24.9,28.0)$ & $40(24.9,28.0)$ \\
\hline 13 & BF\#2 WB & $40(24.9,28.0)$ & $40(24.9,28.0)$ \\
\hline 14 & Lanvale EB & $50(29.8,36.0)$ & $50(29.8,36.0)$ \\
\hline 15 & Walmart WB & $8(20,25)$ & $8(20,25)$ \\
\hline 16 & Walmart WB & $8(20,25)$ & $8(20,25)$ \\
\hline 17 & Ploof WBR & Leland_mod2 $(35.2,56.8)$ & Leland_mod2 $(35.2,56.8)$ \\
\hline 18 & Ploof WBR & Leland_mod2 $(35.2,56.8)$ & Leland_mod2 $(35.2,56.8)$ \\
\hline 19 & Poole EBR & Leland_mod2 $(35.2,56.8)$ & Leland_mod2 $(35.2,56.8)$ \\
\hline 20 & Poole EBR & Leland_mod2 (35.2, 56.8) & Leland_mod2 $(35.2,56.8)$ \\
\hline 21 & $\mathrm{P} / \mathrm{P}$ SUT & $9(25,35)$ & $9(25,35)$ \\
\hline 22 & $\mathrm{P} / \mathrm{P}$ SUT & $9(25,35)$ & $9(25,35)$ \\
\hline 23 & Walmart WBR & Leland_mod2 $(35.2,56.8)$ & Leland_mod2 $(35.2,56.8)$ \\
\hline 24 & Walmart WBR & Leland_mod2 $(35.2,56.8)$ & Leland_mod2 $(35.2,56.8)$ \\
\hline 25 & Gregory EBR & Leland_mod2 (35.2, 56.8) & Leland_mod2 $(35.2,56.8)$ \\
\hline 26 & Gregory EBR & Leland_mod2 $(35.2,56.8)$ & Leland_mod2 $(35.2,56.8)$ \\
\hline 27 & WestGate WBR & Leland_mod2 $(35.2,56.8)$ & Leland_mod2 $(35.2,56.8)$ \\
\hline 28 & WestGate WBR & Leland_mod2 $(35.2,56.8)$ & Leland_mod2 $(35.2,56.8)$ \\
\hline 29 & Grandiflora EBR & Leland_mod2 $(35.2,56.8)$ & Leland_mod2 $(35.2,56.8)$ \\
\hline 30 & Grandiflora EBR & Leland_mod2 $(35.2,56.8)$ & Leland_mod2 $(35.2,56.8)$ \\
\hline 31 & BrunswickForeset WBR & Leland_mod2 $(35.2,56.8)$ & Leland_mod2 $(35.2,56.8)$ \\
\hline 32 & BF\#2 WBR & Leland_mod2 $(35.2,56.8)$ & Leland_mod2 $(35.2,56.8)$ \\
\hline 33 & BF\#2 WBR & Leland_mod2 $(35.2,56.8)$ & Leland_mod2 $(35.2,56.8)$ \\
\hline 34 & BF\#2 WBR & $9(25,35)$ & $9(25,35)$ \\
\hline 35 & BF\#2 WBR & $9(25,35)$ & $9(25,35)$ \\
\hline 36 & Lanvale EBR & Leland_mod2 $(35.2,56.8)$ & Leland_mod2 $(35.2,56.8)$ \\
\hline 37 & Lanvale EBR & Leland_mod2 $(35.2,56.8)$ & Leland_mod2 $(35.2,56.8)$ \\
\hline 38 & Lanvale SUT & $9(25,35)$ & $9(25,35)$ \\
\hline 39 & BF NUT & $9(25,35)$ & $9(25,35)$ \\
\hline 40 & BF NUT to U-17SB & Leland_mod2 $(35.2,56.8)$ & Leland_mod2 $(35.2,56.8)$ \\
\hline 41 & BF NUT to U-17SB & Leland_mod2 $(35.2,56.8)$ & Leland_mod2 $(35.2,56.8)$ \\
\hline 42 & L/BF NUT to US-17SB & Leland_mod2 $(35.2,56.8)$ & Leland_mod2 $(35.2,56.8)$ \\
\hline 43 & L/BF NUT to US-17SB & Leland_mod2 $(35.2,56.8)$ & Leland_mod2 $(35.2,56.8)$ \\
\hline 44 & $\mathrm{~L} / \mathrm{BF}$ SUT to US-17NB & Leland_mod2 (35.2, 56.8) & Leland_mod2 $(35.2,56.8)$ \\
\hline 45 & L/BF SUT to US-17NB & Leland_mod2 $(35.2,56.8)$ & Leland_mod2 $(35.2,56.8)$ \\
\hline 46 & G/WG SUT to US-17NB & Leland_mod2 $(35.2,56.8)$ & Leland_mod2 $(35.2,56.8)$ \\
\hline 47 & G/WG SUT to US-17NB & Leland_mod2 $(35.2,56.8)$ & Leland_mod2 $(35.2,56.8)$ \\
\hline 48 & G/WG NUT to US-17SB & Leland_mod2 $(35.2,56.8)$ & Leland_mod2 $(35.2,56.8)$ \\
\hline 49 & G/WG NUT to US-17SB & Leland_mod2 $(35.2,56.8)$ & Leland_mod2 $(35.2,56.8)$ \\
\hline 50 & W/G SUT to US-17NB & Leland_mod2 (35.2, 56.8) & Leland_mod2 $(35.2,56.8)$ \\
\hline 51 & W/G SUT to US-17NB & Leland_mod2 $(35.2,56.8)$ & Leland_mod2 $(35.2,56.8)$ \\
\hline
\end{tabular}


- Desired speed decision - US-17 (cont.)

\begin{tabular}{|c|c|c|c|}
\hline No. & Name & $\begin{array}{c}\text { Speed Dist car } \\
\text { (min, max) }\end{array}$ & $\begin{array}{c}\text { Speed Dist HGV } \\
\text { (min, max) }\end{array}$ \\
\hline 52 & W/G NUT to US-17SB & Leland_mod2 $(35.2,56.8)$ & Leland_mod2 $(35.2,56.8)$ \\
\hline 53 & W/G NUT to US-17SB & Leland_mod2 $(35.2,56.8)$ & Leland_mod2 $(35.2,56.8)$ \\
\hline 54 & $\mathrm{P} / \mathrm{P}$ SUT to US-17NB & Leland_mod2 $(35.2,56.8)$ & Leland_mod2 $(35.2,56.8)$ \\
\hline 55 & $\mathrm{P} / \mathrm{P}$ SUT to US-17NB & Leland_mod2 $(35.2,56.8)$ & Leland_mod2 $(35.2,56.8)$ \\
\hline 56 & $\mathrm{P} / \mathrm{P}$ NUT to US-17SB & Leland_mod2 $(35.2,56.8)$ & Leland_mod2 $(35.2,56.8)$ \\
\hline 57 & $\mathrm{P} / \mathrm{P}$ NUT to US-17SB & Leland_mod2 $(35.2,56.8)$ & Leland_mod2 $(35.2,56.8)$ \\
\hline 58 & $\mathrm{P} / \mathrm{P}$ NUT & $9(25,35)$ & $9(25,35)$ \\
\hline 59 & W/G NUT & $9(25,35)$ & $9(25,35)$ \\
\hline 60 & W/G SUT & $9(25,35)$ & $9(25,35)$ \\
\hline 61 & G/WG NUT & $9(25,35)$ & $9(25,35)$ \\
\hline 62 & G/WG NUT & $9(25,35)$ & $9(25,35)$ \\
\hline 63 & G/WG SUT & $9(25,35)$ & $9(25,35)$ \\
\hline 64 & G/WG SUT & $9(25,35)$ & $9(25,35)$ \\
\hline 65 & Ploof EB & $50(29.8,36.0)$ & $50(29.8,36.0)$ \\
\hline 66 & Poole WB & $50(29.8,36.0)$ & $50(29.8,36.0)$ \\
\hline 67 & Poole WB & $50(29.8,36.0)$ & $50(29.8,36.0)$ \\
\hline 68 & Walmart EB & $8(20,25)$ & $8(20,25)$ \\
\hline 69 & Walmart EB & $8(20,25)$ & $8(20,25)$ \\
\hline 70 & Gregory WB & $9(25,35)$ & $9(25,35)$ \\
\hline 71 & WestGate EB & $50(29.8,36.0)$ & $50(29.8,36.0)$ \\
\hline 72 & WestGate EB & $50(29.8,36.0)$ & $50(29.8,36.0)$ \\
\hline 73 & Grandiflora WB & $50(29.8,36.0)$ & $50(29.8,36.0)$ \\
\hline 74 & Grandiflora WB & $50(29.8,36.0)$ & $50(29.8,36.0)$ \\
\hline 75 & BrunswickForest EB & $50(29.8,36.0)$ & $50(29.8,36.0)$ \\
\hline 76 & BrunswickForest EB & $50(29.8,36.0)$ & $50(29.8,36.0)$ \\
\hline 77 & BF\#2 EB & $40(24.9,28.0)$ & $40(24.9,28.0)$ \\
\hline 78 & BF\#2 EB & $40(24.9,28.0)$ & $40(24.9,28.0)$ \\
\hline 79 & Lanvale WB & $50(29.8,36.0)$ & $50(29.8,36.0)$ \\
\hline 80 & $\mathrm{P} / \mathrm{P}$ NUT to US-17SB & $50(29.8,36.0)$ & $50(29.8,36.0)$ \\
\hline 81 & W/G NBR & $9(25,35)$ & $9(25,35)$ \\
\hline 82 & W/G SBR & $9(25,35)$ & $9(25,35)$ \\
\hline 83 & $\mathrm{P} / \mathrm{P} \mathrm{NBT}$ & $9(25,35)$ & $9(25,35)$ \\
\hline 84 & $\mathrm{P} / \mathrm{P} \mathrm{SBR}$ & $9(25,35)$ & $9(25,35)$ \\
\hline 85 & G/WG NBR & $9(25,35)$ & $9(25,35)$ \\
\hline 86 & G/WG SBR & $9(25,35)$ & $9(25,35)$ \\
\hline 87 & BF NBR & $9(25,35)$ & $9(25,35)$ \\
\hline 88 & L/BF NBR & $9(25,35)$ & $9(25,35)$ \\
\hline 89 & $\mathrm{~L} / \mathrm{BF}$ SBR & $9(25,35)$ & $9(25,35)$ \\
\hline 90 & $\mathrm{~L} / \mathrm{BF}$ NBL & $9(25,35)$ & $9(25,35)$ \\
\hline 91 & $\mathrm{~L} / \mathrm{BF} \mathrm{SBL}$ & $9(25,35)$ & $9(25,35)$ \\
\hline 92 & $\mathrm{~L} / \mathrm{BF}$ SBL & $9(25,35)$ & $9(25,35)$ \\
\hline 93 & BF SBL & $9(25,35)$ & $9(25,35)$ \\
\hline 94 & BF SBL & $9(25,35)$ & $9(25,35)$ \\
\hline 95 & G/WG NBL & $9(25,35)$ & $9(25,35)$ \\
\hline 96 & G/WG SBL & $9(25,35)$ & $9(25,35)$ \\
\hline 97 & W/G NBL & $9(25,35)$ & $9(25,35)$ \\
\hline 98 & W/G SBL & $9(25,35)$ & $9(25,35)$ \\
\hline 99 & W/G SBL & $9(25,35)$ & $9(25,35)$ \\
\hline 100 & P/P NBL & $9(25,35)$ & $9(25,35)$ \\
\hline 101 & $\mathrm{P} / \mathrm{P} \mathrm{NBL}$ & $9(25,35)$ & $9(25,35)$ \\
\hline 102 & $\mathrm{P} / \mathrm{P} \mathrm{SBL}$ & $9(25,35)$ & $9(25,35)$ \\
\hline
\end{tabular}




\section{APPENDIX C:}

\section{VISSIM Calibration and Validation Results}


- Calibration results by movement:

\begin{tabular}{|c|c|c|c|c|c|c|c|c|c|c|c|}
\hline \multirow[b]{2}{*}{ Site } & \multirow[b]{2}{*}{ Date } & \multirow[b]{2}{*}{ Road } & \multirow[b]{2}{*}{ Movement } & \multirow[b]{2}{*}{ \# runs } & \multirow[b]{2}{*}{ Field } & \multicolumn{2}{|c|}{ SET 1} & \multicolumn{2}{|c|}{ SET 2} & \multicolumn{2}{|c|}{ SET3 } \\
\hline & & & & & & VISSIM & \% Diff. & VISSIM & \% Diff. & VISSIM & \% Diff. \\
\hline \multirow[t]{12}{*}{ Chapel Hill } & \multirow{12}{*}{$\begin{array}{c}\text { 10/27/2009 } \\
\text { 7:30-9:00am } \\
\text { (data set \#1) }\end{array}$} & \multirow[t]{3}{*}{ minor } & WBL & 2 & 235.2 & 119.1 & $-49.3 \%$ & 129.2 & $-45.1 \%$ & 137.10 & $-41.7 \%$ \\
\hline & & & WBR & 1 & 76.8 & 54.1 & $-29.6 \%$ & 56.8 & $-26.0 \%$ & 63.31 & $-17.6 \%$ \\
\hline & & & WBT & 2 & 168.0 & 118.0 & $-29.8 \%$ & 130.6 & $-22.3 \%$ & 128.61 & $-23.4 \%$ \\
\hline & & \multirow[t]{3}{*}{ minor } & EBL & 2 & 240.9 & 136.3 & $-43.4 \%$ & 141.3 & $-41.3 \%$ & 142.04 & $-41.0 \%$ \\
\hline & & & EBR & 1 & 78.0 & 63.2 & $-18.9 \%$ & 66.6 & $-14.7 \%$ & 66.53 & $-14.7 \%$ \\
\hline & & & EBT & 2 & 199.2 & 126.3 & $-36.6 \%$ & 132.0 & $-33.7 \%$ & 124.07 & $-37.7 \%$ \\
\hline & & \multirow[t]{3}{*}{ major } & NBL & 2 & 173.4 & 102.2 & $-41.1 \%$ & 112.0 & $-35.4 \%$ & 119.19 & $-31.3 \%$ \\
\hline & & & NBR & 1 & 42.0 & 27.3 & $-35.0 \%$ & 28.0 & $-33.3 \%$ & 32.37 & $-22.9 \%$ \\
\hline & & & NBT & 2 & 43.5 & 44.0 & $1.2 \%$ & 46.3 & $6.3 \%$ & 51.13 & $17.5 \%$ \\
\hline & & \multirow[t]{3}{*}{ major } & SBL & 2 & 180.3 & 129.4 & $-28.2 \%$ & 133.7 & $-25.8 \%$ & 125.54 & $-30.4 \%$ \\
\hline & & & SBR & 1 & 34.8 & 52.5 & $50.9 \%$ & 55.1 & $58.4 \%$ & 57.03 & $63.9 \%$ \\
\hline & & & SBT & 2 & 39.0 & 61.5 & $57.6 \%$ & 64.9 & $66.4 \%$ & 64.48 & $65.3 \%$ \\
\hline \multirow[t]{11}{*}{ Myrtle Grove } & \multirow{11}{*}{$\begin{array}{r}\text { 7/17/2009 } \\
12: 00-1: 30 p m \\
\text { (data set \#1) }\end{array}$} & \multirow[t]{3}{*}{ minor } & WBL & 6 & 158.0 & 110.8 & $-29.9 \%$ & 113.9 & $-27.9 \%$ & 126.13 & $-20.2 \%$ \\
\hline & & & WBR & 2 & 89.4 & 41.0 & $-54.2 \%$ & 40.9 & $-54.2 \%$ & 47.01 & $-47.4 \%$ \\
\hline & & & $\overline{\text { WBT }}$ & & & & & & & & \\
\hline & & & EBR & 2 & 78.0 & 51.8 & $-33.6 \%$ & 50.9 & $-34.7 \%$ & 55.46 & $-28.9 \%$ \\
\hline & & & EBT & 5 & 141.8 & 103.0 & $-27.4 \%$ & 102.8 & $-27.6 \%$ & 102.58 & $-27.7 \%$ \\
\hline & & major & NBL & 5 & 105.0 & 53.9 & $-48.7 \%$ & 53.1 & $-49.4 \%$ & 51.59 & $-50.9 \%$ \\
\hline & & & NBR & 2 & 39.9 & 39.8 & $-0.2 \%$ & 39.4 & $-1.2 \%$ & 37.15 & $-6.9 \%$ \\
\hline & & & NBT & 2 & 45.9 & 55.3 & $20.5 \%$ & 54.5 & $18.8 \%$ & 50.51 & $10.0 \%$ \\
\hline & & major & SBL & 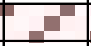 & $\overline{1+2}$ & $E^{-1}$ & E & E & E & E & E \\
\hline & & & SBR & 2 & 42.0 & 33.8 & $-19.5 \%$ & 34.9 & $-16.9 \%$ & 35.07 & $-16.5 \%$ \\
\hline & & & SBT & 2 & 58.2 & 53.6 & $-7.8 \%$ & 52.9 & $-9.1 \%$ & 53.02 & $-8.9 \%$ \\
\hline US-17 corridor & $7 / 17 / 2009$ & minor & WBL & 5 & 124.8 & 82.0 & $-34.3 \%$ & 91.9 & $-26.3 \%$ & 124.32 & $-0.4 \%$ \\
\hline Walmart & 7:30-9:00am & & WBR & 4 & 49.4 & 39.8 & $-19.4 \%$ & 42.6 & $-13.6 \%$ & 48.44 & $-1.8 \%$ \\
\hline & (data set \#1) & & WBT & E & & 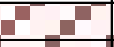 & $\square^{-1}$ & & & - & $\bar{\square}$ \\
\hline & & minor & $\mathrm{EBL}$ & + & 물 & 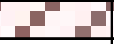 & E & $\bar{E}$ & E & Eـ & ت \\
\hline & & & EBR & 2 & 42.0 & 32.8 & $-21.9 \%$ & 34.1 & $-18.8 \%$ & 31.03 & $-26.1 \%$ \\
\hline & & & EBT & 6 & 139.0 & 76.7 & $-44.9 \%$ & 81.9 & $-41.1 \%$ & 105.67 & $-24.0 \%$ \\
\hline & & major & NBL & 5 & 75.7 & 54.3 & $-28.3 \%$ & 59.3 & $-21.7 \%$ & 80.21 & $5.9 \%$ \\
\hline & & & NBR & 2 & 38.4 & 24.0 & $-37.6 \%$ & 26.9 & $-30.1 \%$ & 27.39 & $-28.7 \%$ \\
\hline & & & NBT & 2 & 41.1 & 38.8 & $-5.5 \%$ & 43.6 & $6.0 \%$ & 37.67 & $-8.3 \%$ \\
\hline & & major & SBL & 1 & 78.0 & 48.7 & $-37.6 \%$ & 52.8 & $-32.3 \%$ & 65.89 & $-15.5 \%$ \\
\hline & & & SBR & 3 & 24.0 & 22.6 & $-5.8 \%$ & 24.2 & $1.0 \%$ & 23.32 & $-2.8 \%$ \\
\hline & & & SBT & 2 & 34.2 & 30.9 & $-9.5 \%$ & 36.8 & $7.6 \%$ & 34.89 & $2.0 \%$ \\
\hline US-17 corridor & 7/17/2009 & minor & WBL & 1 & 115.8 & 0.0 & & 90.7 & $-21.7 \%$ & 61.83 & $-46.6 \%$ \\
\hline Lanvale Rd. & 5:00-6:30pm & & WBR & 2 & 76.2 & 0.0 & & 40.6 & $-46.7 \%$ & 38.89 & $-49.0 \%$ \\
\hline & (data set \#1) & & WBT & 2 & 165.9 & 0.0 & & 56.8 & $-65.8 \%$ & 104.08 & $-37.3 \%$ \\
\hline & & minor & EBL & 6 & 156.8 & 86.2 & $-45.0 \%$ & 98.6 & $-37.1 \%$ & 127.27 & $-18.8 \%$ \\
\hline & & & EBR & 2 & 61.5 & 43.5 & $-29.3 \%$ & 48.1 & $-21.8 \%$ & 49.18 & $-20.0 \%$ \\
\hline & & & EBT & 2 & 124.5 & 66.9 & $-46.3 \%$ & 68.4 & $-45.1 \%$ & 94.36 & $-24.2 \%$ \\
\hline & & major & NBL & 5 & 94.9 & 60.9 & $-35.8 \%$ & 67.6 & $-28.7 \%$ & 90.38 & $-4.8 \%$ \\
\hline & & & NBR & 2 & 43.8 & 0.0 & & 32.0 & $-27.0 \%$ & 36.19 & $-17.4 \%$ \\
\hline & & & NBT & 口 & E & E & $\underline{1}$ & $=$ & + & E & E \\
\hline & & major & $\mathrm{SBL}$ & 2 & 101.4 & 43.6 & $-57.0 \%$ & 50.7 & $-50.0 \%$ & 77.8 & $-23.3 \%$ \\
\hline & & & SBR & 2 & 42.3 & 28.0 & $-33.8 \%$ & 33.8 & $-20.2 \%$ & 28.12 & $-33.5 \%$ \\
\hline & & & SBT & 4 & 45.2 & 43.3 & $-4.1 \%$ & 52.2 & $15.5 \%$ & 51.16 & $13.3 \%$ \\
\hline & & total $n$ & . field runs: & 110 & mean & fference: & $-23.7 \%$ & & $-20.6 \%$ & & $-16.0 \%$ \\
\hline
\end{tabular}


- Calibration results by movement (cont.):

\begin{tabular}{|c|c|c|c|c|c|c|c|c|c|}
\hline \multirow[b]{2}{*}{ Site } & \multirow[b]{2}{*}{ Date } & \multirow[b]{2}{*}{ Road } & \multirow[b]{2}{*}{ Movement } & \multirow[b]{2}{*}{ \# runs } & \multirow[b]{2}{*}{ Field } & \multicolumn{2}{|c|}{ SET 4} & \multicolumn{2}{|c|}{ SET 5} \\
\hline & & & & & & VISSIM & \% Diff. & VISSIM & \% Diff. \\
\hline \multirow[t]{12}{*}{ Chapel Hill } & \multirow{12}{*}{$\begin{array}{c}\text { 10/27/2009 } \\
\text { 7:30-9:00am } \\
\text { (data set \#1) }\end{array}$} & \multirow[t]{3}{*}{ minor } & WBL & 2 & 235.2 & 137.10 & $-41.7 \%$ & 138.92 & $-40.9 \%$ \\
\hline & & & WBR & 1 & 76.8 & 63.31 & $-17.6 \%$ & 63.85 & $-16.9 \%$ \\
\hline & & & WBT & 2 & 168.0 & 128.61 & $-23.4 \%$ & 128.93 & $-23.3 \%$ \\
\hline & & \multirow[t]{3}{*}{ minor } & EBL & 2 & 240.9 & 142.04 & $-41.0 \%$ & 143.82 & $-40.3 \%$ \\
\hline & & & EBR & 1 & 78.0 & 66.53 & $-14.7 \%$ & 67.58 & $-13.4 \%$ \\
\hline & & & EBT & 2 & 199.2 & 124.07 & $-37.7 \%$ & 124.24 & $-37.6 \%$ \\
\hline & & \multirow[t]{3}{*}{ major } & NBL & 2 & 173.4 & 119.19 & $-31.3 \%$ & 119.36 & $-31.2 \%$ \\
\hline & & & NBR & 1 & 42.0 & 32.37 & $-22.9 \%$ & 32.31 & $-23.1 \%$ \\
\hline & & & NBT & 2 & 43.5 & 51.13 & $17.5 \%$ & 51.32 & $18.0 \%$ \\
\hline & & \multirow[t]{3}{*}{ major } & SBL & 2 & 180.3 & 125.54 & $-30.4 \%$ & 126.26 & $-30.0 \%$ \\
\hline & & & SBR & 1 & 34.8 & 57.03 & $63.9 \%$ & 56.77 & $63.1 \%$ \\
\hline & & & SBT & 2 & 39.0 & 64.48 & $65.3 \%$ & 64.52 & $65.4 \%$ \\
\hline \multirow[t]{12}{*}{ Myrtle Grove } & \multirow{12}{*}{$\begin{array}{r}\text { 7/17/2009 } \\
\text { 12:00-1:30pm } \\
\text { (data set \#1) }\end{array}$} & \multirow[t]{3}{*}{ minor } & WBL & 6 & 158.0 & 126.13 & $-20.2 \%$ & 132.56 & $-16.1 \%$ \\
\hline & & & WBR & 2 & 89.4 & 47.01 & $-47.4 \%$ & 46.86 & $-47.6 \%$ \\
\hline & & & B & & & & & & \\
\hline & & \multirow[t]{3}{*}{ minor } & EBL & $C^{2}$ & & - & - & & 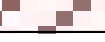 \\
\hline & & & EBR & 2 & 78.0 & 55.46 & $-28.9 \%$ & 55.07 & $-29.4 \%$ \\
\hline & & & EBT & 5 & 141.8 & 102.58 & $-27.7 \%$ & 111.60 & $-21.3 \%$ \\
\hline & & \multirow[t]{3}{*}{ major } & NBL & 5 & 105.0 & 51.59 & $-50.9 \%$ & 58.36 & $-44.4 \%$ \\
\hline & & & NBR & 2 & 39.9 & 37.15 & $-6.9 \%$ & 39.58 & $-0.8 \%$ \\
\hline & & & NBT & 2 & 45.9 & 50.51 & $10.0 \%$ & 50.9 & $10.9 \%$ \\
\hline & & major & $\mathrm{SBL}$ & $\overline{15}$ & & E & $=$ & $\overline{1}$ & E \\
\hline & & & SBR & 2 & 42.0 & 35.07 & $-16.5 \%$ & 36.92 & $-12.1 \%$ \\
\hline & & & SBT & 2 & 58.2 & 53.02 & $-8.9 \%$ & 53.89 & $-7.4 \%$ \\
\hline US-17 corridor & 7/17/2009 & minor & WBL & 5 & 124.8 & 123.92 & $-0.7 \%$ & 129.71 & $3.9 \%$ \\
\hline Walmart & 7:30-9:00am & & WBR & 4 & 49.4 & 48.71 & $-1.3 \%$ & 48.84 & $-1.0 \%$ \\
\hline & (data set \#1) & & WBT & & & & 5 & & $F^{2}$ \\
\hline & & minor & EBL & ב & ב & - & - & ב & 口 \\
\hline & & & EBR & 2 & 42.0 & 31.67 & $-24.6 \%$ & 34.8 & $-17.1 \%$ \\
\hline & & & EBT & 6 & 139.0 & 105.19 & $-24.3 \%$ & 106.17 & $-23.6 \%$ \\
\hline & & major & NBL & 5 & 75.7 & 80.56 & $6.4 \%$ & 79.24 & $4.6 \%$ \\
\hline & & & NBR & 2 & 38.4 & 28.58 & $-25.6 \%$ & 27.22 & $-29.1 \%$ \\
\hline & & & NBT & 2 & 41.1 & 37.77 & $-8.1 \%$ & 38.25 & $-6.9 \%$ \\
\hline & & major & SBL & 1 & 78.0 & 65.92 & $-15.5 \%$ & 65.6 & $-15.9 \%$ \\
\hline & & & SBR & 3 & 24.0 & 22.86 & $-4.8 \%$ & 23.67 & $-1.4 \%$ \\
\hline & & & SBT & 2 & 34.2 & 34.94 & $2.2 \%$ & 34.86 & $1.9 \%$ \\
\hline US-17 corridor & 7/17/2009 & minor & WBL & 1 & 115.8 & 61.3 & $-47.1 \%$ & 60.54 & $-47.7 \%$ \\
\hline Lanvale Rd. & 5:00-6:30pm & & WBR & 2 & 76.2 & 40.31 & $-47.1 \%$ & 40.28 & $-47.1 \%$ \\
\hline & (data set \#1) & & WBT & 2 & 165.9 & 102.33 & $-38.3 \%$ & 102.78 & $-38.0 \%$ \\
\hline & & minor & EBL & 6 & 156.8 & 127.21 & $-18.9 \%$ & 117.87 & $-24.8 \%$ \\
\hline & & & EBR & 2 & 61.5 & 50.29 & $-18.2 \%$ & 50.26 & $-18.3 \%$ \\
\hline & & & EBT & 2 & 124.5 & 93.48 & $-24.9 \%$ & 85.58 & $-31.3 \%$ \\
\hline & & major & NBL & 5 & 94.9 & 90.81 & $-4.3 \%$ & 88.54 & $-6.7 \%$ \\
\hline & & & NBR & 2 & 43.8 & 35.59 & $-18.7 \%$ & 33.76 & $-22.9 \%$ \\
\hline & & & NBT & $\overline{5}$ & 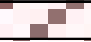 & $\bar{E}$ & $\overline{5}$ & - & 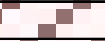 \\
\hline & & major & SBL & 2 & 101.4 & 79.97 & $-21.1 \%$ & 81.27 & $-19.9 \%$ \\
\hline & & & SBR & 2 & 42.3 & 28.65 & $-32.3 \%$ & 27.8 & $-34.3 \%$ \\
\hline & & & SBT & 4 & 45.2 & 51.26 & $13.5 \%$ & 52.64 & $16.6 \%$ \\
\hline & & total $n$ & field runs: & 110 & & & $-15.8 \%$ & & $-15.2 \%$ \\
\hline
\end{tabular}


- Validation results by movement:

\begin{tabular}{|c|c|c|c|c|c|c|c|}
\hline \multirow[b]{2}{*}{ Site } & \multirow[b]{2}{*}{ Date } & \multirow[b]{2}{*}{ Road } & \multirow[b]{2}{*}{ Movement } & \multirow[b]{2}{*}{ \# runs } & \multirow[b]{2}{*}{ Field } & \multicolumn{2}{|c|}{ SET 1} \\
\hline & & & & & & VISSIM & \% Diff. \\
\hline \multirow{12}{*}{ Chapel Hill } & \multirow{12}{*}{$\begin{array}{c}10 / 27 / 2009 \\
11: 30-1: 00 p m \\
\text { (data set \#2) }\end{array}$} & \multirow[t]{3}{*}{$\overline{\text { minor }}$} & WBL & 2 & 138.9 & 132 & $-4.8 \%$ \\
\hline & & & WBR & 2 & 62.4 & 63.62 & $2.0 \%$ \\
\hline & & & WBT & 2 & 137.4 & 124.52 & $-9.4 \%$ \\
\hline & & \multirow[t]{3}{*}{ minor } & EBL & 2 & 90.0 & 146.71 & $63.0 \%$ \\
\hline & & & EBR & 2 & 81.9 & 60.89 & $-25.7 \%$ \\
\hline & & & EBT & 3 & 131.4 & 121.49 & $-7.5 \%$ \\
\hline & & \multirow[t]{3}{*}{ major } & NBL & 3 & 99.2 & 117.89 & $18.8 \%$ \\
\hline & & & NBR & 2 & 39.0 & 32.33 & $-17.1 \%$ \\
\hline & & & NBT & 2 & 53.1 & 51.45 & $-3.1 \%$ \\
\hline & & \multirow{3}{*}{ major } & SBL & 2 & 115.5 & 124.34 & $7.7 \%$ \\
\hline & & & SBR & 2 & 41.1 & 56.93 & $38.5 \%$ \\
\hline & & & SBT & 2 & 59.4 & 62.41 & $5.1 \%$ \\
\hline \multirow[t]{11}{*}{ Myrtle Grove } & \multirow{11}{*}{$\begin{array}{c}7 / 18 / 2009 \\
\text { 10:30-11:45am } \\
\text { (data set \#2) }\end{array}$} & \multirow[t]{3}{*}{ minor } & WBL & $0^{-1}$ & $\mathrm{E}^{-1}$ & 131.6 & $\mathrm{CO}^{-2}$ \\
\hline & & & WBR & 2 & 81.0 & 48.7 & $-39.9 \%$ \\
\hline & & & WBT & 6 & 103.4 & 116.0 & $12.2 \%$ \\
\hline & & \multirow[t]{2}{*}{ minor } & EBL & 6 & 143.0 & 122.4 & $-14.4 \%$ \\
\hline & & & EBR & 2 & 110.4 & 55.7 & $-49.5 \%$ \\
\hline & & \multirow[t]{3}{*}{ major } & \begin{tabular}{|c|} 
EBT \\
$\mathrm{NBL}$ \\
\end{tabular} & \begin{tabular}{|l|}
0 \\
0 \\
\end{tabular} & $\mathrm{H}$ & $\begin{array}{l}118.9 \\
58.7 \\
\end{array}$ & $\mathrm{~F}^{2}$ \\
\hline & & & NBR & 2 & 53.1 & 39.2 & $-26.1 \%$ \\
\hline & & & NBT & 2 & 48.0 & 51.0 & $6.3 \%$ \\
\hline & & \multirow[t]{3}{*}{ major } & SBL & 6 & 56.5 & 73.4 & $29.9 \%$ \\
\hline & & & SBR & 2 & 43.5 & 36.6 & $-15.8 \%$ \\
\hline & & & SBT & 2 & 52.5 & 54.1 & $3.1 \%$ \\
\hline \multirow{12}{*}{$\begin{array}{l}\text { US-17 corridor } \\
\text { Walmart }\end{array}$} & & minor & WBL & 1 & 100.2 & 143.22 & $42.9 \%$ \\
\hline & 1:45-3:15pm & & WBR & 2 & 60.9 & 59.97 & $-1.5 \%$ \\
\hline & & & WBT & 4 & 125.6 & 127.65 & $1.7 \%$ \\
\hline & & minor & EBL & 5 & 147.2 & 131.98 & $-10.4 \%$ \\
\hline & & & EBR & 2 & 74.7 & 40.34 & $-46.0 \%$ \\
\hline & & & EBT & 1 & 157.2 & 119.14 & $-24.2 \%$ \\
\hline & & major & NBL & 1 & 42.0 & 82.00 & $95.2 \%$ \\
\hline & & & NBR & 2 & 38.4 & 35.75 & $-6.9 \%$ \\
\hline & & & NBT & 3 & 54.0 & 40.46 & $-25.1 \%$ \\
\hline & & major & SBL & 5 & 75.1 & 64.77 & $-13.8 \%$ \\
\hline & & & SBR & 2 & 23.4 & 25.35 & $8.3 \%$ \\
\hline & & & SBT & 3 & 35.6 & 37.47 & $5.3 \%$ \\
\hline US-17 corridor & & minor & WBL & 1 & 115.8 & 61.63 & $-46.8 \%$ \\
\hline Lanvale Rd. & NO 2nd DATA SET & & WBR & 2 & 76.2 & 40.07 & $-47.4 \%$ \\
\hline & (volume inputs & & WBT & 2 & 165.9 & 104.04 & $-37.3 \%$ \\
\hline & from 1st data set, & minor & EBL & 6 & 156.8 & 135.43 & $-13.6 \%$ \\
\hline & so compare to TT & & EBR & 2 & 61.5 & 58.38 & $-5.1 \%$ \\
\hline & from 1st data set) & & EBT & 2 & 124.5 & 94.91 & $-23.8 \%$ \\
\hline & & major & NBL & 5 & 94.9 & 97.21 & $2.4 \%$ \\
\hline & & & NBR & 2 & 43.8 & 36.99 & $-15.5 \%$ \\
\hline & & & NBT & - & - & 20.00 & 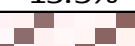 \\
\hline & & major & SBL & 2 & 101.4 & 71.3 & $-29.7 \%$ \\
\hline & & & SBR & 2 & 42.3 & 43.62 & $3.1 \%$ \\
\hline & & & SBT & 4 & 45.2 & 54.24 & $20.1 \%$ \\
\hline & & total $n$ & . field runs: & 117 & mean d & fference: & $-4.4 \%$ \\
\hline
\end{tabular}

*excluding values because no TT runs conducted in field for data set \#1 